\author{
UNIVERSIDADE DE SÃO PAULO \\ FACULDADE DE ODONTOLOGIA DE BAURU
}

PAULA MARTINS SAID

Contributos da musicalização infantil no desenvolvimento das habilidades perceptivas, cognitivas e sociais em crianças com implante coclear 



\section{Contributos da musicalização infantil no desenvolvimento das habilidades perceptivas, cognitivas e sociais em crianças com implante coclear}

Tese apresentada à Faculdade de Odontologia de Bauru da Universidade de São Paulo para obtenção do título de Doutor em Ciências pelo Programa de Pós-Graduação em Fonoaudiologia.

Orientadora: Profa. Dra. Dagma Venturini Marques Abramides

Versão corrigida 
Said, Paula Martins

Contributos da musicalização infantil no desenvolvimento das habilidades perceptivas, cognitivas e sociais em crianças com implante coclear / Paula Martins Said. -- Bauru, 2020.

157 p. : il. ; $30 \mathrm{~cm}$.

Tese (Doutorado) - Faculdade de Odontologia de Bauru. Universidade de São Paulo, 2020.

Orientadora: Profa. Dra. Dagma Venturini Marques Abramides

Nota: A versão original desta tese encontra-se disponível no Serviço de Biblioteca e Documentação da Faculdade de Odontologia de Bauru - FOB/USP.

Autorizo, exclusivamente para fins acadêmicos e científicos, a reprodução total ou parcial desta tese, por processos fotocopiadores e outros meios eletrônicos.

Nome: Paula Martins Said

Data: $06 / 10 / 2020$

Comitê de Ética da FOB-USP

Protocolo $\mathrm{n}^{\mathrm{o}} 2.820 .891$.

Data: 04/12/2018 
FOLHA DE APROVAÇÃO 



\section{Dedicatória}

Dedico esse trabalho aos meus pais, Pérsida e Alcides, que nunca mediram seus esforços e com todo apoio me fizeram chegar até aqui. A minha irmã, Perla, que sempre esteve presente me dando base e orientação em tudo que precisei. Ao meu marido Fabio, por me apoiar, me incentivar e por seu companheirismo. A minha amiga Luciana, quem admiro pela pesquisadora dedicada e amorosa que se tornou, por todo apoio, trocas e conversas sem fim sobre esse estudo. Ao meu sócio e irmão de coração e música, Marcos, por todo suporte e paciência. A minha orientadora Profa. Dra. Dagma Venturini Marques Abramides, por seu carinho, paciência e ensinamentos preciosos.

Acima de tudo, dedico esse trabalho a cada criança e familiar que participou desse estudo. A Música não possui fronteiras, ela quebra barreiras. Todo esse trabalho é insignificante sem vocês.

"Follow the sound..." 



\section{AGRADECIMENTOS}

\section{A Deus pelo dom da vida e da sabedoria.}

Ao meu pai, por ser meu maior incentivador a encarar a loucura que é "viver" de música. Se não fosse seu empenho, não teria conseguido chegar até aqui.

A minha mãe, por seus puxões de orelha e por ser um exemplo de mulher. Obrigada por ser minha melhor amiga.

Ao meu marido Fabio, por sempre estar "aqui", com paciência e dedicação, me fazendo rir em momentos difíceis da minha trajetória.

A minha irmã, Perla. Que consegue ser tão parecida e tão diferente de mim.

Obrigada por me ajudar a adentrar ao universo da pesquisa e a USP.

Aos meus sogros, que não são sogros, são verdadeiros pais. Raymond e Felomena, obrigada por todo amor e suporte.

Ao irmão que a vida me presenteou. Beto, você é tão parecido comigo que com certeza não é só meu cunhado. É meu irmão.

Aos meus familiares, que mesmo longe estão sempre por perto. Famílias Martins, Nascimento, Said e Kassis, vocês são a base de tudo.

Aos meus amigos, os que estão perto e os que estão longe. Cada um de vocês é essencial em minha vida.

A Profa. Dra. Natália Barreto Frederigue Lopes, por sua amizade, ajuda e orientação em tudo que precisei.

Aos meus professores do curso e aos funcionários do departamento e da pósgraduação.

A orientadora Profa. Dra. Dagma Venturini Marques Abramides, agradeço por essa parceria de seis anos. Muito obrigada por tudo!

A Danielle Mecheseregian, por me ajudar na coleta e por toda a paciência!

Muito obrigada!

Aos queridos funcionários e amigos da Bravo Academia de Música, por todo empenho e amizade. 

"A música é o verbo do futuro." Victor Hugo 



\section{RESUMO}

Objetivos: Realizar uma revisão sistemática com o intuito de analisar os benefícios das abordagens musicais em crianças e adolescentes usuários de implante coclear (Estudo 1) e investigar o efeito da Musicalização Infantil sobre o repertório de habilidades perceptivas, cognitivas e sociais em crianças com implante coclear (IC) entre 06 e 10 anos de idade (Estudo

2). Métodos: Para isso foi realizada uma busca bibliográfica nas bases de dados para pesquisa de artigos científicos indexados em abril de 2020, sem limite de data ou idioma. Buscamos por estudos clínicos randomizados, que incluíssem pelo menos um dos nossos desfechos primários ou secundários, afim de usar a diferença média para dados contínuos, com intervalos de confiança de 95\%, e usar o modelo estatístico de efeitos aleatórios quando as estimativas de efeito de dois ou mais estudos pudessem ser combinadas em uma meta-análise (Estudo 1). Para o Estudo 2 foram selecionados para o presente estudo 10 sujeitos com IC, ambos os sexos, faixa etária de 06 a 10 anos, que formaram o grupo experimental. Este foi um estudo clínico randomizado que foi adotado por envolver a condição experimental permitindo múltiplas comparações, onde todos os sujeitos participaram de um semestre de aulas de musicalização infantil e foram avaliados quatro vezes, dois meses antes do início, no início, no meio e ao final da coleta, por meio do Sistema de Avaliação de Habilidades Sociais (SSRS), Inventário multimídia de habilidades sociais (IMHS), Teste de Classificação de Cartas de Wisconsin (WCST) e Escala de Bem-estar e Envolvimento, utilizado para avaliar os sujeitos durante as aulas, que foram gravadas e foram avaliadas por três juízes (educadores musicais externos a coleta), pré e pós intervenção. As Educadoras Musicais envolvidas na coleta também avaliaram os sujeitos durante e após o término da coleta, por meio do diário de classe. O teste de Kappa de Fleiss verificou a confiabilidade intrajuizes nas análises da escala de bem-estar e envolvimento e para avaliar os dados gerados pelo referido instrumento foi utilizado o Teste de Wilcoxon. Para comparação das múltiplas avaliações dos outros instrumentos foi utilizado o Teste ANOVA para análise de variância de medidas repetidas. $(\mathrm{p}<0,05)$. Para a revisão sistemática, seguiu-se as diretrizes para elaboração de revisões sistemáticas do PRISMA e a mesma foi registrada no PROSPERO. Resultados: No Estudo 1 não foram encontrados estudos clínicos randomizados que utilizassem abordagens musicais em crianças e adolescentes usuários de implante coclear. Os resultados do Estudo 2 apontam que houve melhora estatisticamente significativa no SSRS-M no escore global e nos fatores, responsabilidade, desenvoltura social e civilidade e nos problemas de comportamento externalizantes e escore global. SSRS-P no escore global, autocontrole, assertividade e desenvoltura social, afetividade 

e cooperação e nos problemas de comportamento externalizantes, hiperatividade e no escore global, bem como na competência acadêmica. O IMHS apresentou diferença estatisticamente significante na assertividade e enfrentamento-habilidoso, habilidoso passivo e Participação Não Habilidoso Passivo. O WSCT apontou significância no nível conceitual, categorias completadas, número de ensaios e aprendendo a aprender. O teste de Wilcoxon apontou diferença estatisticamente significante na visão dos juízes na escala de bem-estar e envolvimento. No que se refere a revisão sistemática, não foram encontrados estudos clínicos randomizados que pudessem ser incluídos na mesma. Conclusão: Não foram encontradas evidências disponíveis de estudos clínicos randomizados para embasar o julgamento sobre a eficácia das abordagens musicais em crianças e adolescentes usuários de implante coclear (Estudo 1). O Estudo 2 mostrou que crianças usuárias de implante coclear, expostas a Musicalização Infantil, obtiveram melhora no repertório de Habilidades Cognitivas (funções executivas), Sociais (responsabilidade, afetividade, cooperação, assertividade, desenvoltura social, civilidade, autocontrole, enfrentamento e participação) com redução de problemas de comportamento externalizantes e hiperatividade e incremento da competência acadêmica. No que se refere aos níveis de bem-estar e envolvimento, também houve melhora estatisticamente significante.

Palavras-chaves: Música. Aprendizado Musical. Implante Coclear. Percepção. Habilidades Sociais. Cognição. 



\section{ABSTRACT \\ Contributions of musicalization in the development of perceptual, cognitive and social skills in children with cochlear implants}

Objectives: Conduct a systematic review in order to analyze the benefits of musical approaches in children and adolescents using cochlear implants (Study 1) and investigate the effect of Child Musicalization on the repertoire of perceptual, cognitive and social skills in children with cochlear implants (HF) between 06 and 10 years of age (Study 2). Methods: For this, a bibliographic search was carried out in the databases to search for scientific articles indexed in April 2020, without date or language limit. We searched for randomized clinical studies, which included at least one of our primary or secondary outcomes, in order to use the mean difference for continuous data, with $95 \%$ confidence intervals, and to use the statistical model of random effects when the effect estimates of two or more studies could be combined in a meta-analysis (Study 1). For Study 2, 10 subjects with HF were selected for the present study, both sexes, aged from 06 to 10 years old, who formed the experimental group. This was a randomized clinical study that was adopted because it involves the experimental condition allowing multiple comparisons, where all subjects participated in one semester of children's music classes and were evaluated four times, two months before the beginning, at the beginning, in the middle and at the end of the collection, through the Social Skills Assessment System (SSRS), Multimedia Social Skills Inventory (IMHS), Wisconsin Card Classification Test (WCST) and Well-Being Scale to be and Involvement, used to evaluate the subjects during the classes, which were recorded and evaluated by three judges (music educators external to the collection), pre and post intervention. The Musical Educators involved in the collection also evaluated the subjects during and after the end of the collection, through the class diary. The Kappa de Fleiss test verified intra-juvenile reliability in the analysis of the well-being and involvement scale and the Wilcoxon test was used to assess the data generated by the instrument. To compare the multiple assessments of the other instruments, the ANOVA test was used to analyze the variance of repeated measures. $(\mathrm{p}<0.05)$. For the systematic review, the guidelines for the preparation of systematic reviews of PRISMA were followed and it was registered in PROSPERO. Results: At the Study 1, no randomized clinical studies were found using musical approaches in children and adolescents using cochlear implants. The results of Study 2 show that there was a statistically significant improvement in the SSRS-M in the global score and in the factors, responsibility, social resourcefulness and civility and in the externalizing behavior 

problems and the global score. SSRS-P in the global score, self-control, assertiveness and social resourcefulness, affectivity and cooperation and in externalizing behavior problems, hyperactivity and in the global score, as well as in academic competence. The IMHS showed a statistically significant difference in assertiveness and skillful coping, skillful passive and Participation - Not Skilled Passive. The WSCT pointed out significance at the conceptual level, completed categories, number of essays and learning to learn. The Wilcoxon test showed a statistically significant difference in the judges' view on the scale of well-being and involvement. Regarding the systematic review, no randomized clinical studies were found that could be included in the review. Conclusion: We conclude that there is no evidence available from randomized clinical studies to base a judgment on the effectiveness of musical approaches to children and adolescents using cochlear implants (Study 1). Study 2 shows us that children using cochlear implants exposed to Children's Musicalization, showed improvement in the Cognitive Skills: executive functions and Social Skills: responsibility, affectivity, cooperation, assertiveness, social resourcefulness, civility, self-control, coping and participation, externalizing behavior problems and hyperactivity, academic competence, well-being and involvement.

Keywords: Music. Music Trainning. Cochlear implant. Perception. Social skills. Cognition. 



\section{LISTA DE ILUSTRAÇÕES}

\section{FIGURAS}

Figura 1 - Processamento auditivo (CHING ET AL., 2015) ..................................... 22

Figura 2 - Representação Esquemática do Cérebro Musical. (LEVITIN, 2010)........... 37

Figura 3 - Esquema simplificado de um hemisfério cerebral da via auditiva ascendente entre a cóclea e o córtex auditivo primário, mostrando algumas das estruturas subcorticais envolvidas no processamento auditivo. (PATEL E IVERSEN, 2007)

Figura 4 - Diagrama esquemático do sistema auditivo, ilustrando as várias estações de processamento subcortical entre a cóclea e o córtex. (CHANDRASEKARAN E KRAUS, 2010) ......................................... 40

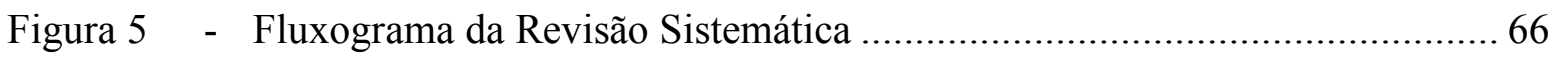

Figura 6 - Modelo de estrutura de aula.............................................................. 101

\section{QUADROS}

Quadro 1 - Tipos de perda (Guia de Orientações na Avaliação Audiológica Básica.

Sistema de Conselhos de Fonoaudiologia, 2017)

Quadro 2 - Graus de perda (Guia de Orientações na Avaliação Audiológica Básica.

Sistema de Conselhos de Fonoaudiologia, 2017) ................................. 23

Quadro 3 - Audiação preparatória (GORDON, 2008).............................................. 32

Quadro 4 - Correlação entre as teorias de Vygotsky e Gordon....................................... 33

Quadro 5 - Quadro Síntese dos estudos excluídos da Revisão Sistemática.................... 70

Quadro 6 - Quadro de estudos excluídos da Revisão Sistemática................................ 76

Quadro 7 - Quadro de métodos não utilizados na Revisão Sistemática ........................ 87 



\section{LISTA DE TABELAS}

Tabela 1 - Caracterização dos participantes da amostra 106

Tabela 2 - Análise descritiva das variáveis qualitativas nominais nível S.E., escala e perda da amostra 106

Tabela 3 - Comparação das habilidades sociais na percepção dos pais, entre os resultados das quatro avaliações do grupo experimental.

Tabela 4 - Comparação dos problemas de comportamento na percepção dos pais, entre os resultados das avaliações do grupo experimental.

Tabela 5 - Comparação das habilidades sociais na percepção dos professores, entre os resultados das avaliações do grupo experimental.

Tabela 6 - Comparação dos problemas de comportamento na visão dos professores, entre as avaliações do grupo experimental.

Tabela 7 - Comparação da competência acadêmica na percepção dos professores, entre os resultados das avaliações do grupo experimental.

Tabela 8 - IMHS, entre os resultados das avaliações da frequência de emissão dos fatores do grupo experimental.

Tabela 9 - Comparação WSCT, entre os resultados das avaliações do grupo experimental.......

Tabela 10 - Confiabilidade interjuízes para a escala de bem estar e envolvimento

Tabela 11 - Comparação da variável escala de bem-estar e envolvimento pré e pós intervenção da amostra 



\section{LISTA DE ABREVIATURA E SIGLAS}

IC Implante Coclear

AASI Aparelho de Amplificação Sonora Individual

MLT Music Learning Theory

GE Grupo Experimental

HS Habilidades sociais

OMS Organização Mundial da Saúde

SSRS-BR Sistema de Avaliação de Habilidades Sociais - Brasil

SSRS-M Sistema de Avaliação de Habilidades Sociais - Mães

SSRS-P Sistema de Avaliação de Habilidades Sociais - Professores

WCST Teste de Classificação de Cartas de Winsconsin

IMHS Inventário Multimidia de Habilidades Sociais

TCLE Termo de Consentimento Livre e Esclarecido

TALE Termo de Assentimento Livre e Esclarecido

CEP Comitê de Ética em Pesquisa 



\section{SUMÁRIO}

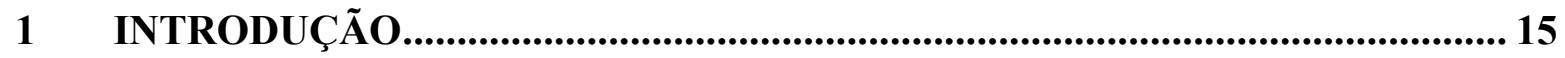

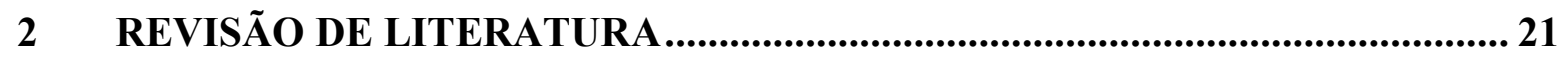

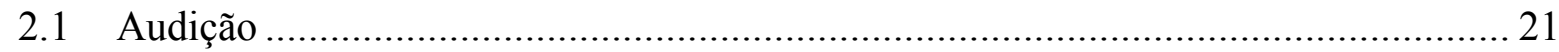

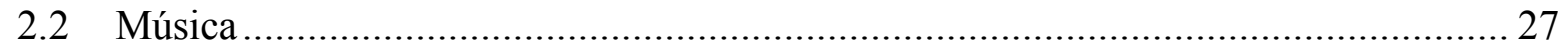

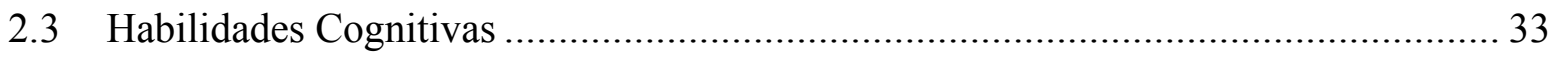

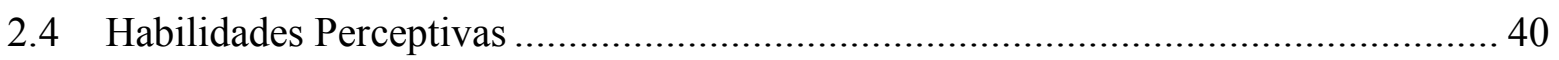

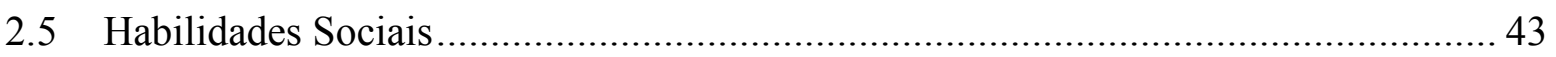

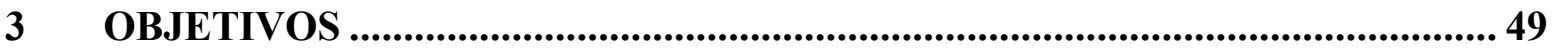

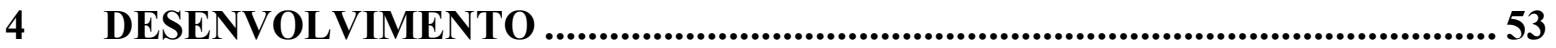

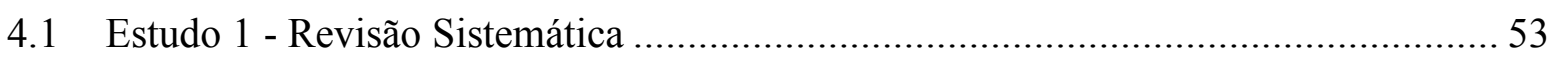

4.2 Estudo 2- Contributos da musicalização infantil no desenvolvimento das habilidades perceptivas, cognitivas e sociais em crianças com implante coclear........................... 92

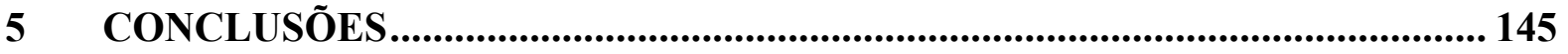

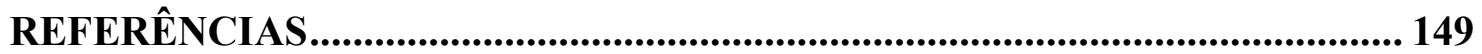






\section{INTRODUÇÃO}

Segundo o dicionário Música é Arte e Ciência de combinar harmoniosamente os sons; combinação de sons a fim de torná-los harmoniosos e expressivos. Ação de se expressar através de sons, pautando-se em normas que variam de acordo com a cultura e sociedade (FERREIRA, 2004).

Podemos dizer que Música é um conjunto de sons e silêncios, de modo organizado e agradável ou não, ao ouvido. Ela manipula o som e organiza o tempo, talvez seja por isso que está sempre fugindo a qualquer definição, pois ao busca-la a música já se modificou, já evoluiu. O som é a acústica. É a sensação causada no ouvido por meio da vibração de um corpo.

A quantidade de vibrações por segundo é chamada de Hertz (Hz). O ouvido humano não percebe sons menores que $20 \mathrm{~Hz}$, chamados de infrassom, e nem maiores que 20.000,00 $\mathrm{Hz}$, chamados ultrassom. Quanto maior o número de vibrações por segundo, mais agudo será o som. Quanto menor, mais grave. O contrário do som é o silêncio.

O som possui características, chamadas de parâmetros do som. São elas: Altura - Grave, médio ou agudo. Duração - O tempo da duração do som. Intensidade - Forte ou fraco e o Timbre - Qualidade que permite reconhecer a origem do som.

Em música os sons são chamados de notas musicais e para compreende-la melhor, vamos pensar em seus elementos básicos: harmonia, melodia e ritmo.

A harmonia é uma combinação de notas e a relação das distâncias, também conhecidas como intervalos, que existe entre eles. Então dependendo de como você mistura as notas musicais, a sonoridade dessa combinação pode expressar sensações e emoções subjetivas como felicidade, tristeza, medo, etc.

A melodia é uma sequência de notas tocadas sucessivamente, que geralmente é aquilo com que nos familiarizamos mais quando pensamos em uma música. É aquilo que nós cantamos ou assobiamos.

O ritmo é a organização de cada som ao longo do tempo, isto é, ele determina a sucessão de tempos dentro da música, sequenciando os sons temporalmente e possibilitando o progresso da harmonia e melodia. O ritmo nos diz a ordem e em que momentos cada som deve ser tocado, de acordo com a marcação do tempo (pulsação) e o andamento (lento ou rápido) que o ritmo determina dentro de cada música. A música é uma arte que acontece no tempo. Assim como um pintor possui sua tela, o músico tem o compasso, que irá determinar o tamanho de tempo 
para os sons acontecerem.

Música é arte, é ciência e é um meio de comunicação, verbal e não-verbal. É também uma manifestação sociocultural.

Hoje em dia, ouvimos muito que música é saúde. Mas que música? Qualquer música? Qualquer manifestação musical?

Ao pensarmos em música, devemos pensar em uma "grande área", composta por subáreas. Dentro da grande área da Música nós temos a Performance, a Educação Musical e a Musicoterapia. Também temos a área comercial, relacionada a área da indústria fonográfica, porém essa área não corresponde ao que iremos abordar no presente estudo.

A Educação Musical, como o próprio nome já sugere, é a área que estuda e capacita o profissional para o ensino musical. Educadores Musicais não são necessariamente interpretes musicais e vice-versa. Dentro da educação musical, nós temos a musicalização. Primeira etapa do contato humano com os elementos que compõe a música. Qualquer pessoa que seja introduzida ao universo do aprendizado musical, será musicalizada.

A Performance é a área da música mais visível do meio musical. É a área onde encontram-se os instrumentistas, cantores, maestros, compositores, dentre outros. Para nos tornarmos um intérprete musical, necessitamos passar pelo aprendizado musical, ou seja, pela educação musical.

A musicoterapia dedica-se em melhorar a saúde e a qualidade de vida das pessoas por meio da música. Ela consiste na utilização da música e de seus elementos (ritmo, melodia, harmonia) por um musicoterapeuta qualificado, sem um fim musical. Ou seja, em sessões de musicoterapia você não $f a z$ música, você é exposto a ela. Para tornar-se musicoterapeuta, é necessário o estudo dos elementos básicos que compões a música, ou seja, é necessário o mínimo de contato com a educação musical.

Diante dessas definições, voltamos ao questionamento, que música promove saúde de forma global?

Ao adentrarmos ao universo acadêmico musical nos deparamos com uma literatura sem um delineamento controlado. Na literatura da área musical, são raros os estudos baseados em evidências científicas. Por outro lado, na literatura da área da saúde, encontramos estudos controlados e que perseguem níveis de evidência científicas satisfatórios, porém, que confundem as áreas da música, por exemplo, nomeando e comparando por vezes estudos de ensino musical com musicoterapia e vice-versa.

Em síntese tais equívocos ocorrem porque a área científica musical, é algo relativamente novo, porém, ao observarmos a literatura, o que fica claro é que hoje, quando se fala em "música 
é saúde”, o que se quer dizer em categorias mais específicas é, aprender música é saúde. Física e mental.

Em virtude desses fatores, o presente estudo é uma continuidade do estudo realizado no meu mestrado, intitulado "Efeito da educação musical na promoção das habilidades sociais e escolares em crianças", no qual os resultados indicaram diferença estatisticamente significante nas crianças expostas ao aprendizado musical, evidenciando que houve melhoria no repertório de habilidades sociais e acadêmicas das mesmas (SAID e ABRAMIDES; 2014). A continuidade do estudo vem com um diferencial no delineamento do estudo, abordando áreas da música, saúde e educação afim de aprofundar e quiçá responder questionamentos a respeito dos benefícios do contato musical com o ser humano. O olhar voltado para crianças com deficiência também é um diferencial, pois as funções da música na vida cotidiana estão claramente relacionadas às relações interpessoais e o aumento do número de pesquisas relacionando a música no campo da saúde e educação tem demonstrado o seu papel como importante aliado às alternativas de tratamento, especialmente, quando utilizada como técnica de intervenção nos processos comportamentais e estados emocionais. Entretanto, estudos controlados sobre a investigação do impacto do aprendizado musical, e mais especificamente, a Musicalização Infantil em crianças com implante coclear (IC) não foram encontrados.

Sendo a Fonoaudiologia a Ciência que estuda a comunicação humana, no que se refere à audição, linguagem, voz e motricidade orofacial, e a Psicologia a Ciência que estuda o comportamento humano, podemos relacioná-las diretamente à Música, ou mais especificamente, ao aprendizado musical, por terem fatores primordiais em comum.

Portanto, este estudo aponta para a utilização das atividades musicais, como a musicalização infantil, na promoção das habilidades de vida englobando as habilidades sociais e interpessoais, cognitivas e perceptivas, que devem ser utilizadas como fatores de proteção para o desenvolvimento satisfatório da infância.

Dessa forma esse estudo propõe como metodologia inovadora a utilização da Musicalização Infantil, que é a primeira etapa da Educação Musical, para verificar os seus efeitos nas habilidades perceptivas, cognitivas e sociais, na forma de categorias de comportamentos, na população de crianças com IC.

No processo comunicativo também estão incluídos os componentes não-verbais que complementam, ilustram, regulam, substituem e algumas vezes se opõem até mesmo aos componentes verbais. Portanto, a utilização da linguagem como veículo de comunicação, em suas modalidades verbal e não- verbal, possibilita a criança com IC interagir com seus pares e 
com os adultos favorecendo a troca de informação, experiências, emoções, aprendizado e, consequentemente, a oralidade.

Considerando os aspectos de interação social, habilidades sociais, cognitivas e perceptivas são fatores essenciais e importantes para o pleno desenvolvimento da criança em idade escolar, pelo fato dessa faixa etária representar o período de aquisição e desenvolvimento do repertório de tais habilidades. A atuação do educador musical pode contribuir tanto na avaliação quanto na promoção dessas habilidades desenvolvendo metodologias e técnicas que otimizem o repertório social, bem como gerar a possibilidade de outras pesquisas futuras.

Dada a natureza do ser humano que engloba aspectos biológicos, psicológicos e sociais que se entrelaçam criando uma estrutura única, não existe uma disciplina que, em si, produza o saber absoluto havendo, portanto, a necessidade de se promover a interface entre as diversas áreas do conhecimento. E nisto consiste o caráter inovador do presente estudo na medida em que a Música enquanto Ciência Humana se une à Fonoaudiologia e Psicologia para o estabelecimento de abordagem interdisciplinar. 
2 Revisão de Literatura 



\section{REVISÃO DE LITERATURA}

\subsection{Audição}

O sistema auditivo humano executa inúmeras tarefas e durante a evolução humana, uma das tarefas fundamentais do sistema auditivo era de alertar algo por meio do som. Uma das principais tarefas do sistema auditivo é a comunicação. Os humanos usam sons e gestos em comunicar-se com os outros. Alguns gestos e sons evoluíram para a linguagem humana, enquanto outros evoluíram para música e dança. (MITHEN ET AL., 2006; TORPPA E HUOTILAINEM, 2019).

Ele é um dos sistemas mais complexos do nosso organismo; é ele o responsável por captar as ondas sonoras e dar início ao processo de percepção e interpretação dos sons. Ele é constituído por duas partes distintas interrelacionadas: a primeira é o sistema auditivo periférico, formado pelas estruturas da orelha externa, média e interna e pelo sistema nervoso periférico, composto pelo nervo coclear; e a segunda parte é formada pelo sistema auditivo central, constituído pelas vias auditivas localizadas no tronco encefálico e pelas áreas corticais (BEVILACQUA ET AL., 2011)

A orelha é um órgão capaz de decifrar precisamente as diferentes frequências e intensidades de uma mistura de ondas sonoras que é constantemente gerada no ambiente, enquanto, ao mesmo tempo, transfere as informações coletadas para o cérebro e nos permite categorizar cada som e identificar sua direção e distância relativa. Segundo os autores a orelha está abrigada no osso temporal e é dividida em três compartimentos anatômicos: a orelha externa, a média e a interna; cada um com características estruturais e funcionais distintas. A orelha externa é formada pelo pavilhão auricular, responsável pela captação do som, e pelo canal auditivo externo, responsável por conduzir o som captado até a membrana timpânica. A orelha média é formada pela cavidade timpânica e por três ossículos, o martelo, a bigorna e o estribo, que são montados em conjunto e servem como um elo entre o tímpano e a orelha interna, que é preenchida por fluido (DROR E AVRAHAM, 2009).

Ouvir é uma função neurológica. Logo, nós ouvimos com o cérebro, por meio do processamento auditivo. Podemos dizer que o processamento auditivo é a conversa entre a orelha e o cérebro. 


\section{Processamento auditivo}

Os sons são vibrações do meio externo, que se transmitem ao órgão receptor da audição e são transformadas em potenciais bioelétricos para o processamento no sistema auditivo, dividindo-se em submodalidades: discriminação da intensidade sonora, identificação de timbres, discriminação tonal, compreensão da fala, localização espacial dos sons e a interpretação de sons complexos. Sendo assim, para que as informações sejam processadas auditivamente, os sons devem ser detectados e interpretados, ou seja, os estímulos acústicos são recebidos pelo sistema periférico e codificados neuralmente (LENT, 2005; RIOS, 2007).

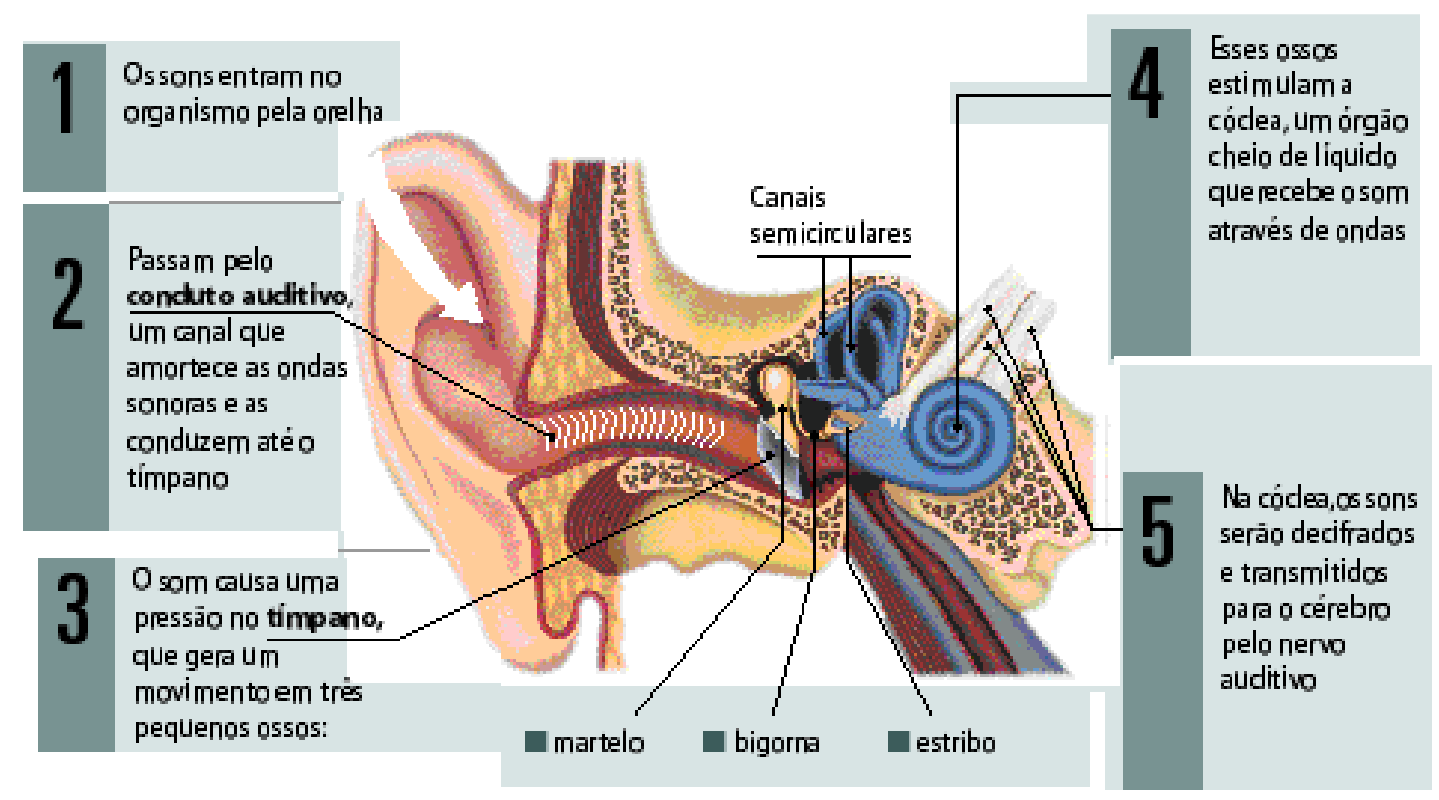

Figura 1 - Processamento auditivo - Ching et al. (2015)

Segundo Ching et al. (2015) a audição humana é uma função complexa, que envolve a conversão da energia acústica original em energia mecânica, hidráulica e, por fim, elétrica. Com finalidade didática, o sistema auditivo é dividido em duas porções, sendo que na porção periférica ocorre a citada transdução do sinal acústico em elétrico para que o seu produto seja processado ao longo da porção central.

Para Bevilacqua et al. (2011), a audição é configurada como fator fundamental para o desenvolvimento global do indivíduo. É por meio dela que o ser humano adentra o mundo sonoro, permitindo que o processo de aquisição e desenvolvimento da linguagem ocorra. 


\section{Perda auditiva}

Durante muito tempo, a deficiência auditiva foi considerada uma doença incapacitante. Nos últimos anos, muito tem sido feito para amenizar esse estigma e proporcionar a melhora da qualidade de vida dos indivíduos portadores de deficiência auditiva.

Tipos de perda:

\begin{tabular}{|c|c|}
\hline TIPO DE PERDA & CARACTERÍSTICAS \\
\hline $\begin{array}{c}\text { Perda auditiva } \\
\text { condutiva }\end{array}$ & Limiares de via óssea menores ou iguais a $15 \mathrm{~dB}$ NA e limiares de via \\
\hline $\begin{array}{c}\text { Perda auditiva } \\
\text { sensorioneural }\end{array}$ & aérea maiores que $25 \mathrm{~dB}$ NA, com gap aéreo-ósseo maior ou igual a $15 \mathrm{Db}$ \\
\hline $\begin{array}{c}\text { Perda auditiva } \\
\text { mista }\end{array}$ & maiores que $25 \mathrm{~dB}$ NA, com gap aéreo-ósseo de até $10 \mathrm{Db}$ \\
\hline
\end{tabular}

Quadro 1 - Guia de Orientações na Avaliação Audiológica Básica. Sistema de Conselhos de Fonoaudiologia. 2017.

Graus de perda:

\begin{tabular}{|r|c|c|}
\hline \multicolumn{2}{|c|}{$\begin{array}{c}\text { MÉDIA QUADRTONAL (OMS, 1997) } \\
\text { LimiarQuar } \\
\text { auditivo }\end{array}$} & Grau de handicap \\
\hline $25 \mathrm{~dB}$ & Não significativo & Sem dificuldade \\
\hline 26 a $40 \mathrm{Db}$ & Leve & Dificuldade somente na fala fraca \\
\hline $41 \mathrm{a} 60 \mathrm{~dB}$ & Moderado & Frequente dificuldade com fala normal \\
\hline 60 a $80 \mathrm{~dB}$ & Severa & Só entende fala gritada/amplificada \\
\hline+ de $81 \mathrm{~dB}$ & Profunda & Não entende a fala mesmo com \\
\hline
\end{tabular}

Quadro 2 - Guia de Orientações na Avaliação Audiológica Básica. Sistema de Conselhos de Fonoaudiologia. 2017. 
A audição é considerada a principal via para a aquisição da linguagem oral. Desta forma, a deficiência auditiva é um fator que compromete diretamente a linguagem do indivíduo. Esse comprometimento pode variar de acordo com o tipo e o grau da perda de audição. Sabe-se que a perda auditiva sensorioneural de grau severo a profundo é a que mais pode causar danos linguísticos, uma vez que dificulta a aquisição e desenvolvimento da linguagem oral, principalmente em indivíduos com perda auditiva pré-lingual. Os impactos da perda auditiva permanente na infância agem negativamente no desenvolvimento das habilidades auditivas, de fala, de linguagem, psicossociais e nos níveis de escolaridade da criança. A perda auditiva acarreta em diversas consequências negativas para a vida de um indivíduo, interferindo decisivamente na sua qualidade de vida, uma vez que provoca isolamento social e familiar (CAMPOS ET AL., 2008; CHING ET AL. ,2015; TEIXEIRA E GARCES, 2011).

A (re)habilitação auditiva pode ser definida como um processo de resolução de problemas, com o objetivo de minimizar a dificuldade (limitação de atividade) e a desvantagem (restrição de participação de um indivíduo com uma deficiência de audição em atividades) (NÓBREGA ET AL. ,1998; THEUNISSEN E SWANEPOEL 2008; PINTO ET AL., 2012).

O processo de reabilitação auditiva possibilita que os indivíduos retomem a sua vida social, participando de atividades em grupo, melhorando sua autoestima e bem-estar. Dentro da abordagem oralista e bilíngue, o processo de (re)habilitação auditiva contempla, entre outros, o Implante Coclear (IC) (WILKERSON, 2000; TEIXEIRA ET AL., 2011).

\section{Implante Coclear (IC)}

Desde a década de sessenta indivíduos com surdez profunda passaram a ter a possibilidade de obter sensações de som através de estimulação elétrica direcionada aos neurônios cocleares sobreviventes (GFELLER e LANSING, 1992). Diferentemente dos aparelhos de audição, que essencialmente amplificam os sons, através do implante coclear a pessoa passa a ser capaz de, a partir de um dispositivo, captar o som e transformá-lo em sinal elétrico que pode ser interpretado pelo cérebro como um sinal sonoro (GFELLER ET AL., 2000). O implante é composto por dois componentes: um interno, que é colocada na cóclea mediante um processo cirúrgico, e outro externo, afixado na cabeça do usuário. A pessoa com implante coclear pode desenvolver a habilidade de entender a fala normalmente, taxa que pode chegar a $70 \%-80 \%$ das frases em ambientes com pouco ruído. No entanto, ainda apresentam diversas limitações perceptivo-auditivas. 
Segundo Gfeller (2000), um processo de reabilitação tem como objetivo básico a restauração de habilidades ou o apoio e estímulo para que o indivíduo possa compensar habilidades que supram aquelas que não possam ser totalmente reabilitadas.

O implante coclear é, atualmente, o recurso tecnológico mais eficaz para favorecer o acesso do indivíduo com perda auditiva sensorioneural de grau severo e ou profundo ao mundo sonoro. Até então nenhum outro dispositivo eletrônico tornava possível que o indivíduo que adquiriu surdez severa ou profunda antes da aquisição da linguagem pudesse compreendê-la e expressá-la com funcionalidade e abstração (FORTUNATO ET AL., 2009; BEVILACQUA ET AL., 2011).

Os critérios de indicação ao implante coclear são multifatoriais e os centros auditivos se baseiam na Portaria GM/MS N².776, de 18 de dezembro de 2014 do Ministério da Saúde.

Critérios para a perda auditiva sensorioneual de grau severo e ou profundo bilateral em crianças:

Crianças com até 4 anos de idade incompletos, que apresentem perda auditiva sensorioneural, de grau severo e ou profundo bilateral, quando preenchidos todos os seguintes critérios:

a) Experiência com uso de aparelhos de amplificação sonora individual - AASI (por um período mínimo de três meses) e idade mínima de 18 meses na perda auditiva severa. Idade mínima de 6 meses em casos de meningite e/ou surdez profunda de etiologia genética comprovada, e nestes casos, não é obrigatória a experiência com AASI;

b) Falta de acesso aos sons de fala em ambas as orelhas com AASI, ou seja, limiares em campo livre com AASI piores que 50dBNA nas frequências da fala $(500 \mathrm{~Hz}$ a $4 \mathrm{kHz})$;

c) Adequação psicológica e motivação da família para o uso do implante coclear, manutenção/cuidados e para o processo de reabilitação fonoaudiológica;

d) Acesso à terapia fonoaudiológica com condições adequadas de reabilitação auditiva na região de origem (referência/contra referência);

e) Compromisso em zelar dos componentes externos do implante coclear e realizar o processo de reabilitação fonoaudiológica.

Crianças a partir de 4 até 7 anos de idade incompletos, que apresentem perda auditiva sensorioneural, de grau severo e ou profundo bilateral, quando preenchidos todos os seguintes critérios:

a) Resultado igual ou menor que $60 \%$ de reconhecimento de sentenças em conjunto aberto com uso de AASI na melhor orelha e igual ou menor do que $50 \%$ na orelha a ser 
implantada;

b) Presença de indicadores favoráveis para o desenvolvimento de linguagem oral mensurado por protocolos padronizados;

c) Adequação psicológica e motivação da família para o uso do implante coclear, manutenção/cuidados e para o processo de habilitação e reabilitação fonoaudiológica;

d) Acesso e adesão à terapia fonoaudiológica com condições adequadas de habilitação e reabilitação auditiva na região de origem (referência/contra referência);

e) Compromisso em zelar dos componentes externos do implante coclear e realizar o processo de reabilitação fonoaudiológica.

Crianças a partir de 7 até 12 anos de idade incompletos, que apresentem perda auditiva sensorioneural, de grau severo e ou profundo bilateral, quando preenchidos todos os seguintes critérios:

a) Resultado igual ou menor que $60 \%$ de reconhecimento de sentenças em conjunto aberto com uso de AASI na melhor orelha e igual ou menor que 50\% na orelha a ser implantada, com percepção de fala diferente de zero em conjunto fechado;

b) Presença de código linguístico oral em desenvolvimento mensurados por protocolos padronizados. Devem apresentar comportamento linguístico predominantemente oral. Podem apresentar atraso no desenvolvimento da linguagem oral considerando a sua idade cronológica, manifestado por simplificações fonológicas, alterações sintáticas (uso de frases simples compostas por três a quatro palavras), alterações semânticas (uso de vocabulário com significado em menor número e em menor complexidade, podendo ser restrito para as situações domiciliares, escolares e outras situações do seu cotidiano) e alterações no desenvolvimento pragmático, com habilidades de narrativa e argumentação ainda incipientes;

c) Adequação psicológica, motivação e expectativa adequada do paciente e da família para o uso do implante coclear;

d) Acesso à terapia fonoaudiológica com condições adequadas para reabilitação auditiva na região de origem (referência/contra referência);

e) Uso de AASI contínuo e efetivo desde no mínimo 2 (dois) anos de idade sugerindo a estimulação das vias auditivas centrais desde a infância;

f) Compromisso em zelar dos componentes externos do implante coclear e realizar o processo de reabilitação fonoaudiológica.

Diversos estudos apontam que o implante coclear é capaz de possibilitar a integração ao mundo sonoro e a percepção dos sons da fala favorecendo satisfatoriamente muitas crianças, 
porém os benefícios não são idênticos para todas. Os autores referem que os resultados a serem alcançados pelas crianças implantadas dependem de um processo complexo e multidimensional, pois a variabilidade dos resultados pós-implantação exibem a necessidade de outras avaliações além das audiológicas e de linguagem, como por exemplo, dos processos neurocognitivos, a fim de adequar as expectativas e de melhorar os resultados (BEVILACQUA E FORMIGONI, 2003; MORET ET AL., 2007; CAMPOS ET AL., 2008; PISONI ET AL., 2011; GFELLER, 2016; TORPPA ET AL., 2019).

\subsection{Música}

Música é a arte de combinar sons simultaneamente e sucessivamente, com ordem, equilíbrio e proporção dentro do tempo. É a ciência que desde os primórdios da sociedade é considerada veículo de aprendizado e bem-estar, em que se observam elementos culturais, pessoais, subjetivos, criativos, fisiológicos, emocionais e comunicativos, por isso também é uma forma de comunicação. Verbal e não verbal.

A música, como arte de combinação dos sons, é praticamente tão antiga quanto o ser humano, posto que o próprio ato comunicativo verbal é uma sequência de combinações sonoras e, portanto, em certa medida, poderia também ser considerado música (FERREIRA, 2012).

Areias (2016) descreve a música como uma forma de expressão inerente ao ser humano, suscetível de partilha de emoções ou afetos. Uma interação que promove e fortalece as relações humanas, aumentando a empatia e o prazer nesse relacionamento. Favorecendo ainda a evocação de memórias emocionais, sendo, assim, um veículo para sentimentos inatingíveis de outro modo. O conhecimento de que a música interfere na saúde e no bem-estar das pessoas já existia no tempo de Aristóteles e Platão. No entanto, somente em meados do século passado foi possível estabelecer, com evidências científicas, uma relação entre a música e a saúde.

A música não é simplesmente um espelho que reflete sistemas culturais e redes de crenças e tradições, mas pode ser uma janela que abre novas possibilidades (SWANWICK, 2018).

\section{Aprendizado Musical}

O aumento do número de pesquisas relacionando o aprendizado musical no campo da saúde e educação tem demonstrado o seu papel como importante aliado às alternativas de tratamento, especialmente, quando utilizada como técnica de intervenção nos processos comportamentais e estados emocionais (DE ALMEIDA SILVA, 2010; DASTGHEIB ET AL, 
2013; GORDON ET AL. 2015; PATSCHEKE ET AL., 2018, GFELLER, 2016, YANG ET AL., 2019; SAID E ABRAMIDES, 2020).

A neuroeducação musical, área interdisciplinar que alia os conhecimentos entre neurociência, educação, psicologia e música (CONSENZA \& GUERRA, 2011) é uma subárea da neurociência que busca potencializar a compressão e a adequação de práticas pedagógicas, fundamentando estratégias didáticas de acordo com o conhecimento já adquirido acerca do funcionamento do cérebro, permitindo o uso adequado de novas ferramentas para aprendizado, incluindo o aprendizado musical (FERNANDES E RIZZO, 2018).

Segundo Aguiar (2019), músicos consagrados como Villa-Lobos e Mário de Andrade, utilizaram a música como instrumento facilitador da aprendizagem e estimulante da autoestima da criança e, também, no processo de comunicação e socialização. A comunicação, seja ela verbal ou não verbal, é desenvolvida sob influência do meio sociocultural. Vygotsky considera a comunicação como um sistema simbólico fundamental em todos os grupos humanos, elaborado no curso da história social, desempenhando um papel imprescindível na formação das características psicológicas humanas (TORMIN, 2018).

Dentre as principais modalidades de intervenção musical temos a educação musical, que é um processo de construção do conhecimento e tem como objetivo despertar e desenvolver o gosto musical, favorecendo o desenvolvimento da sensibilidade, criatividade, senso rítmico, do prazer de ouvir música, da imaginação, memória, concentração, atenção, autodisciplina, do respeito ao próximo, socioafetivo, psicomotor e cultural (BRÉSCIA, 2003; MUZKAT 2016).

$\mathrm{Na}$ educação musical para crianças encontramos a Musicalização Infantil, uma abordagem específica que está definida no terceiro volume do Referencial Curricular Nacional para Educação Infantil. Através do lúdico e por meio de canções, jogos, danças, exercícios de movimento, relaxamento, improvisação, prática instrumental são trabalhadas as noções de ritmo, melodia, compasso, métrica, leitura musical, promovendo o desenvolvimento de aspectos psicológicos, cognitivos e motores, estimulando assim a psicomotricidade (BRASIL, 1998; LOURO, 2012; BROOCK, 2013).

Para Tormin (2018) embora a lei n. 11.769 que trata da obrigatoriedade da música na educação básica (BRASIL, 2008) tenha sido homologada, muito pouco tem sido feito na educação musical infantil no Brasil. Após mais de uma década, as novas orientações da base nacional comum curricular (BNCC/18) na área da educação infantil apontam a importância do ensino musical, ao tratar dos sons, no campo da experiência "traços, sons, cores e formas", bem como do movimento, no campo da experiência "corpo, gestos e movimentos" (brasil, 2018, p. 
45 e 46), que trazem a aprendizagem da música como um dos direitos da criança na educação infantil.

Estudos apontam que apesar de a música estar no contexto escolar regular, ela tem sido abordada de maneira meramente ornamental. Além dos educadores desconhecerem e pouco explorarem seus potenciais educativos, os mesmos não se sentem preparados para uma abordagem propriamente musical. Existe um grande equívoco ao se pensar que para trabalhar música com crianças, não há necessidade de muita capacitação. Assim os autores concluem que no caso da música, não basta gostar de crianças e de música, é preciso saber e saber fazer (BELLOCHIO, 2003; FIGUEIREDO, 2012; TORMIN, 2018).

Como base para as abordagens em educação musical temos os principais educadores musicais que estudaram e desenvolveram suas teorias de ensino (SWANWICK, 2018):

Zoltán Kodály (1882-1967) - A partir de 1945 desenvolveu um sistema de educação musical para as escolas públicas da Hungria, que enfatiza as canções do folclore nacional. Ele defendia que na música, assim como na linguagem e na literatura, um país deve começar com a língua musical nativa ("musical mother tongue"), que para ele era a cancão folclórica, e através dela ir expandindo até alcançar a compreensão da literatura musical universal.

Shin'ichi Suzuki (1898-1998) - Lançou o Movimento de Educação para o Talento no Japão. Sua premissa é que todo indivíduo possui talentos que podem ser desenvolvidos pela educação. O método Suzuki se baseia na sua observação do modo rápido e natural como as crianças pequenas aprendem a língua materna, na primeira infância, através da habilidade de comunicação entre os pais e a criança. Utilizou de uma adaptação dos princípios de aprendizagem da língua materna à educação musical

Edgar Willems (1890-1978) - Fazia e amava a música antes de tudo como linguagem, mas também como uma arte e ciência. Desenvolveu um trabalho de desenvolvimento auditivo para adultos e inovou a iniciação musical para crianças. Estabeleceu as bases da arte musical desenvolvendo o ouvido musical e o sentido rítmico, solicitando todas as faculdades sensório motoras, afetivas, mentais e intelectuais a fim de desenvolvê-las e harmonizá-las entre si.

Émile Jaques-Dalcroze (1865-1950) - Desenvolveu o sistema que ficou conhecido como "Dalcroze Eurhythmics" de treinamento musical, que tinha por objetivo criar através do ritmo, uma corrente de comunicação rápida e regular e constante entre o cérebro e o corpo, transformando o sentido rítmico numa experiência física corporal. Acreditava que processos corporais, ritmos e movimento eram a base da expressividade e pedagogia musical.

A abordagem Dalcroze tem muitas facetas incorporadas, mas é principalmente organizada em torno de anacruses motores. Tanto a música quanto o movimento envolvem o 
motor preparação (anacrusis), ação (crusis) e reação (metacrusis). Aquilo é uma fase única, a primeira uma preparação da segunda, a segunda a inevitável resultado do primeiro (DALCROZE, 1967). Isto é assim porque o coração do movimento rítmico é a duração (agogismo), intensidade (dinâmica) e espaço (SEITZ, 2005).

Dalcroze (1930) explica que (1) Ritmo é movimento, (2) movimento é essencialmente físico, (3) todo movimento requer espaço e tempo, (4) experiência física forma consciência musical, (5) melhoria dos meios físicos resulta em clareza de percepção, (6) A melhoria dos movimentos no tempo garante a consciência dos efeitos ritmo, assim como a melhoria dos movimentos no espaço garante a consciência de ritmo plástico.

Carl Orff (1895-1982) - Muito ligado ao teatro, à literatura e à educação, desenvolveu sua obra "Schulwerk" (Music for Children, 1930-33, revisada em 1950-54), baseada em padrões rítmicos simples que progridem até complexas e sonoras peças para conjuntos de xilofones, glockenspiels e outros instrumentos de percussão. Destina-se a todas as crianças, não buscando os talentos privilegiados, pois defendia o aprendizado por habilidades. Segundo ele há um lugar para cada criança, e cada uma contribui de acordo com sua habilidade. Muitos de seus alunos não tinham qualquer conhecimento musical prévio, e por isso ele enfatizava o uso de sons e gestos corporais para expressar o ritmo e a voz como primeiro e mais natural dos instrumentos.

Edwin Gordon (1927-2015) - Foi um músico e pesquisador que atuou nas áreas da psicologia do desenvolvimento e aprendizagem aplicados à música e educação musical. Gordon desenvolveu uma teoria de aprendizagem musical, conhecida como Music Learning theory (MLT). Ela foi elaborada durante a década de 70 e construída a partir da publicação de "Psychology of Music Teaching, (1971) e Learning Theory, Patterns, and Music (1975) no qual aparece, pela primeira vez, o termo audiação" (FREIRE, 2006).

\section{Music Learning Theory e Psicologia}

A MLT foi baseada e referenciada principalmente em Jerome Bruner (1915- 2016), um dos principais teóricos da psicologia da aprendizagem e da fundamentação teórica da corrente cognitivista. Além de Bruner, o psicólogo russo Vygotsky (1896-1924), um dos mais importantes do século XX, também possui suas teorias abrangendo o tema, e teve grande impacto para a consolidação da MLT. Os educadores musicais em questão possuem pontos em comum em suas abordagens. Todos partem de um material já familiar à criança, valorizando o material sonoro que ela já conhece previamente e criando vínculos de associação entre este material e novas ideias musicais, defendem que a prática vem antes da teoria, enfatizam a 
importância do movimento corporal junto à música e valorizam o processo de aprendizagem mais do que o resultado musical propriamente dito.

Vygotsky desenvolveu uma teoria histórico-cultural de crianças. Nela ele prima pela relevância que a educação tem, uma vez que ele enfatiza a importância da ligação entre as pessoas e o contexto cultural em que vivem e são educadas (TORMIN, 2014). Também se dedicou ao estudo das chamadas funções psicológicas superiores como um modo de funcionamento psicológico tipicamente humano que abrange a capacidade de planejamento, memória voluntária, imaginação, consciência, entre outros.

É importante registrar a correspondência de pensamentos e concepções que se interrelacionam entre estes autores. O nexo entre Vygotsky, Bruner e Gordon permite dizer que Bruner considerou muitos aspectos das concepções de Vygotsky em seus estudos sobre desenvolvimento e aprendizagem e que Gordon recebeu influências e contribuições de Bruner na elaboração da teoria da aprendizagem musical. Além disso, eles possuem formação acadêmica em Psicologia e Pedagogia; interesse pela educação, pelo ensino-aprendizagem; interesse nos estudos de neuropsicologia e psicologia cognitiva, além de considerarem a importância da dimensão social e cultural no desenvolvimento humano. (TORMIN, 2014).

Sousa (2020), explica que para Vygotsky o processo de aprendizagem acontece de forma colaborativa, ou seja, é uma ação conjunta, uma interação, entre educador e aluno. Seguindo essa perspectiva, dentro de uma aula que é embasada na Teoria de Aprendizagem Musical, a interação do educador musical com a criança é fundamental para identificar qual etapa da Audiação Preparatória essa criança se encontra e, é a partir dessa relação que o educador poderá potencializar para que a criança se desenvolva para atingir os estágios seguintes.

Gordon (2008) desenvolveu dois modelos que estão relacionados aos estágios e tipos da aprendizagem musical: o modelo de audiação preparatória, que tem como foco o desenvolvimento de estruturas sintáticas através da imersão em um ambiente musicalmente apropriado e rico; o modelo de aprendizagem musical formal. A audiação preparatória é dividida em 3 tipos e 7 estágios, conforme o quadro: 


\begin{tabular}{|c|c|}
\hline TIPOS & ESTÁGIOS \\
\hline $\begin{array}{l}\text { ACULTURAÇÃO: A criança participa com } \\
\text { pouca consciência do ambiente }\end{array}$ & $\begin{array}{l}\text { 1. Absorção: a criança ouve e absorve os } \\
\text { sons musicais do ambiente } \\
\text { 2. Resposta sem intenção: a criança se } \\
\text { move e faz balbucios, mas sem } \\
\text { relação com os sons musicais do } \\
\text { ambiente } \\
\text { 3. Reposta com intenção: a criança tenta } \\
\text { relacionar o movimento e o balbucio } \\
\text { com os sons musicais do ambiente }\end{array}$ \\
\hline $\begin{array}{l}\text { IMITAÇÃO: a criança participa com } \\
\text { pensamento consciente focado no ambiente }\end{array}$ & $\begin{array}{l}\text { 4. Saindo do egocentrismo: a criança } \\
\text { percebe que seu movimento e } \\
\text { balbucio não coincidem com os sons } \\
\text { musicais do ambiente } \\
\text { 5. Decifrando o código: a criança imita } \\
\text { com alguma precisão os sons } \\
\text { musicais do ambiente, como padrões } \\
\text { tonais e rítmicos }\end{array}$ \\
\hline $\begin{array}{l}\text { ASSIMILAÇÃO: a criança participa com o } \\
\text { pensamento consciente focado nela mesma }\end{array}$ & $\begin{array}{l}\text { 6. Introspecção: a criança reconhece a } \\
\text { falta de coordenação entre cantar, } \\
\text { respirar e se mover } \\
\text { 7. Coordenação: a criança consegue } \\
\text { cantar, respirar e se mover de forma } \\
\text { coordenada. }\end{array}$ \\
\hline
\end{tabular}

Quadro 3 - Audiação preparatória (GORDON, 2008)

Para Gordon, a aprendizagem musical acontece através da discriminação e da inferência. Dentro desses dois modos existem diferentes níveis que podem se revisitar, pois elas ocorrem juntas, porém ora uma recebe maior ênfase e ora a outra (GORDON, 2015).

Dessa forma, as considerações sobre o desenvolvimento da criança segundo a Teoria histórico-cultural parecem ter similaridades que possam contribuir para e entender e aplicar a Teoria de Aprendizagem Musical na primeira infância, que tem como foco o desenvolvimento da audiação preparatória. São elas: 


\begin{tabular}{|c|c|}
\hline \multicolumn{2}{|c|}{ APRENDIZAGEM } \\
\hline $\begin{array}{c}\text { Teoria Histórico-cultural } \\
\text { (LEV VYGOTSKY) }\end{array}$ & $\begin{array}{c}\text { Teoria de Aprendizagem Musical } \\
\text { (EDWIN GORDON) }\end{array}$ \\
\hline $\begin{array}{l}\text { Organizado e estruturado para gerar } \\
\text { possibilidade de desenvolvimento }\end{array}$ & $\begin{array}{l}\text { Organizado e estruturado para gerar } \\
\text { possibilidade de desenvolvimento da } \\
\text { audiação }\end{array}$ \\
\hline $\begin{array}{l}\text { Elementos herdados biologicamente e } \\
\text { elementos que surgem na interação } \\
\text { social, ou seja, depende da interação com } \\
\text { o meio }\end{array}$ & $\begin{array}{l}\text { Aptidão musical pode ser herdada } \\
\text { biologicamente, mas é o meio que irá } \\
\text { potencializar, ou seja, depende da } \\
\text { interação com o meio }\end{array}$ \\
\hline $\begin{array}{l}\text { Interpsicológico: depende da interação } \\
\text { social que é guiada pelo outro }\end{array}$ & $\begin{array}{l}\text { Discriminação: depende da interação } \\
\text { social que é guiado pelo outro }\end{array}$ \\
\hline $\begin{array}{l}\text { Intrapsicológico: toma as próprias } \\
\text { decisões na resolução de problemas, não } \\
\text { é guiado pelo outro }\end{array}$ & $\begin{array}{l}\text { Inferência: identifica o vocabulário } \\
\text { musical por si só, é capaz de "se ensinar", } \\
\text { não é guiado pelo outro }\end{array}$ \\
\hline $\begin{array}{l}\text { A função social da fala ocorre desde os } \\
\text { primeiros meses de vida da criança }\end{array}$ & $\begin{array}{l}\text { A função social da música como } \\
\text { linguagem/comunicação pode ser } \\
\text { iniciada nos primeiros meses de vida da } \\
\text { criança }\end{array}$ \\
\hline $\begin{array}{l}\text { O objetivo do desenvolvimento da } \\
\text { linguagem é que se torne um instrumento } \\
\text { do pensamento e meio de comunicação }\end{array}$ & $\begin{array}{l}\text { O objetivo da Teoria de Aprendizagem } \\
\text { Musical é desenvolver a audiação, ou } \\
\text { seja, o "pensamento musical" para poder } \\
\text { se comunicar musicalmente }\end{array}$ \\
\hline A função primordial da fala é social & A função primordial da música é social \\
\hline
\end{tabular}

Quadro 4 -Correlação entre as teorias de Vygotsky e Gordon

\subsection{Habilidades Cognitivas}

Muitas pesquisas relacionadas à cognição musical são desenvolvidas por neurocientistas interessados em descobrir como o cérebro opera, quando está envolvido em atividades musicais, sejam estas de criação, de performance ou de apreciação (PATEL, 2003; MORENO E BILDEMAN, 2014; BIRD ET AL., 2019; KHALIL ET AL., 2019; JACOBY ET AL., 2020).

A neurociência cognitiva tem a atenção prevalente ao estudo das capacidades mentais mais complexas, tais como a linguagem, memória, inteligências múltiplas, aprimoramento do processamento auditivo, funções executivas, desenvolvimento musical, entre outros. Com o intuito de entender como o cérebro funciona, especialmente no que diz respeito aos aspectos cognitivos, possibilitando a melhor compreensão de como se dá o processo de aprendizagem musical (PATEL 2011; EUGÊNIO ET AL., 2012; CASAROTTO ET AL., 2017; SWAMINATHAN ET AL., 2017; TRIMBLE E HESDORFFER, 2017; HASLBECK E 
BASSLER, 2018; MORREALE ET AL., 2018; ZHANG 2018; SCHELLENBERG, 2019, BASHWINER E BACON, 2020).

Nos últimos anos, a música tem sido utilizada em muitos programas de intervenção e de reabilitação para melhorar as habilidades cognitivas em pacientes, incluindo as funções executivas, que são responsáveis por gerenciar o comportamento como a tomada de decisão, monitoramento mental, planejamento, iniciativa, inibição e a organização. Inúmeras pesquisas mostram que a música pode ajudar a melhorar as competências linguísticas em diferentes pacientes, incluindo aqueles com deficiência auditiva (DASTGHEIB ET AL., 2013; GORDON ET AL., 2015; LOPES ET AL., 2017; PATSCHEKE ET AL., 2018).

\section{Processamento musical, Plasticidade cerebral e Neurodesenvolvimento}

Os neurocientistas referem que a música se constitui em um modelo ideal para pesquisa sobre o funcionamento cerebral, uma vez que estudos têm revelado a existência de interações neurais que provocam as reações humanas ao estímulo musical, mostrando como o cérebro integra tarefas perceptuais, cognitivas e comportamentais complexas (CARVALHO, 2011; PATEL, 2011; CASAROTTO ET AL., 2017; TRIMBLE E HESDORFFER, 2017; HASLBECK E BASSLER, 2018; MORREALE ET AL., 2018; ZHANG 2018; SCHELLENBERG, 2019, BASHWINER E BACON, 2020).

Devido às novas tecnologias de neuroimagem, houve uma grande expansão nos conhecimentos das bases neurobiológicas do processamento da música e podemos revelar em tempo real como o cérebro processa, dá sentido e emoção à impalpabilidade de sons organizados e silêncios articulados. Permitindo que os neurocientistas localizem de maneira razoavelmente precisa as áreas cerebrais ativadas na realização de determinadas tarefas musicais ou mesmo as áreas ativas nos processos de escuta e compreensão musicais (KOELSCH ET AL., 2005; KOELSCH \& SIEBEL, 2005; MUZKAT, 2015).

Zatorre (2005) comenta que a música ativa diversas áreas cerebrais, mesmo aquelas que estão envolvidas com outros tipos de cognição, tornando-se um estudo complexo, mas que permite o conhecimento do funcionamento cerebral, desde o aprendizado de uma habilidade motora, da linguagem, até a origem das emoções.

Segundo Muzkat (2015) as áreas temporais do cérebro são aquelas que recebem e processam os sons, algumas áreas específicas do lobo frontal são responsáveis pela decodificação da estrutura e ordem temporal, isto é, do comportamento musical mais planejado. Há uma especialização hemisférica para a música no sentido do predomínio do lado direito para a discriminação da direção das alturas, como a melodia, do conteúdo emocional da música e 
dos timbres (nas áreas temporais e frontais) enquanto o ritmo e duração e a métrica, a discriminação da tonalidade se dá predominantemente no lado esquerdo do cérebro. $\mathrm{O}$ hemisfério cerebral esquerdo também analisa os parâmetros de ritmo e altura interagindo diretamente com as áreas da linguagem, que identificam a sintaxe musical.

A literatura aponta que as diversas atividades relacionadas ao fazer musical, envolvem ampla circuitaria cerebral, promovendo a plasticidade cerebral e o neurodesenvolvimento. Em síntese, os estudos apontam que o aprendizado musical é a única atividade que ativa os dois lados do cérebro simultaneamente (PATEL, 2003; LEVITIN, 2011; ARAÚJO ET AL., 2013; MUZKAT, 2015; ALTENMULLER, 2016; ZHU, 2018; KER E NELSON, 2019; SCHELLENBERG, 2019; ALTENMULLER E JAMES, 2020; ZHANG, 2020). Segundo os autores são ativadas as seguintes áreas:

- Lobo Frontal (Córtex motor) - Encarregado tanto do planejamento do movimento quanto de transmitir as ordens aos músculos para que eles entrem em ação, e o córtex pré-frontal, que é a base, em última instância, da cognição, do comportamento e da resposta emocional dos humanos. É a parte que tem um papel chave na tomada de decisões.

No lobo frontal que encontramos a Área de broca, encarregada da percepção e produção da linguagem. Sua função é coordenar os músculos fonológicos para que a pessoa possa falar e pronunciar. Também está relacionada com a produção da escrita e a capacidade de percepção musical.

Ao percebemos uma melodia familiar e acompanharmos ela, seja cantando ou acompanhando o ritmo por meio de movimentos corporais, ativamos o hipocampo, que é o centro da memória, e subáreas do lobo frontal, como particularmente uma área do córtex frontal inferior.

- Lobo parietal (Córtex somatossensorial) - Responsável por receber e processar as informações dos sentidos, onde processamos todas as informações relacionadas à pele: toque, pressão, temperatura e dor.

Fundamental para processar todos os estímulos que vemos e para coordenar todos os movimentos, orientação espacial e habilidades motoras finas. Também é responsável por relacionar expressões faciais com emoções. Ao mesmo tempo, também é essencial para executar a linguagem ou a expressão corporal. Podemos relaciona-lo a reação táctil ao tocar um instrumento. 
- Lobo occipital (Córtex visual) - Processa os estímulos visuais de forma permanente, analisando distâncias, formas, cores e movimentos. É responsável por estimular a memória. Ou seja, podemos associar estímulos visuais a outros vistos anteriormente.

Em música podemos relaciona-lo a leitura musical e ao movimento (observação e ação).

- Lobo temporal (Córtex auditivo) - Envolvido em diversas funções sensoriais e comportamentais no ser humano. É considerado "polissensorial" pois integra vias neurais auditivas, sensoriais, visuais e límbicas. Em linhas gerais, o lobo temporal está relacionado à formação de memórias, percepção auditiva e interpretação de imagens.

Nele encontramos também a área de Wernicke, responsável pela compreensão e produção da linguagem. Lesões ocasionam uma fala repleta de erros, afetando principalmente o conteúdo fonológico das palavras.

Aqui ocorre a primeira etapa de audição de sons. Ao fazermos música podemos pensar na percepção rítmica e melódica e na produção sonora em um instrumento musical.

Ao ouvir música é liberado no cérebro dopamina, endorfina e serotonina. Substâncias que ativam um neurotransmissor que está associado diretamente com o sistema do prazer e recompensa do cérebro, o sistema Límbico, responsável pelas nossas emoções. Nele encontramos o hipotálamo, tálamo, hipocampo, amigdala e núcleo accumbens.

- Cerebelo - Região do cérebro que capta os impulsos sensitivos das articulações, tendões, músculos, além de receptores do equilíbrio e visuais. Coordena as complexas sequências dos músculos esqueléticos.

Sem ele seria impossível desempenhar todas as atividades motoras que requerem habilidade, desde apanhar um objeto qualquer, até realizar uma atividade física que requeira um pouco mais de coordenação motora, como a dança, por exemplo.

Acompanhar o ritmo musical, bater os pés e as mãos, tocar um instrumento musical, envolve os circuitos de regulação temporal do cerebelo, responsável pela percepção rítmica e pelas interações auditivas motoras (MORREALE ET AL., 2018):

Feedback - Capacidade do indivíduo de prever eventos. Ao perceber a regularidade rítmica da música (estímulo auditivo) e consegue prever e sincronizar o movimento dos pés com ela (resultado motor) e Feedfoward - Capacidade relacionada a quem faz música, pois realiza alterações no processo motor através da audição de um estímulo sonoro. 

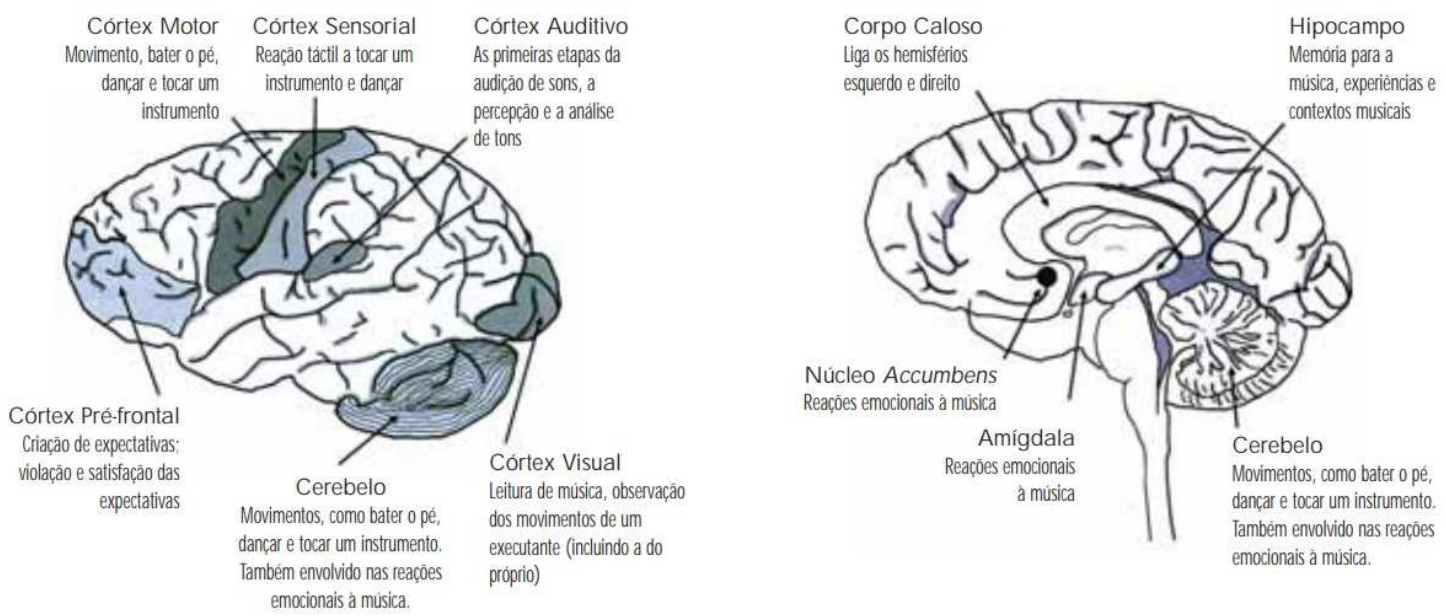

Figura 2 - Representação Esquemática do Cérebro Musical. (LEVITIN, 2010)

Música e linguagem necessitam de parâmetros acústicos para transmitir e decodificar informações, porém a música é um estímulo acusticamente mais complexo do que a linguagem. Devido a esta complexidade de características, supõe-se que por estimular mecanismos sensoriais e cognitivos relacionados ao processamento de linguagem, a música pode melhorar o processamento da fala (TORPPA E HUOTILAINEM, 2019).

Segundo Patel (2011) o treinamento musical é capaz de modificar circuitos de processamento de fala, com a chamada hipótese "OPERA". A sigla refere-se a cinco aspectos fundamentais para que o treino musical induza a neuroplasticidade, influenciando em mecanismos relacionados à fala. Ao pensarmos de uma perspectiva neurobiológica, por que o treinamento musical impulsionaria a plasticidade adaptativa em redes de processamento de fala em primeiro lugar? Kraus e Chandrasekaran (2010) apontam que tanto a música quanto a fala usam tom, tempo e timbre para transmitir informações e sugerem que anos de processamento dessas pistas de uma forma refinada na música podem aprimorar seu processamento no contexto da fala. A hipótese "OPERA" baseia-se nesta ideia e a torna mais específica. Ela propõe que a plasticidade adaptativa impulsionada pela música em redes de processamento de fala ocorre porque cinco condições essenciais são atendidas: Overlap, Precision, Emotion, Repetition e Attention.

- Overlap: indica a sobreposição de redes neurais na codificação de características acústicas comuns à música e fala. Como por exemplo, a frequência. 
- Precision: o processamento musical exige mais dessas redes do que o da fala. No que se refere a precisão do processamento, é necessário que o indivíduo processe características acústicas. Por exemplo, entonação de sílabas e atingir uma nota musical (altura) de forma afinada.

- Emotion: as atividades musicais que estimulam esta rede provocam fortes emoções positivas.

- Repetition: indica a oportunidade de melhorar aptidões com a repetição.

- Attention: indica a atenção focada responsável pelo direcionamento e distribuição da energia mental dentro do cérebro.

De acordo com a hipótese do OPERA, quando essas condições são satisfeitas, a plasticidade neural leva as redes em questão a funcionarem com maior precisão do que a necessária para a comunicação de fala comum. No entanto, como a fala compartilha essas redes com a música, o processamento da fala se beneficia (PATEL, 2011). A hipótese OPERA prevê que as atividades musicais que não atendam às cinco condições não levarão a tais aprimoramentos.

Conforme observado por Chandrasekaran e Kraus (2010), antes que a fala possa ser percebida e integrada com representações linguísticas armazenadas de longo prazo, pistas acústicas relevantes devem ser representadas por meio de um código neural e fornecidas ao córtex auditivo com precisão temporal e espectral por estruturas subcorticais. A via auditiva é notável pela complexidade de seu processamento subcortical, que envolve muitas regiões distintas e uma rica rede de conexões ascendentes e descendentes (PATEL, 2011).

Existe uma teoria de que o processamento auditivo é estritamente hierárquico, com circuitos subcorticais conectados transmitindo sinais neurais para regiões corticais. Porém para Kraus e Chandrasekaran (2010), o processamento auditivo envolve ricas interações bidirecionais entre as regiões subcortical e cortical, com maleabilidade estrutural em ambos os níveis, conhecida como a "teoria da hierarquia reversa" do processamento auditivo (AHISSAR ET AL., 2009). Do ponto de vista prático, os autores propõem que a codificação neural da fala pode ser aprimorada por um treinamento auditivo não linguístico, por exemplo, aprender a tocar um instrumento musical ou cantar. Isso tem significado prático porque a qualidade da codificação da fala do tronco cerebral foi diretamente associada a importantes habilidades de linguagem, como audição no ruído e habilidade de leitura (BANAI ET AL., 2009; PARBERY-CLARK ET AL., 2009). 


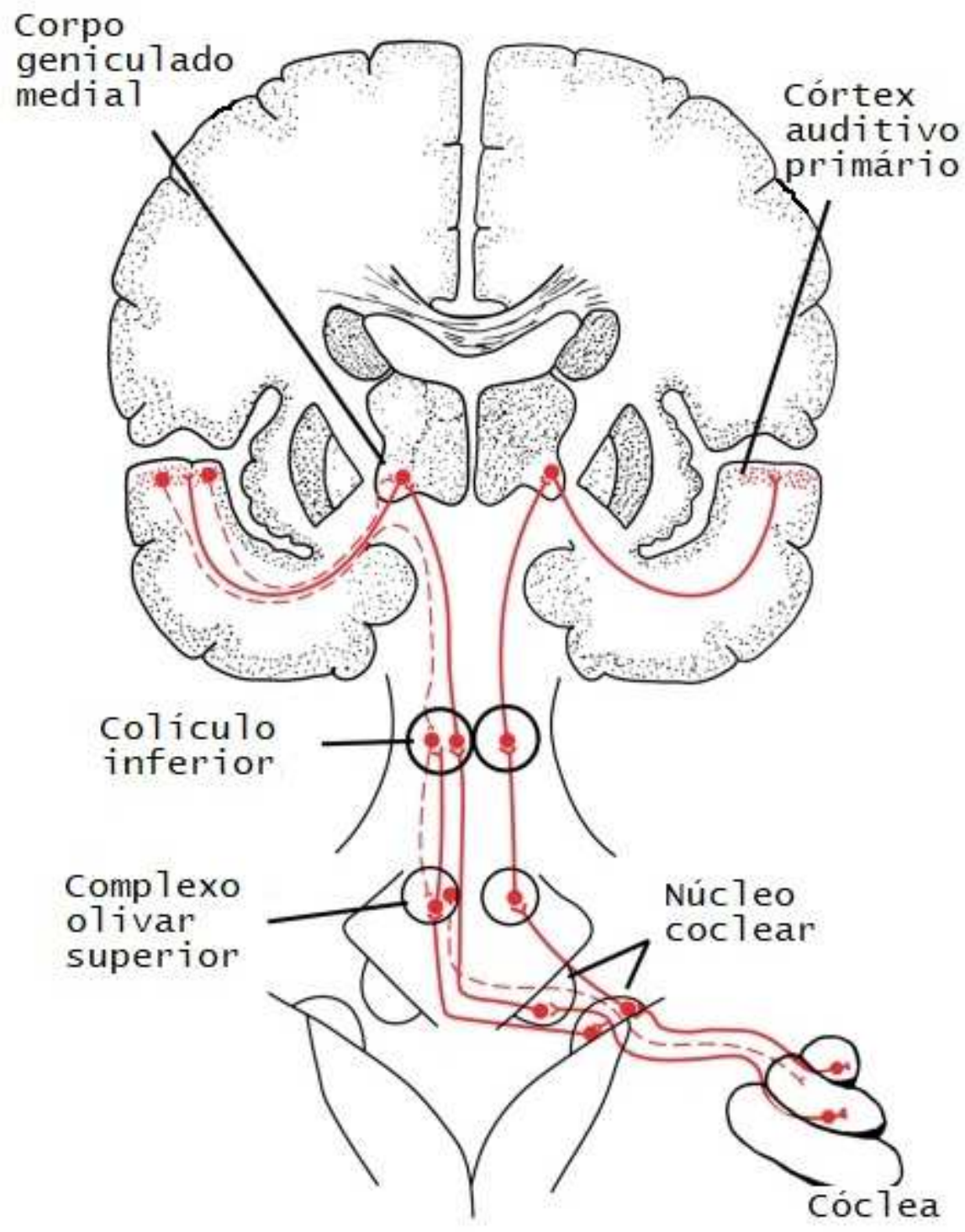

Figura 3: Esquema simplificado de um hemisfério cerebral da via auditiva ascendente entre a cóclea e o córtex auditivo primário, mostrando algumas das estruturas subcorticais envolvidas no processamento auditivo, como os núcleos cocleares no tronco encefálico e o colículo inferior no mesencéfalo. Linhas vermelhas sólidas mostram vias auditivas ascendentes, linhas tracejadas mostram vias auditivas descendentes ("corticofugal") (PATEL E IVERSEN, 2007). 


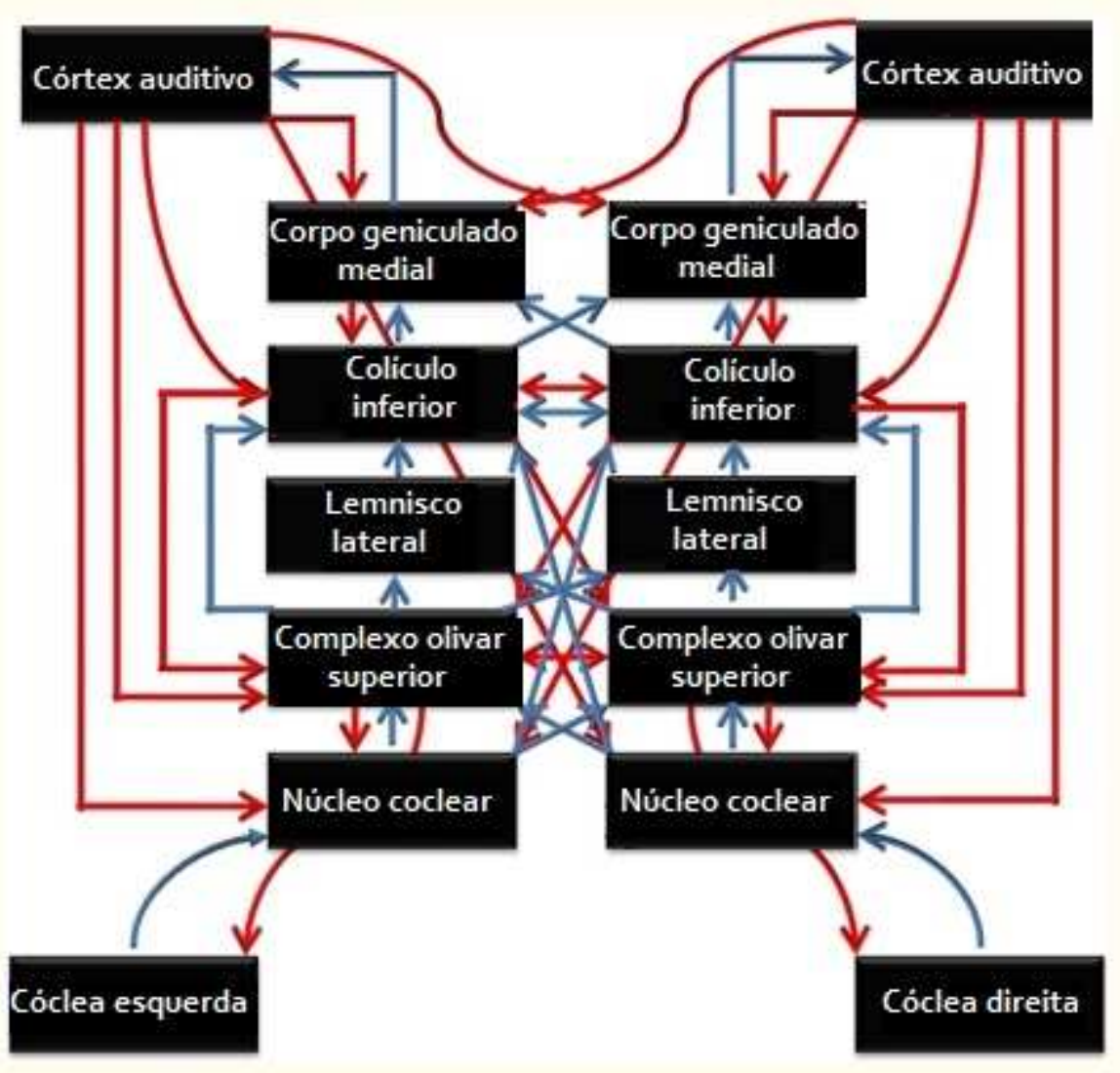

Figura 4: Diagrama esquemático do sistema auditivo, ilustrando as várias estações de processamento subcortical entre a cóclea (em baixo) e o córtex (em cima). As setas azuis representam caminhos ascendentes (de baixo para cima); setas vermelhas representam projeções descendentes (CHANDRASEKARAN E KRAUS, 2010).

\subsection{Habilidades Perceptivas Auditivas}

A partir da entrada sensorial, ou seja, da percepção sonora na cóclea, a mensagem auditiva continua pelo nervo auditivo através de estruturas do tronco encefálico, até ser codificada no córtex auditivo e, por fim gerar uma resposta auditiva (SHINN, 2003; TEIXEIRA ET AL., 2011):

- Núcleo coclear: única estrutura que recebe informações de ipsilaterias, ou seja, de um único lado.

- Complexo Olivar Superior: recebe fibras ipsi e contralaterais dos núcleos cocleares. Sua enorme quantidade de informações dá a base anatômica da representação e interação binaural. Há a convergência da atividade neural de cada orelha, tornando tal estrutura importante na avaliação funcional do tronco encefálico. A fusão binaural e a 
compreensão de discurso dependem dessa integração dos sinais apresentados bilateralmente. Há organização tonotópica em seus núcleos e os padrões de descarga dos neurônios pós-estímulos são variados.

- Lemnisco lateral: recebe fibras dos núcleos cocleares e dos complexos olivares superiores, e contém a maior parte das fibras ascendentes e descendentes. A maioria dos neurônios do seu segmento dorsal recebe estimulação binaural e a maioria do seu segmento ventral é ativada somente por estimulação contralateral. Uma comissura permite a ligação entre os lemniscos laterais de cada lado, e assim como as demais estruturas, também possui organização tonotópica.

- Colículo inferior: é provavelmente a estrutura que mais recebe fibras sensitivas auditivas das estruturas auditivas do tronco encefálico - recebe fibras dos núcleos cocleares dorsal e ventral, núcleos lateral e medial do complexo olivar superior, núcleos dorsal e ventral do lemnisco lateral, e do colículo inferior contralateral. É composto por dois núcleos, o núcleo central com fibras puramente auditivas, e o núcleo pericentral com fibras auditivas e somatossensitivas. Possui muitos neurônios sensíveis ao tempo, espaço e estimulação binaural, sendo considerado, portanto estrutura fundamental para codificação e localização sonora. Assim como o lemnisco lateral, possui uma comissura que permite a ligação com o colículo inferior contralateral. A organização tonotópica é mantida nessas estruturas, com alto nível de resolução de frequência.

- Corpo Geniculado Medial: situado no tálamo, possui três divisões: a divisão ventral, composta por células primariamente responsivas a estímulos acústicos, que transmite informação de discriminação para o córtex auditivo; a divisão dorsal, sensível a estímulos acústicos e somatossensitivos, que transmite informações à áreas de associação do córtex auditivo e parece ser responsável pela manutenção da atenção auditiva; e a divisão ventral, que assim como a anterior, é sensível a estímulos acústicos e somatossensitivos, e parece funcionar como sistema de alerta multissensorial. Como no colículo inferior, muitos neurônios são sensíveis a estimulação binaural e diferenças interaurais de intensidade. Há a manutenção da organização tonotópica.

- Formação reticular: estrutura medial no tronco encefálico, que vai do mesencéfalo à corda espinal, e atua no estado de alerta auditivo, no controle da motricidade somática, do sistema nervoso autônomo, neuroendócrino e na integração de reflexos e habituação. Por esse motivo, parece ser responsável pela capacidade de ouvir na presença de ruído. 
- Córtex auditivo: recebe informações ipsilaterais do corpo geniculado medial e do colículo inferior, além das informações transferidas através do corpo caloso. Fazem parte o giro de Heschl, considerado a área primária; o plano temporal, que se estende posteriormente ao giro de Heschl e é associado à linguagem receptiva; o giro supramarginal, localizado próximo à área de Wernicke e responsável pela estimulação acústica; e a fissura de Sylvian, também relacionada à área de linguagem.

- Corpo caloso: estrutura altamente mielinizada, que conecta o hemisfério direito e o esquerdo, possibilitando a troca de informações entre os mesmos. Cada hemisfério cerebral é atribuído para determinadas atividades, em tarefas que envolvem não somente a codificação do som, como também a decodificação (por exemplo, a nomeação), e por esse motivo a atividade do corpo caloso é fundamental no processamento da informação sonora. Sua maturação tem início a partir dos 7 a 8 anos e sua formação é completa aos 12 anos de idade.

Todas as estruturas descritas estão diretamente envolvidas no processamento da informação sonora ou Processamento Auditivo Central (PAC).

Considerando que a maior parte das características da informação sonora é influenciada pelo tempo, Shinn (2003) propõe que o processamento temporal seja provavelmente o componente "base" da maioria das capacidades do PAC. Segundo a autora, pode ser definido como a percepção do som (ou da alteração do som) no domínio do tempo e ocorre desde a sensibilidade neuronal até o processamento cortical.

O processamento temporal pode ser subdivido nas seguintes categorias (SHINN, 2003):

- Ordenação ou sequência temporal: de extrema importância para a percepção de fala, esta habilidade diz respeito ao processamento de estímulos auditivos múltiplos na ordem em que ocorrem. É afetada pelo número de estímulos, a forma de apresentação da sequência (simultânea ou continuamente), a tarefa exigida ao sujeito e o tempo de treino.

- Discriminação ou resolução temporal: diz respeito ao menor tempo com que a pessoa consegue discriminar dois estímulos sonoros.

- Integração ou Somação temporal: resultante da soma da atividade neuronal decorrente da duração adicional de energia sonora, levando à diminuição do limiar na população com audição normal. Se um som tem sua duração diminuída para um décimo de sua duração original, o limiar aumenta cerca de $10 \mathrm{~dB}$, e o inverso ocorre com o aumento da duração. Este fenômeno é conhecido como 
"time-intensity trade off" (relação entre intensidade e tempo) e também influencia a loudness ou sonoridade em sons supraliminares.

- Mascaramento temporal: é a mudança do limiar de um som na presença de outro subsequente. Ocorre quando um som é apresentado em duração e intensidade suficientes para reduzir a sensibilidade de outro estímulo apresentado logo antes ou após o primeiro. É dependente da frequência, com maior efeito quando o som mascarador é apresentado na mesma frequência do estímulo mascarado.

Além da atenção e da percepção auditiva, é preciso lembrar que a compreensão sonora e de fala, envolve memória e cognição (DRYDEN ET AL., 2017).

\subsection{Habilidades Sociais}

O campo das habilidades sociais, desenvolvido na área da Psicologia, vem possibilitando a interface com várias áreas do conhecimento de forma interdisciplinar, considerando que as habilidades sociais são comportamentos sociais necessários para construção de relações interpessoais saudáveis e produtivas. O desenvolvimento deste campo cresceu juntamente com a necessidade de avaliação deste construto, que é definido como um desempenho e não como um traço. Enquanto desempenho, as habilidades sociais apresentam uma característica de especificidade situacional, o que pressupõe uma avaliação a partir de variadas dimensões situacionais e culturais (BANDEIRA, 2000).

O desempenho social é o conjunto de comportamentos emitidos por um indivíduo num contexto interpessoal, que expressa sentimentos, atitudes, desejos, opiniões ou direitos desse indivíduo adequadamente à situação, respeitando esses comportamentos nos demais, e que geralmente resolvem problemas imediatos ao mesmo tempo em que minimiza a probabilidade de futuros problemas. Segundo Del Prette e Del Prette (2006) o conjunto de habilidades sociais relevantes pode ser organizado em classes e subclasses de maior ou menor abrangência, entre elas:

- Habilidades de comunicação: fazer e responder perguntas, dar e pedir feedback, elogiar, iniciar, manter e encerrar conversação;

- Habilidades de civilidade: dizer por favor, agradecer, apresentar-se, cumprimentar;

- Habilidades assertivas de enfrentamento ou defesa de direitos e cidadania: expressar opinião, discordar, fazer e recusar pedidos, interagir com autoridades, lidar com 
críticas, expressar desagrado, lidar com a raiva do outro, pedir mudança de comportamento entre outros;

- Habilidades empáticas e de expressão de sentimento positivo;

- Habilidades sociais profissionais ou de trabalho: coordenação de grupo, falar em público;

- Habilidades sociais educativas de pais, professores e outros agentes envolvidos na educação ou treinamento.

$\mathrm{Na}$ base de qualquer desempenho socialmente competente, destacamos a automonitoria, enquanto habilidade geral de observar, descrever, interpretar e regular pensamentos, sentimentos e comportamentos em situações sociais (DEL PRETTE e DEL PRETTE, 2001). Fundamental, conforme os autores, diferenciar os conceitos de habilidades sociais e competência social que qualificam um tipo especial de desempenho social. Esse conceito refere-se à emissão de um comportamento ou sequência de comportamentos em uma situação social qualquer. Já o termo habilidades sociais aplica-se à noção de existência de diferentes classes de comportamentos sociais no repertório do indivíduo para lidar com as demandas das situações interpessoais. A competência social tem sentido avaliativo que remete aos efeitos do desempenho das habilidades nas situações vividas pelos indivíduos.

Além disso, o conceito de HS refere-se à dimensão descritiva do desempenho social e abrange as seguintes dimensões: (a) dimensão pessoal, que inclui os componentes cognitivoafetivos (pensamentos e sentimentos envolvidos na decodificação das demandas interpessoais, na decisão sobre o desempenho requerido na situação e na elaboração e automonitoria desse desempenho, como, por exemplo, estilos de resolução de problemas interpessoais) e as variáveis fisiológicas (processos sensoriais e de regulação ou controle autonômico); (b) a dimensão situacional, que abrange o ambiente imediato, as demandas, os interlocutores envolvidos, as regras sociais, os objetivos, a sequência de interações, o contexto físico, etc.(incluindo normas, valores e regras culturais); (c) dimensão comportamental, que inclui os componentes comportamentais molares (como expressar opiniões, manter conversação, recusar pedidos) e os moleculares (como contato visual, sorrisos, gestos) (DEL PRETTE e DEL PRETTE, 1999, 2001).

Murta (2005) afirma que tais habilidades dizem respeito a comportamentos necessários a uma relação interpessoal bem-sucedida, conforme parâmetros típicos de cada contexto e cultura. Desta maneira, as HS têm sido relacionadas à melhor qualidade de vida, a relações interpessoais mais gratificantes, a maior realização pessoal e a sucesso profissional (CABALLO, 2003; DEL PRETTE E DEL PRETTE, 2005; GRESHAMM, 2002, 2009). 
Outro aspecto a ser considerado é que as habilidades sociais são aprendidas e/ou aperfeiçoadas na interação do indivíduo com seu ambiente. Embora as bases de algumas habilidades sejam inatas (por exemplo, a tendência para comportamentos pró-sociais), o repertório destas habilidades começa a ser desenvolvido na infância por meio de diferentes processos de aprendizagem (modelos de pessoas próximas, modelagem social e esquemas de reforçamento) no exercício crescente de novos papéis e assimilação de normas culturais (DEL PRETTE e DEL PRETTE, 1999; HIDALGO e ABRCA, 1992).

Para Skinner (1989), essas habilidades podem ser aperfeiçoadas ou deterioradas, na história de vida das pessoas, dependendo das contingências a que são submetidas. Portanto, os comportamentos sociais emitidos por um adulto refletem contingências passadas e atuais (que sejam de reforçamento positivo ou de reforçamento negativo, com ou sem envolvimento de regras) e podem também ser recuperados por meio de programas especiais de treinamento ou terapia (VIILLA, 2005).

Portanto, tal aprendizado remete ao papel do processo comunicativo englobando os componentes não-verbais que complementam, ilustram, regulam, substituem e algumas vezes se opõem até mesmo aos componentes verbais. A utilização da linguagem como veículo de comunicação, em suas modalidades verbal e não-verbal, possibilita a criança interagir com seus pares e com os adultos favorecendo a troca de informação, experiências, emoções e, consequentemente, o aprendizado, conforme Del Prette e Del Prette (2001).

A partir da literatura especializada consultada, não foram encontrados estudos sobre os efeitos das diversas abordagens musicais, como a musicalização infantil, no repertório de habilidades sociais de crianças com implante coclear. 

3 Objetivos 



\section{OBJETIVOS GERAIS}

3.1 Investigar o efeito da Musicalização Infantil sobre o repertório de habilidades perceptivas, cognitivas e sociais em crianças com implante coclear entre 06 e 10 anos de idade;

3.2 Realizar uma revisão sistemática com o intuito de analisar os benefícios das abordagens musicais em crianças e adolescentes usuários de implante coclear. 

4 Desenvolvimento 



\section{DESENVOLVIMENTO}

\subsection{Estudo 1: Revisão Sistemática}

\section{Introdução \\ RESUMO}

A literatura aponta que abordagens musicais são estratégias eficazes para promover diversos tipos de habilidades, o que pode justificar a sua aplicabilidade nos vários contextos vivenciados por seres humanos. Todo indivíduo possui uma aptidão musical e quanto mais cedo se beneficiar de um ambiente musical, mais cedo sua aptidão irá aumentar. Além disso-, as experiências auditivas nos primeiros anos de vida são fundamentais para que o indivíduo se torne um bom ouvinte e desenvolva diversas habilidades necessárias ao desenvolvimento global. No caso de pessoas com deficiência auditiva, observa-se que geralmente as mesmas têm dificuldade em desenvolver habilidades, principalmente aquelas com perdas auditivas do tipo sensorioneural, de grau severo a profundo e usuárias de Implante Coclear.

\section{Objetivos}

Analisar os contributos de abordagens musicais (educação musical, musicoterapia, apreciação e percepção musical) para crianças e adolescentes usuários de implante coclear.

\section{Métodos de Busca}

Foi realizada a busca bibliográfica nas bases de dados para pesquisa de artigos científicos indexados em abril de 2020: CENTRAL (2015 até 2020), MEDLINE (2009 até 2018), EMBASE (2012 até 2018), CINAHL (2012), ICTPR (2017), PubMed (1995 até abril/2020), LILACS (2012 até o ano de 2018), SciELO (2012 até 2018), A\&HCI (2009 até 2017), SSCI (2009 até 2017), CPCI-SSH (2009 até 2017) e WORLDCAT (todos os anos disponíveis). Não foram aplicados limites de data e idioma.

\section{Critério de Seleção}

Nós planejamos incluir nessa revisão estudos clínicos randomizados, que incluíssem pelo menos um dos nossos desfechos primários ou secundários

\section{Coleta de Dados e Análises}

Foram analisados todos os títulos e resumos identificados por meio da estratégia de pesquisa para determinar sua elegibilidade. Foi utilizada a diferença média para dados contínuos, com intervalos de confiança de 95\%, e o modelo estatístico de efeitos aleatórios quando as estimativas de efeito de dois ou mais estudos pudessem ser combinadas em uma meta-análise. 


\title{
Resultados
}

Foram encontrados 619 estudos por meio da estratégia de busca, mas nenhum estudo clínico randomizado que utilizasse abordagem musical em crianças e adolescentes usuários de implante coclear.

\section{Conclusão dos Autores}

Não há evidências disponíveis de ECR para basear um julgamento sobre a eficácia das abordagens musicais em crianças e adolescentes usuários de implante coclear. Essa revisão encoraja futuras pesquisas a fazer uso de um modelo metodológico controlado por meio de estudos clínicos randomizados conduzidos por equipe multidisciplinar que inclua um músico profissional experiente na área.

\section{Número de Registro da Revisão Sistemática}

CRD42020205581

Descritores: Music; Music Therapy; Pitch Perception; Cochlear Implants.

\begin{abstract}
Background

The literature points out that musical approaches are effective strategies to promote different types of skills, which may justify their applicability in the various contexts experienced by human beings. Every individual has a musical aptitude and the sooner you benefit from a musical environment, the sooner your aptitude will increase. In addition, hearing experiences in the first years of life are essential for the individual to become a good listener and develop the various skills necessary for global development. In the case of people with hearing loss, it is observed that they usually have difficulty in developing skills, especially those with sensorineural hearing loss, from severe to profound and who use Cochlear Implants.
\end{abstract}

\section{Objectives}

Analyze the contributions of musical approaches (music education, music therapy, appreciation and musical perception) for children and adolescents with cochlear implants.

\section{Search Methods}

We searched the following electronic databases in April 2020: CENTRAL (2015 to 2020), MEDLINE (2009 to 2018), EMBASE (2012 to 2018), CINAHL (2012), ICTPR (2017), PubMed (1995 to Abril/2020), LILACS (2012 to 2018), SciELO (2012 to 2018), A\&HCI (2009 
to 2017), SSCI (2009 to 2017), CPCI-SSH (2009 to 2017) and WorldCat (all years included).

We also searched the reference lists of studies. We did not apply any date or language limits.

\section{Selection Criteria}

We planned to include randomized controlled trials. We looked for studies that included at least one of our primary outcomes.

\section{Data collection and analysis}

Through a rigorous analysis, we analyzed all titles and abstracts that we found using the research strategy to determine their eligibility. For our analysis we had planned to use mean difference for continuous data, with $95 \%$ confidence intervals, and to use the random-effects statistical model when the effect estimates of two or more studies could be combined in a metaanalysis.

\section{Main Results}

We retrieved 619 references via the search strategy. No randomized controlled trials testing musical approaches for children and adolescents with cochlear implants could be included in this review.

\section{Author's Conclusions}

We conclude that there is no evidence available from randomized clinical studies to base a judgment on the effectiveness of musical approaches to children and adolescents with cochlear implants. This review encourages future research using a methodological model controlled through randomized clinical studies through a multidisciplinary team that includes a professional musician.

\section{Systematic Review Registration Number}

CRD42020205581

Descriptors: Music; Music Therapy; Pitch Perception; Cochlear Implants.

\section{PERGUNTA DA REVISÃO}

Abordagens Musicais para Crianças e Adolescentes Usuários de Implante Coclear: Uma Revisão Sistemática 
Usuários de Implante Coclear (IC) têm dificuldades com o reconhecimento preciso ou fluente de sons e palavras, o que resulta na dificuldade do desenvolvimento de diversas habilidades, como habilidades perceptivas, cognitivas e sociais. Tal fator pode ser atribuído a falta de reabilitação precoce por meio de diversas abordagens clínicas e de outras intervenções, como abordagens musicais. Alguns estudos sugerem que essa população, quando exposta a abordagens musicais tem melhora das referidas habilidades. Como informação sobre a eficácia das diversas abordagens musicais para crianças e adolescentes usuários de implante coclear, este estudo buscou por evidências de alta qualidade na forma de estudos controlados. Entretanto, não foram encontrados estudos com tal rigor metodológico, portanto, não foi possível avaliar com segurança as vantagens, ou até mesmo desvantagens, das abordagens musicais para essa população. É necessário que o delineamento do estudo seja conduzido por equipe multidisciplinar na qual participe ou atue um musico profissional experiente, com rigor metodológico e coerência na abordagem musical escolhida, para que sejam melhor evidenciados os efeitos em potencial das abordagens musicais para crianças e adolescentes usuários de implante coclear.

\section{INTRODUÇÃO}

\section{Descrição da População}

A audição é configurada como fator fundamental para o desenvolvimento global do indivíduo. É por meio dela que o ser humano adentra o mundo sonoro, permitindo que o processo de aquisição e desenvolvimento da linguagem ocorra (BEVILACQUA ET AL., 2011).

Segundo Ching et al. (2009) a audição é considerada a principal via para a aquisição da linguagem oral. Desta forma, a deficiência auditiva é um fator que compromete diretamente a linguagem do indivíduo. Esse comprometimento pode variar de acordo com o tipo e o grau da perda de audição. Sabe-se que a perda auditiva sensorineural de grau severo a profundo é a que mais pode causar danos linguísticos, uma vez que dificulta a aquisição e desenvolvimento da linguagem oral, principalmente em indivíduos com perda auditiva pré-lingual.

Os impactos da perda auditiva permanente na infância agem negativamente no desenvolvimento das habilidades auditivas, de fala, de linguagem, psicossociais e nos níveis de escolaridade da criança. A perda auditiva acarreta em diversas consequências negativas para a vida de um indivíduo, interferindo decisivamente na sua qualidade de vida, uma vez que provoca isolamento social e familiar (BEVILACQUA ET AL., 2011; CHING ET AL., 2009; TEIXEIRA E GARCES, 2011). 
A (re)habilitação auditiva pode ser definida como um processo de resolução de problemas, com o objetivo de minimizar a dificuldade da limitação de participação em atividades de um indivíduo (NÓBREGA ET AL.,1998; PINTO ET AL., 2012; THEUNISSEN E SWANEPOEL 2008). O processo de reabilitação auditiva possibilita que os indivíduos retomem a sua vida social, participando de atividades em grupo, melhorando sua autoestima e bem-estar. Dentro da abordagem oralista e bilíngue, o processo de (re)habilitação auditiva contempla, entre outros, o Implante Coclear (IC) (WILKERSON, 2000; TEIXEIRA ET AL., 2011).

Para Fortunato et al. (2009) o implante coclear é, atualmente, o recurso tecnológico mais eficaz para favorecer o acesso do indivíduo com perda auditiva sensorioneural de grau severo e ou profundo ao mundo sonoro. Até então nenhum outro dispositivo eletrônico tornava possível que o indivíduo que adquiriu surdez severa ou profunda antes da aquisição da linguagem pudesse compreendê-la e expressá-la com funcionalidade e abstração.

Diversos estudos apontam que o implante coclear é capaz de possibilitar a integração ao mundo sonoro e a percepção dos sons da fala favorecendo satisfatoriamente muitas crianças, porém os benefícios não são idênticos para todas. Os autores referem que os resultados a serem alcançados pelas crianças implantadas dependem de um processo complexo e multidimensional, pois a variabilidade dos resultados pós-implantação exibe a necessidade de outras avaliações além das audiológicas e de linguagem, como por exemplo, dos processos neurocognitivos, a fim de adequar as expectativas e de melhorar os resultados (BEVILACQUA E FORMIGONI, 2003; MORET ET AL., 2007; CAMPOS ET AL., 2008; GFELLER, 2016).

Semelhanças do processamento sintático da linguagem e música, bem como as semelhanças no nível acústico, deram surgimento de modelos e propostas sobre os efeitos da música na percepção de fala e capacidades de linguagem. Além das tais semelhanças, há evidência neural de que atividades musicais podem afetar as habilidades de linguagem (PATEL 2003, 2011, 2014).

Segundo Torppa (2019) música e fala são muito semelhantes em seus elementos básicos, porém a música tem características acústicas muito específicas quando comparada a linguagem. Melodias incluem progressões rápidas de notas normalmente escolhidas a partir de escalas que normalmente incluem etapas irregulares. Os acordes são coleções de notas tocadas simultaneamente, formando harmonias. Timbres musicais são caracterizados por seus picos espectrais e suas mudanças rápidas de sons e ruído por meio de ondas sonoras e várias outras características. 
Pantev et al. (1998) mostraram a primeira evidência dos benefícios da aprendizagem musical nas estruturas cerebrais humanas mostrando áreas corticais motoras e somatossensoriais aumentadas em músicos profissionais. Esses efeitos foram originalmente interpretados como sendo causados pela plasticidade cerebral devido à prática musical.

Apenas alguns estudos abordaram a correlação de atividades musicais com o desenvolvimento de habilidades de percepção, de fala ou de linguagem para crianças usuárias de IC. As restrições biomecânicas do implante coclear resultam em pistas espectrais empobrecidas e de baixa resolução de frequência, tornando difícil para os usuários perceberem características como tom e timbre. Há evidências emergentes de que o treinamento musical pode melhorar a percepção musical mediada pelo IC; no entanto, muitos dos estudos existentes envolvem paradigmas por conta de treinos musicais sem controle experimentais rigorosos, porém não há evidência de estudos controlados sobre o impacto das intervenções de treinamento musical nas citadas habilidades em crianças com IC (JIAM, 2019; TORPPA, 2019).

Para Gfller (2016) o número limitado de estudos não é surpreendente. Projetar e implementar um treinamento musical com crianças usuárias de IC pode ser assustador por uma série de razões, incluindo: recrutar e manter um tamanho de amostra adequado e suficiente; financiamento adequado para apoiar a metodologia; viabilidade de agendamento de treinamentos e testes e manter a consistência dos parâmetros de treinamento ao longo do tempo. Todos esses representam desafios significativos para a montagem de um estudo bem projetado.

\section{Descrição da Intervenção}

Todo indivíduo possui uma aptidão musical inicial inata e quanto mais cedo se beneficiar de um ambiente musical rico, mais cedo sua aptidão irá aumentar, sendo assim, a aprendizagem musical pode e deve ser iniciada antes ou desde o nascimento da criança (GORDON, 2000).

Esta revisão tem como intuito analisar o efeito potencial que as diversas abordagens musicais, como, educação musical, musicoterapia, apreciação e percepção musical, entre outras, podem ter em crianças e adolescentes usuários de implante coclear. Nas abordagens musicais, cada um dos elementos musicais, como, ritmo, harmonia e melodia, podem ser estudados separadamente, usando diferentes estratégias a fim de estimular e desenvolver a percepção humana.

É importante esclarecer que abordagens de aprendizagem musical, como a educação musical, são completamente diferentes da musicoterapia. Aprendizagem musical, como o 
próprio nome diz, tem um fim de aquisição de conhecimento teórico-prático musical. Musicoterapia são abordagens clínicas de tratamento por meio da música, sem a aquisição de um conhecimento musical propriamente dito.

Essa revisão foi realizada usando diferentes tipos de atividades musicais, como cantar (sozinho ou em um grupo), rítmicas (via movimento corporal ou percussão corporal), de prática instrumental (que poderia ser um aprendizado técnico de um instrumento musical específico ou sando o instrumento de forma informal com o foco na interação entre o som e a criança e não na técnica musical), de musicalização (diversas abordagens simultâneas de forma lúdica), musicoterapia (terapia clinica utilizando a música para tratar estados emocionais) e de apreciação e percepção musical (crianças expostas a determinadas músicas ou conceitos musicais).

\section{Como o procedimento de intervenção pode funcionar}

Para Gfeller (2016), os benefícios do treino musical são baseados, em parte, na sobreposição de redes cerebrais que processam características acústicas importantes como a música e voz. Enquanto fala e música podem compartilhar as redes neurais, alguns estudos sugerem que ouvir ou fazer música pode ter benefícios particulares no desenvolvimento de processos eficientes e auditivos mais robustos. Os efeitos da música sobre o cérebro humano parece ser muito promissor e terapêutico em vários tipos de desordens e condições, incluindo implante coclear (DASTGHEIB ET AL, 2013).

A percepção e apreciação da música têm sido associadas à autopercepção de qualidade de vida após a implantação coclear. Vários estudos apontam para uma tendência de aumento dos hábitos de escuta de música, de apreciação musical e da percepção auditiva, após a implantação coclear (COFFEY ET AL., 2017; DRISCOLL ET AL., 2015; FU, 2015; KOSANER ET AL., 2012; LASSALETTA ET AL, 2008; PETERSEN ET AL., 2015; TORPPA ET AL., 2010; TORPPA, 2014; TORPPA ET AL., 2018; VONGPAISAL ET AL., 2016; YUCEL ET AL, 2009;).

Além da percepção auditiva e musical, estudos enfatizam que crianças e adolescentes usuários de implante coclear tem melhora das habilidades linguísticas, da percepção e produção da fala (ROCHETTE ET AL., 2014; CASON ET AL., 2015; GOOD ET AL., 2017; HIDALGO ET AL., 2017; BEDOIN, ET AL., 2018; FULLER ET AL., 2018; YANG ET AL., 2019).

Estudos apontam que crianças e adolescentes usuários de implante coclear expostas a atividades musicais, como a educação musical têm melhora significativa da percepção dos elementos básicos da música, como, pitch, intensidade, ritmo e timbre (ABDI ET AL. 2001; 
CHEN ET AL, 2010; GFELLER, 2016; INNES-BROWN ET AL., 2013; KOSANER, 2012; PETERSEN ET AL., 2015; POLONENKO ET AL, 2017; ROCCA, 2012), sendo que a maior parte dos estudos encontrados apontam que os usuários de IC tem melhora em seu desempenho social e autoestima, principalmente quando existe a participação da família, pois desfrutam juntos das atividades musicais. A maioria das famílias que conhecem os benefícios da música ou apreciam música frequentemente encorajam seus filhos a participarem de atividades musicais e também a estudarem música em casa (DRISCOLL ET AL., 2015).

Todos os estudos citados acima mostram melhorias de habilidades musicais, sociais, de fala, perceptivas e cognitivas por meio de abordagens com atividades musicais; nenhum deles relata efeitos negativos.

\section{Qual é a importância dessa revisão}

Como elencado acima, diversos estudos apontam os benefícios das atividades musicais em crianças e adolescentes usuários de implante coclear. Outros estudos visam discutir por meio de revisões de literatura a correlação entre abordagens musicais e seus possíveis desfechos para a população de crianças e adolescentes usuários IC (BRANDALISE, 2015; GFELLER, 2016; GALVÃO, 2018; TORPPA, 2019; LEROUSSEAU ET AL., 2020). Portanto, é importante analisar criticamente e sintetizar as evidências para avaliar se há eficácia nas diversas abordagens musicais como um meio de melhora de diversas habilidades e possíveis desordens em crianças e adolescentes usuários de implante coclear. Pois já é sabido que a música pode ter consequências positivas para a vida de crianças com deficiência auditiva, mas mesmo que os resultados sejam promissores, são necessárias mais evidências.

\section{OBJETIVOS}

Analisar os contributos de abordagens musicais para crianças e adolescentes usuários de implante coclear.

\section{MÉTODOS}

\section{Protocolo e registro}

Essa Revisão foi registrada no "PROSPERO", e pode ser acessada pelo endereço eletrônico: https://www.crd.york.ac.uk/prospero/

Número do Protocolo: CRD42020205581 


\section{Critérios para considerar os estudos dessa revisão}

\section{Tipos de Estudos}

Estudos Clínicos Randomizados (incluindo estudos clínicos controlados cruzados e estudos clínicos controlados fatoriais).

\section{Tipos de Participantes}

Crianças e adolescentes usuários de implante coclear.

\section{Tipos de Intervenção}

Qualquer abordagem musical relacionada a atividades de aprendizagem musical, musicoterapia, apreciação musical e percepção musical, podendo haver comparação com um grupo controle, sujeitos de uma lista de espera ou nenhum grupo de controle.

As formas elegíveis de abordagens musicais eram: atividades musicais individuais ou Coletivas. Aulas ou treino musical com educador musical particular ou professor de música em casa, ou escola de ensino regular, seja como parte do plano geral do currículo ou como aula extracurricular. Aulas em escolas de música. Sessões de Musicoterapia em clínicas ou consultórios. Apreciação e percepção musical em casa, escolas ou instituições.

\section{Tipos de Desfechos}

\section{Desfecho Primário}

Por ser uma revisão com o intuito de mostrar os contributos das diversas abordagens musicais em usuários de implante coclear, planejamos incluir apenas estudos que relataram pelo menos um dos seguintes resultados: desenvolvimento de habilidades perceptivas (incluindo auditivas, da fala e linguagem e musicais), cognitivas e sociais, que podem ser avaliados por meio de instrumentos validados, como os seguintes exemplos: Habilidades Perceptivas: Teste de avaliação do processamento fonológico (CTOPP) (WAGNER, 1999); Habilidades Cognitivas: Teste de Classificação de Cartas de Wisconsin (WCST) (CHELUNE E BAER, 1986) e Habilidades Sociais: Sistema de avaliação de habilidades sociais (SSRS) (GRESHAM E ELLIOTT, 1990).

\section{Desfecho Secundário}

Melhora nos problemas de comportamento e competência acadêmica.

Foram analisados resultados em curto prazo (até três meses), médio prazo (entre três e seis meses) e longo prazo (12 meses ou mais). 


\section{Métodos de pesquisa para identificação dos estudos}

Fizemos as pesquisas em julho de 2019 e atualizamos em março e abril de 2020.

Foram importados os registros para o software de gerenciamento de referências (EndNote) que identificou e descartou possíveis duplicidades.

\section{Buscas Eletrônicas}

Para esta revisão foram realizadas buscas bibliográficas, no intuito de encontrar estudos que descrevessem os resultados de abordagens musicais para crianças e adolescente usuários de implante coclear. As buscas foram feitas nas bases de dados para pesquisa de artigos científicos indexados na Cochrane Central Register of Controlled Trials (CENTRAL) em 04/2020(no período de 2015 até 2020), Excerpta Medica dataBASE (EMBASE) em 04/2020 (no período de 2012 até 2018), Cumulative Index to Nursing and Allied Health Literature (CINAHL) em 04/2020 (no período de 2012), WHO Institute for Conflict, Transition, and Peace Research (ICTPR) em 04/2020 (no período de 2017), Biblioteca Nacional de Medicina (PubMed) em 04/2020 (no período de 1995 até abril/2020), Literatura Latino Americana e do Caribe em Ciências da Saúde (LILACS) em 04/2020 (no período de 2012 até o ano de 2018), Biblioteca Eletrônica Científica Online (SciELO) em 04/2020 (no período de 2012 até 2018), Arts and Humanities Citation Index (A\&HCI) em 04/2020 (no período de 2009 até 2017), Social Science Citation Index (SSCI) em 04/2020 (no período de 2009 até 2017), Conference Proceedings Citation Index - Social Sciences and Humanities (CPCI-SSH) em 04/2020 (no período de 2009 até 2017) e na The World's Largest Library Catalog (WorldCat) em 04/2020 (todos os anos disponíveis). Não foram aplicados limites de data e idioma.

Foi realizada uma estratégia de busca em 04/2020 na MEDLINE (no período de 2009 até 2018), para identificar todos os estudos relevantes a fim de responder à pergunta clínica por meio de uma estratégia de pesquisa altamente sensível da Cochrane para identificar estudos randomizados (Lefebvre 2008). Também houve a utilização de unitermos (terminologia comum para pesquisa por assunto de interesse) e sinônimos, que utilizamos em outras bases de dados. Não foram aplicados limites de data e idioma (Consultar Apêndice 1).

\section{Outras fontes de busca}

Houve busca manual e também foram utilizadas as listas de referências nos estudos para citações adicionais em 04/2020. 
Para a elaboração da presente revisão foi realizada a busca de artigos com os seguintes descritores: "Music", "Music Therapy", "Pitch Perception" e "Cochlear Implants". Como palavras chave foram utilizados os seguintes termos: "Music Education", "Music Training”, “Music Perception”, “Hearing Aids”, entre outros (Consultar Apêndice 1).

\section{Coleta de Dados e Análises}

\section{Seleção dos Estudos}

Um autor (PMS) examinou minuciosamente todos os títulos e resumos identificados por meio da estratégia de busca. Foram feitos relatórios completos de qualquer título ou resumo que parecia estar de acordo com nossos critérios de inclusão. PMS leu com o segundo autor (DVMA) todos os relatórios para determinar sua elegibilidade. Em caso de divergências havia o planejamento de uma discussão com um terceiro autor (NBFL), porém isso não foi necessário.

\section{Extração e Gerenciamento de Dados}

Consultar o Apêndice 2 para ver a Tabela de métodos que planejávamos utilizar, porém não foi possível, pois não houveram estudos inclusos na revisão. Porém a mesma será utilizada em qualquer atualização desta revisão.

\section{RESULTADOS}

\section{Descrição dos Estudos}

\section{Resultados da Busca}

Dos artigos encontrados, foram incluídos os estudos que envolveram crianças e adolescentes com até 18 anos de idade, com perda sensorioneural severa a profunda, usuários de implante coclear, unilateral ou bilateral, e que tivessem sido expostos há algum tipo de abordagem musical, como procedimento de intervenção. Como critérios de exclusão foram excluídos os estudos com jovens acima de 18 anos de idade, adultos, idosos, estudos duplicados, estudos que utilizaram usuários de implante coclear e outros dispositivos para surdez, estudos 
que não avaliaram os contributos da música e estudos que não utilizaram abordagens musicais como procedimento de intervenção.

Após a busca, todos os resumos incluídos foram avaliados na integra para assim determinar sua elegibilidade para inclusão no estudo. Foi realizada uma análise crítica dos artigos incluídos identificando as características metodológicas do estudo, intervenções e resultados encontrados.

Nas bases de dados pesquisadas foram encontradas 619 citações, após excluirmos possíveis duplicidades utilizando o software EndNote. Como os critérios para inclusão eram claros (Apêndice 3) para orientar a seleção de estudos com potencial para serem incluídos em nossa revisão, dois revisores realizaram esta seleção independentemente (PMS e LCR) e a concordância entre eles foi medida pelo coeficiente KAPPA (KC). O nível de concordância foi de 0,89 (intervalo de confiança de $95 \%$ - 0,87 a 0,91). O nível de concordância foi considerado alto e a principal razão para a concordância imediata foi a presença de conceitos claros sobre as abordagens musicais, provavelmente devido às origens científicas e musicais dos referidos revisores.

Em uma primeira análise 15 estudos: Abdi et al., 2001; Yucel et al., 2009; Chen et al., 2010; Torppa et al., 2010; Rocca, 2012; Innes-Brown et al., 2013; Fu et al., 2015; Petersen et al., 2015; Rocca, 2015; Good et al., 2017; Hidalgo et al., 2017; Polonenko et al., 2017; Bedoin et al., 2018; Torppa, 2018; Yang et al., 2019, pareciam estar em concordância com os critérios de inclusão.

O número de estudos e participantes nos estudos revisados é pequeno, os desenhos de estudo variam, e mesmo os estudos com um controle o grupo nem sempre é bem controlado, contendo amostras heterogêneas. As equipes que fazem um estudo mais controlado não possuem um músico profissional para orientar no tipo de abordagem escolhida, gerando assim confusão nas nomenclaturas e equívocos nas abordagens como os estudos de Yucel et al., 2009; Chen et al., 2010; Torppa et al., 2010; Petersen et al., 2015; Good et al., 2017; Polonenko et al., 2017; Bedoin et al., 2018; Torppa, 2018 e Yang et al., 2019. Por outro lado, existem poucas pesquisas realizadas por músicos, e dessas poucas, a grande maioria tende a não ter um rigor metodológico, optando por estudos sem embasamento científico o que resulta em estudos sem controle e cheio de vieses. Não foram incluídos estudos desse tipo nessa revisão. Faz-se necessário que as pesquisas refinem o delineamento metodológico incluindo a avaliação da percepção auditiva, a apresentação detalhada da estrutura da intervenção musical para fins de replicação e de análises mais robustas (quais fatores que afetam os resultados do treinamento 
musical, da perspectiva da percepção da fala no ruído, etc).

Nos estudos selecionados foram encontradas divergências nos termos e abordagens musicais, amostras heterogêneas, faixa etária muito ampla, usuários de IC unilateral e bilateral e/ou usuários de outros dispositivos para surdez, idade auditiva não equivalente entre os sujeitos, estudos sem a aplicação do procedimento de intervenção realizado por um profíssional habilitado, falta de rigor metodológico, entre outros (Consultar quadro síntese). De forma geral foram descartados 147 estudos por não utilizarem ou avaliarem as abordagens musicais, 404 por não avaliarem somente crianças ou adolescentes e 53 por não terem desfechos em comum com a presente revisão. Por fim os 15 estudos que pareciam ser potenciais para inclusão ao final foram excluídos (Consultar Tabela estudos excluídos).

O fluxograma detalhando o processo está na Figura 5. 
Figura 5: Fluxograma

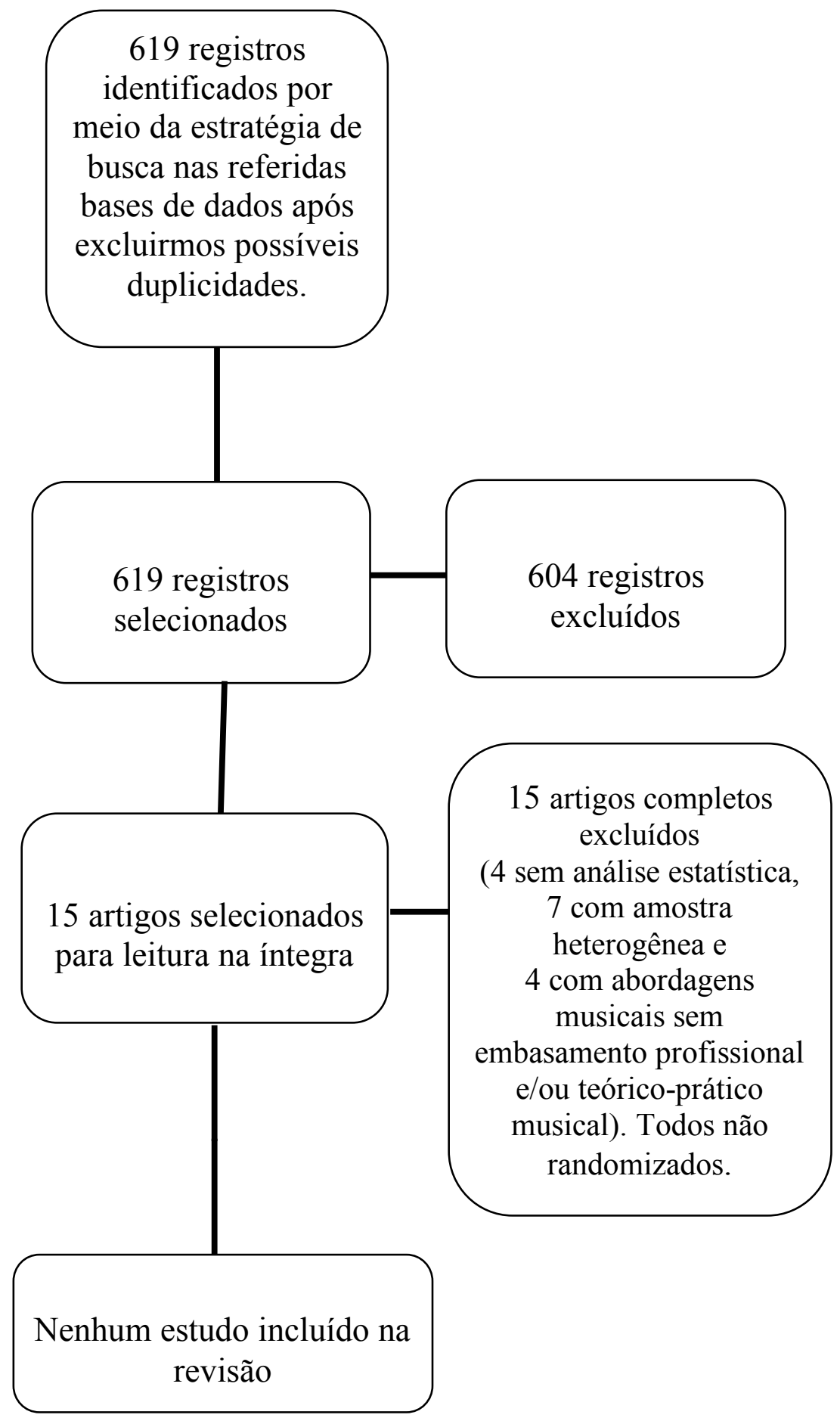




\section{Estudos incluídos}

Não houveram estudos que preencheram nossos critérios de inclusão.

\section{Estudos excluídos}

Através do quadro clínico do procedimento de intervenção de interesse como critérios para seleção do estudo, cinco estudos primários tinham o potencial de serem inclusos nesta revisão, uma vez que mencionaram abordagens musicais para crianças e adolescentes usuárias de implante coclear. No entanto, após ser realizada uma análise crítica de cada estudo, os mesmos foram excluídos por não serem estudos clínicos randomizados e por não usarem abordagens musicais com embasamento teórico-prático ou por não possuírem uma amostra homogênea, permitindo um grande viés nos estudos.

\section{Risco de viés nos estudos incluídos}

Não se aplica a esta revisão, pois não incluímos nenhum estudo.

\section{Efeitos das intervenções}

Não se aplica a esta revisão, pois não incluímos nenhum estudo.

\section{DISCUSSÃO}

\section{Resumo dos principais resultados}

A ausência de estudos controlados randomizados testando os contributos das diversas abordagens musicais para crianças e adolescentes usuárias de implante coclear torna impossível avaliar a eficácia das abordagens musicais adequadamente.

\section{Aplicabilidade de evidências de forma geral}

Apesar de diversos estudos apontarem os benefícios das diversas abordagens musicais em crianças e adolescentes usuários de implante coclear, existe uma falta de estudos com 
evidências científicas mais robustas para basear qualquer decisão sobre a implementação das referidas abordagens. É de extrema importância que os futuros pesquisadores que venham testar formalmente os contributos das diversas abordagens musicais para crianças e adolescentes usuários de implante coclear utilizem um modelo de estudo randomizado e uma equipe multidisciplinar, que inclua um músico com experiência na equipe, evitando assim viés na amostra e possíveis equívocos musicais no procedimento de intervenção.

\section{Qualidade das Evidências}

Não houveram estudos com evidências científicas robustas e controladas inclusos nessa revisão.

\section{Possíveis Vieses no Processo de Revisão}

Desenvolvemos uma estratégia de pesquisa sensível que incluía fontes de estudos não publicados, a fim de minimizar o viés de publicação. Toda a busca foi realizada sem limite de data ou idioma. É importante ressaltar que o processo de seleção dos estudos, inicialmente realizado pelas autoras PMS e DVMA e logo após revisado por duas revisoras (PMS, musicista profissional com experiência em abordagens musicais de alto rigor musical e científico e LCR, educadora musical com ampla experiência em ensino musical de alto rigor pedagógico-musical e científico) foi minucioso.

\section{Acordos e Desacordos com Outros Estudos ou Revisões}

Esperamos que as informações disponíveis nesta revisão possam encorajar pesquisadores a conduzir experimentos sobre os contributos das diversas abordagens musicais em crianças e adolescentes usuários de implante coclear, utilizando o rigor metodológico de um estudo clínico randomizado. Apesar de existirem diversos estudos que relacionem os benefícios das abordagens musicais em diversos contextos e desordens, atualmente, existe a necessidade de que os estudos sejam conduzidos por equipes multidisciplinares que incluam um músico profissional experiente, para que não existam equívocos pedagógicos e musicais que encontramos em grande parte desses estudos. Não existe a possibilidade de compararmos sujeitos com uma faixa etária muito ampla e abordagens musicais que se diferem em nível técnico e prático musical e comportamental. Existe a necessidade de que antes de um estudo 
ser iniciado seja escolhida uma abordagem musical coerente com os sujeitos da pesquisa e que a mesma seja de fato a abordagem escolhida, pois existe um número muito grande de estudos que confundem os termos das abordagens musicais, citando por exemplo estudos de musicoterapia que na verdade estão utilizando procedimentos de aprendizagem musical e viceversa. Devido a esses fatores, justificamos a necessidade de um músico profissional e experiente na abordagem escolhida. Apesar dos vários estudos que apresentam os benefícios das diversas abordagens musicais em usuários de implante coclear, não há evidências robustas disponíveis em relação aos contributos das devidas abordagens, portanto, futuros estudos clínicos randomizados são recomendados.

\section{CONCLUSÕES DOS AUTORES}

\section{Implicações Para a Prática}

Apesar de a música de forma geral ser popular e considerada uma intervenção benéfica na população de usuários de implante coclear, não há evidências de estudos clínicos randomizados para demonstrar vantagens potenciais (ou até mesmo desvantagens) que contribuam com o desenvolvimento de habilidades perceptivas, cognitivas e sociais, além dos problemas de comportamento e competência acadêmica, em crianças e adolescentes usuários de implante coclear.

\section{Implicações para a pesquisa}

Estudos bem elaborados com rigor metodológico são necessários a fim de verificar os contributos das abordagens musicais para melhora de habilidades perceptivas, cognitivas, socias, problemas de comportamento e competência acadêmica, em crianças e adolescentes usuárias de implante coclear. Embora as abordagens musicais em si não tenham como objetivo melhorar as referidas habilidades, alguns estudos mostram uma relação entre a música e o desenvolvimento e melhora de diversas habilidades e desordens, além da comprovação da plasticidade cerebral em indivíduos expostos a atividades musicais, entendemos que seja possível que a música ajude crianças e adolescentes usuários de implante coclear. 
CARACTERÍSTICAS DOS ESTUDOS

\section{Quadro 5 - Quadro Síntese dos estudos excluídos}

\begin{tabular}{|c|c|c|c|c|}
\hline $\begin{array}{c}\text { Ano e } \\
\text { autores }\end{array}$ & Sujeitos & Intervenção & $\begin{array}{l}\text { Objetivos e Análise } \\
\text { Estatística }\end{array}$ & $\begin{array}{l}\text { Desfechos e } \\
\text { Resultados }\end{array}$ \\
\hline $\begin{array}{l}\text { Abdi et al., } \\
2001\end{array}$ & $\begin{array}{l}23 \text { crianças } \\
\text { com idade } \\
\text { entre } 2 \text { a } 12 \\
\text { anos, } \\
\text { usuárias de } \\
\text { IC. } \\
\text { Idade } \\
\text { auditiva dos } \\
\text { sujeitos não } \\
\text { equivalente. }\end{array}$ & $\begin{array}{l}\text { Participaram de } \\
\text { aulas de música } \\
\text { semanais } \\
\text { baseadas no } \\
\text { método Orff. } \\
\text { No período de } 3 \text { a } \\
13 \text { meses. }\end{array}$ & $\begin{array}{l}\text { Avaliar a viabilidade de } \\
\text { métodos que utilizem a } \\
\text { música como meio de } \\
\text { habilitação de crianças } \\
\text { usuárias de IC. } \\
\text { Sem análise estatística. }\end{array}$ & $\begin{array}{l}\text { Desenvolvimento de } \\
\text { habilidades } \\
\text { perceptivas musicais } \\
\text { e da responsabilidade. } \\
\text { Todos as crianças } \\
\text { melhoraram em suas } \\
\text { habilidades musicais } \\
\text { e capacidade de } \\
\text { percepção musical. } \\
\text { Houve envolvimento } \\
\text { e relato de satisfação } \\
\text { familiar ao final. }\end{array}$ \\
\hline $\begin{array}{l}\text { Yucel et al., } \\
2009\end{array}$ & $\begin{array}{l}9 \text { crianças } \\
\text { usuárias de } \\
\text { IC e outros } \\
\text { dispositivos } \\
\text { para surdez } \\
\text { recém } \\
\text { implantadas } \\
(12 \text { a } 36 \\
\text { meses) } \\
\text { Comparadas } \\
\text { com } 9 \\
\text { crianças } \\
\text { sem } \\
\text { intervenção. }\end{array}$ & $\begin{array}{l}\text { Os pais foram } \\
\text { ensinados para } \\
\text { treinar as crianças } \\
\text { em casa, para } \\
\text { reconhecer a } \\
\text { diferenças entre } \\
\text { as notas e para } \\
\text { reconhecer ritmos } \\
\text { usando um } \\
\text { teclado digital. } \\
\text { Também faziam } \\
\text { jogos com } \\
\text { melodias simples } \\
\text { e dançavam com } \\
\text { eles. }\end{array}$ & $\begin{array}{l}\text { Avaliar percepção } \\
\text { musical e de fala no } \\
\text { silêncio e no ruído. } \\
\text { Questionários de } \\
\text { desempenho musical e } \\
\text { questionário da } \\
\text { percepção da fala em } \\
\text { conjunto aberto e } \\
\text { fechado. } \\
\text { Análise: Teste de Mann- } \\
\text { Whitney }\end{array}$ & $\begin{array}{l}\text { Avaliou as } \\
\text { habilidades } \\
\text { perceptivas da fala. } \\
\text { No final do terceiro } \\
\text { mês o grupo } \\
\text { experimental } \\
\text { apresentou melhora } \\
\text { em conjunto aberto da } \\
\text { percepção da fala e na } \\
\text { percepção musical, } \\
\text { quando comparado ao } \\
\text { grupo controle. }\end{array}$ \\
\hline $\begin{array}{l}\text { Chen et al., } \\
2010 .\end{array}$ & $\begin{array}{l}13 \text { crianças } \\
\text { com idade } \\
\text { entre } 5 \text { a } 14 \\
\text { anos, } \\
\text { usuárias de } \\
\text { IC, expostas } \\
\text { a atividade } \\
\text { musical. } \\
\text { Comparadas } \\
\text { a } 14 \\
\text { crianças } \\
\text { sem IC. }\end{array}$ & $\begin{array}{l}2 \text { a } 36 \text { meses de } \\
\text { aulas de música } \\
\text { na escola Yamaha } \\
\text { com atividades } \\
\text { como ouvir, } \\
\text { cantar e tocar o } \\
\text { instrumento. }\end{array}$ & $\begin{array}{l}\text { Avaliar percepção } \\
\text { musical e do pitch. } \\
\text { Crianças tinham que } \\
\text { descobrir as notas que } \\
\text { eram tocadas e a relação } \\
\text { (intervalos) entre elas. } \\
\text { Para análise dos } \\
\text { resultados as crianças } \\
\text { foram divididas em dois } \\
\text { grupos: menores e } \\
\text { maiores de seis anos de } \\
\text { idade. } \\
\text { Sem análise estatística }\end{array}$ & $\begin{array}{l}\text { Correlações com a } \\
\text { percepção de pitch e a } \\
\text { duração do } \\
\text { treinamento. } \\
\text { Os resultados } \\
\text { mostraram melhora } \\
\text { da percepção do pitch } \\
\text { em crianças que } \\
\text { fizeram mais tempo } \\
\text { de aula. } \\
\text { Crianças maiores de } 6 \\
\text { anos tiveram melhora } \\
\text { percepção de forma } \\
\text { geral. }\end{array}$ \\
\hline
\end{tabular}




\begin{tabular}{|c|c|c|c|c|}
\hline & $\begin{array}{l}\text { Idade } \\
\text { auditiva dos } \\
\text { sujeitos não } \\
\text { equivalente. }\end{array}$ & & & \\
\hline $\begin{array}{l}\text { Torppa et } \\
\text { al., } 2010\end{array}$ & $\begin{array}{l}17 \text { crianças } \\
\text { usuárias de } \\
\text { IC com } \\
\text { idade entre } \\
4 \text { a } 12 \text { anos. } \\
\text { Crianças } \\
\text { que tiveram } \\
\text { aula em } \\
\text { escola de } \\
\text { música, } \\
\text { atividades } \\
\text { musicais em } \\
\text { casa ou } \\
\text { ambas } \\
\text { atividades e } \\
\text { crianças que } \\
\text { não tiveram } \\
\text { nenhum } \\
\text { contato com } \\
\text { atividades } \\
\text { musicais. } \\
\text { Idade } \\
\text { auditiva dos } \\
\text { sujeitos não } \\
\text { equivalente. }\end{array}$ & $\begin{array}{l}\text { Diversas } \\
\text { atividades } \\
\text { musicais (cantar, } \\
\text { tocar, ou outra } \\
\text { experiência } \\
\text { musical). }\end{array}$ & $\begin{array}{l}\text { Analisar a percepção da } \\
\text { linguagem. } \\
\text { Avaliação da percepção } \\
\text { da linguagem por meio } \\
\text { de testes e de um } \\
\text { questionário de } \\
\text { antecedentes } \\
\text { relacionados à } \\
\text { apreciação musical. } \\
\text { Sem análise estatística. }\end{array}$ & $\begin{array}{l}\text { Correlação da } \\
\text { quantidade de } \\
\text { estímulos musicais } \\
\text { com o nível de } \\
\text { percepção da } \\
\text { linguagem das } \\
\text { crianças. } \\
\text { A melhora da } \\
\text { percepção da } \\
\text { linguagem foi } \\
\text { correlacionada com } \\
\text { participantes que } \\
\text { tinham estímulos } \\
\text { musicais em casa. } \\
\text { A percepção da } \\
\text { linguagem foi melhor } \\
\text { com participantes de } \\
\text { aula de música. } \\
\text { Correlações com } \\
\text { escuta de música na } \\
\text { televisão ou CDs não } \\
\text { obtiveram resultado } \\
\text { significativo. }\end{array}$ \\
\hline $\begin{array}{l}\text { Rocca, } \\
2012\end{array}$ & $\begin{array}{l}\text { Crianças e } \\
\text { adolescentes } \\
\text { de } 4 \text { a } 14 \\
\text { anos de } \\
\text { idade. } \\
\text { Usuários de } \\
\text { IC, outros } \\
\text { dispositivos } \\
\text { para surdez } \\
\text { ou sem } \\
\text { perda } \\
\text { auditiva. }\end{array}$ & $\begin{array}{l}\text { Os sujeitos } \\
\text { participavam de } \\
\text { atividades } \\
\text { musicais (aulas } \\
\text { semanais) em sua } \\
\text { rotina, seja com } \\
\text { aulas teóricas, } \\
\text { tocando } \\
\text { instrumentos ou } \\
\text { cantando. }\end{array}$ & $\begin{array}{l}\text { Descrever os benefícios } \\
\text { das aulas de música para } \\
\text { comunicação social e } \\
\text { melhora das habilidades } \\
\text { musicais. } \\
\text { Sem análise estatística. }\end{array}$ & $\begin{array}{l}\text { O artigo mostra uma } \\
\text { visão geral do } \\
\text { desenvolvimento de } \\
\text { habilidades musicais } \\
\text { por meio da } \\
\text { abordagem de um } \\
\text { programa social e } \\
\text { aponta que crianças } \\
\text { usuárias de IC podem } \\
\text { tocar, cantar e } \\
\text { participar de eventos } \\
\text { sociais com contextos } \\
\text { musicais. } \\
\text { Ex-alunos do } \\
\text { programa formaram- } \\
\text { se para se tornarem } \\
\text { professores de } \\
\text { música, intérpretes e } \\
\text { compositores. }\end{array}$ \\
\hline
\end{tabular}




\begin{tabular}{|c|c|c|c|c|}
\hline $\begin{array}{l}\text { Innes- } \\
\text { Brown et } \\
\text { al., } 2013\end{array}$ & $\begin{array}{l}17 \text { crianças } \\
\text { usuárias de } \\
\text { de IC, } \\
\text { outros } \\
\text { dispositivos } \\
\text { para surdez } \\
\text { ou sem } \\
\text { perda } \\
\text { auditiva. }\end{array}$ & $\begin{array}{l}\text { Todas as crianças } \\
\text { participaram } \\
\text { semanalmente de } \\
\text { um clube de } \\
\text { música na hora } \\
\text { do almoço da } \\
\text { escola. } 45 \\
\text { minutos de aula } \\
\text { com jogos vocais } \\
\text { e outras } \\
\text { abordagens de } \\
\text { aprendizagem } \\
\text { musical, como a } \\
\text { metodologia } \\
\text { Kodaly. }\end{array}$ & $\begin{array}{l}\text { Avaliar o } \\
\text { desenvolvimento da } \\
\text { percepção musical, } \\
\text { (timbre e ritmo) para } \\
\text { avaliar a função do } \\
\text { dispositivo no } \\
\text { desenvolvimento da } \\
\text { audição. } \\
\text { Por meio de testes para } \\
\text { avaliação da percepção } \\
\text { do timbre, ritmo e notas. } \\
\text { Análise estatística: } \\
\text { ANOVA de medidas } \\
\text { repetidas. }\end{array}$ & $\begin{array}{l}\text { Correlaciona o } \\
\text { desempenho musical } \\
\text { ao desenvolvimento } \\
\text { da percepção } \\
\text { auditiva. } \\
\text { A melhora do } \\
\text { desempenho das } \\
\text { crianças nos testes } \\
\text { não foi significativa. } \\
\text { Os professores } \\
\text { relataram que a } \\
\text { participação no clube } \\
\text { de música melhorou a } \\
\text { confiança das } \\
\text { crianças, o } \\
\text { desenvolvimento } \\
\text { social e o } \\
\text { envolvimento em } \\
\text { aulas de música em } \\
\text { geral. }\end{array}$ \\
\hline $\begin{array}{l}\text { Fu et al., } \\
2015\end{array}$ & $\begin{array}{l}14 \text { crianças } \\
\text { usuárias de } \\
\text { IC, com } \\
\text { idade entre } \\
5 \text { e } 10 \text { anos. } \\
6 \text { crianças } \\
\text { com treino } \\
\text { perceptivo } \\
\text { musical e } 8 \\
\text { sem treino. } \\
\text { Idade } \\
\text { auditiva dos } \\
\text { sujeitos não } \\
\text { equivalente. }\end{array}$ & $\begin{array}{l}\text { O treino musical } \\
\text { era realizado por } \\
\text { uma simples } \\
\text { melodia tocada } \\
\text { por um } \\
\text { computador. } \\
\text { Meia hora por } \\
\text { dia, todos os dias } \\
\text { num período de } \\
10 \text { semanas. }\end{array}$ & $\begin{array}{l}\text { Analisar o } \\
\text { desenvolvimento da } \\
\text { percepção do pitch. } \\
\text { Os participantes } \\
\text { deveriam identificar } \\
\text { mudanças no pitch e } \\
\text { responder a mudança } \\
\text { selecionando uma das } \\
\text { nove possibilidades de } \\
\text { resposta que apareciam } \\
\text { na tela do computador. } \\
\text { Análise estatística: foi } \\
\text { aplicado o teste } \\
\text { ANOVA }\end{array}$ & $\begin{array}{l}\text { Relaciona a } \\
\text { apreciação musical ao } \\
\text { desenvolvimento e } \\
\text { melhora da percepção } \\
\text { do pitch. } \\
\text { Houve uma mudança } \\
\text { considerável em } \\
\text { todos os testes logo } \\
\text { após } 4 \text { semanas de } \\
\text { treino. } \\
\text { Mesmo depois de o } \\
\text { treinamento ser } \\
\text { interrompido, não } \\
\text { houve um declínio na } \\
\text { melhora. }\end{array}$ \\
\hline $\begin{array}{l}\text { Petersen et } \\
\text { al., } 2015\end{array}$ & $\begin{array}{l}21 \\
\text { adolescentes } \\
\text { usuários de } \\
\text { IC, com } \\
\text { idade entre } \\
15 \text { e } 18 \\
\text { anos. } \\
\text { Divididos } \\
\text { em grupos: } \\
11 \text { com IC e } \\
10 \text { com } \\
\text { audição } \\
\text { típica. }\end{array}$ & $\begin{array}{l}\text { O grupo de IC foi } \\
\text { exposto a } \\
\text { diversas } \\
\text { atividades } \\
\text { musicais, como, } \\
\text { cantar, treino } \\
\text { rítmico e treino } \\
\text { computadorizado. } \\
\text { O treino foi } \\
\text { realizado num } \\
\text { total de } 20 \text { horas } \\
\text { dividido em } 6 \\
\text { dias, distribuídos } \\
\text { em } 2 \text { semanas. }\end{array}$ & $\begin{array}{l}\text { Analisar o } \\
\text { desenvolvimento da } \\
\text { percepção auditiva e da } \\
\text { fala } \\
\text { Foram utilizados testes } \\
\text { de comportamento e de } \\
\text { avaliação de percepção } \\
\text { auditiva. } \\
\text { Análise estatística: foi } \\
\text { aplicado o teste } \\
\text { ANOVA }\end{array}$ & $\begin{array}{l}\text { Avalia a contribuição } \\
\text { das atividades } \\
\text { musicais para } \\
\text { desenvolvimento de } \\
\text { habilidades auditivas } \\
\text { e de linguagem. } \\
\text { Não houve melhora } \\
\text { em virtude do } \\
\text { procedimento. }\end{array}$ \\
\hline
\end{tabular}




\begin{tabular}{|c|c|c|c|c|}
\hline & $\begin{array}{l}\text { Idade } \\
\text { auditiva dos } \\
\text { sujeitos não } \\
\text { equivalente. }\end{array}$ & & & \\
\hline $\begin{array}{l}\text { Rocca, } \\
2015\end{array}$ & $\begin{array}{l}15 \text { crianças } \\
\text { de } 5 \text { a } 11 \\
\text { meses de } \\
\text { idade, } \\
\text { usuários de } \\
\text { de IC. }\end{array}$ & $\begin{array}{l}\text { Todas as crianças } \\
\text { participaram do } \\
\text { programa musical } \\
\text { para pais e bebês, } \\
\text { com intuito de } \\
\text { desenvolver a } \\
\text { musicalidade dos } \\
\text { mesmos por meio } \\
\text { do uso de } \\
\text { melodias } \\
\text { gravadas e da voz } \\
\text { dos pais. }\end{array}$ & $\begin{array}{l}\text { Determinar se o } \\
\text { programa poderia ser } \\
\text { usado para monitorar } \\
\text { melhora para os bebês. } \\
\text { Foram aplicados } \\
\text { questionários para os } \\
\text { pais e professores ao } \\
\text { final de oito meses de } \\
\text { intervenção. } \\
\text { Sem análise estatística. }\end{array}$ & $\begin{array}{l}\text { A fim de avaliar se o } \\
\text { programa é projetado } \\
\text { para ajudar os pais na } \\
\text { interação, } \\
\text { comportamento de } \\
\text { escuta, comunicação } \\
\text { social, emocional e } \\
\text { desenvolvimento, pré } \\
\text { e pós implantação. } \\
\text { Concluiu-se que o } \\
\text { programa é } \\
\text { apropriado para a } \\
\text { abordagem dos pais } \\
\text { com as crianças em } \\
\text { suas rotinas diárias. } \\
\text { Os pais apontaram } \\
\text { uma melhora } \\
\text { significativa em } \\
\text { relação percepção da } \\
\text { atenção e vocalização } \\
\text { das crianças. }\end{array}$ \\
\hline $\begin{array}{l}\text { Good et al., } \\
2017\end{array}$ & $\begin{array}{l}18 \text { crianças } \\
\text { usuárias de } \\
\text { IC, com } \\
\text { idade entre } \\
6 \text { e } 15 \text { anos. } \\
\text { Divididos } \\
\text { em dois } \\
\text { grupos. } \\
\text { Idade } \\
\text { auditiva dos } \\
\text { sujeitos não } \\
\text { equivalente. }\end{array}$ & $\begin{array}{l}9 \text { crianças foram } \\
\text { expostas a aulas } \\
\text { de piano, canto e } \\
\text { outras abordagens } \\
\text { musicais e } 9 \\
\text { crianças foram } \\
\text { expostas a aulas } \\
\text { de artes visuais. } \\
\text { Foram expostas a } \\
\text { seis meses de } \\
\text { aula. }\end{array}$ & $\begin{array}{l}\text { Avaliar a percepção da } \\
\text { fala, linguagem e } \\
\text { musical. } \\
\text { Testes utilizados para } \\
\text { avaliar percepção } \\
\text { musical (escalas, } \\
\text { melodias, ritmo, pitch) e } \\
\text { percepção da fala e } \\
\text { linguagem. } \\
\text { Análise estatística: teste } \\
\text { ANOVA. }\end{array}$ & $\begin{array}{l}\text { Correlaciona os } \\
\text { benefícios de } \\
\text { atividades artísticas } \\
\text { (música e artes } \\
\text { visuais) ao } \\
\text { desenvolvimento de } \\
\text { linguagem e musical. } \\
\text { O grupo exposto a } \\
\text { atividades musicais } \\
\text { teve uma melhora de } \\
\text { forma geral em suas } \\
\text { percepções. } \\
\text { O grupo exposto às } \\
\text { atividades artísticas } \\
\text { visuais não obteve } \\
\text { melhora. }\end{array}$ \\
\hline $\begin{array}{l}\text { Hidalgo et } \\
\text { al., } 2017\end{array}$ & $\begin{array}{l}\text { Crianças } \\
\text { usuárias de } \\
\text { IC e/ou } \\
\text { outros } \\
\text { dispositivos } \\
\text { para surdez } \\
\text { com idade } \\
\text { entre } 5 \text { e } 6 \\
\text { anos. }\end{array}$ & $\begin{array}{l}\text { Terapia } \\
\text { fonoaudiológica e } \\
\text { atividades } \\
\text { musicais foram } \\
\text { aplicadas. } \\
\text { Exercícios } \\
\text { rítmicos como } \\
\text { percussão } \\
\text { corporal, bater } \\
\text { palmas, tocar }\end{array}$ & $\begin{array}{l}\text { Analisar o tempo de } \\
\text { adaptação para } \\
\text { percepção e interação na } \\
\text { fala. } \\
\text { Teste feito por um jogo } \\
\text { virtual para nomear } \\
\text { desenhos. Oponente } \\
\text { virtual. } \\
\text { O teste era realizado e } \\
\text { aplicado por uma }\end{array}$ & $\begin{array}{l}\text { Avalia por meio da } \\
\text { comparação de } \\
\text { terapia } \\
\text { fonoaudiológica e } \\
\text { atividades musicais se } \\
\text { existe a melhora da } \\
\text { resposta para o tempo } \\
\text { de percepção e } \\
\text { interação na fala. }\end{array}$ \\
\hline
\end{tabular}




\begin{tabular}{|c|c|c|c|c|}
\hline & & $\begin{array}{l}\text { maracas, entre } \\
\text { outras abordagens } \\
\text { musicais. } \\
\text { A duração da } \\
\text { intervenção era } \\
\text { de uma hora. }\end{array}$ & $\begin{array}{l}\text { fonoaudióloga após uma } \\
\text { hora de terapia } \\
\text { fonoaudiológica ou } \\
\text { atividade musical. } \\
\text { Análise estatística: teste } \\
\text { ANOVA. }\end{array}$ & $\begin{array}{l}\text { Concluiu-se que } \\
\text { houve melhora } \\
\text { parcial da resposta } \\
\text { temporal das } \\
\text { interações verbais } \\
\text { após o treinamento } \\
\text { musical. }\end{array}$ \\
\hline $\begin{array}{l}\text { Polonenko } \\
\text { et al., } 2017\end{array}$ & $\begin{array}{l}50 \text { crianças } \\
\text { usuárias de } \\
\text { IC e outros } \\
\text { dispositivos } \\
\text { de surdez, } \\
\text { com idade } \\
\text { entre } 6 \text { e } 18 \\
\text { anos, } \\
\text { divididos } \\
\text { em dois } \\
\text { grupos: } \\
\text { (dispositivos } \\
\text { para surdez, } \\
\text { audição } \\
\text { normal e IC } \\
\text { bilateral) } \\
\text { expostos a } \\
\text { atividades } \\
\text { musicais e } \\
\text { grupo sem } \\
\text { atividades } \\
\text { musicais. }\end{array}$ & $\begin{array}{l}\text { O grupo } \\
\text { experimental foi } \\
\text { exposto a aulas } \\
\text { de teoria musical, } \\
\text { prática } \\
\text { instrumental de } \\
\text { pelo menos um } \\
\text { instrumento não } \\
\text { percussivo, e/ou } \\
\text { aula de canto. }\end{array}$ & $\begin{array}{l}\text { Analisar a percepção } \\
\text { auditiva e musical. } \\
\text { Foram utilizados testes } \\
\text { para análise da } \\
\text { percepção da } \\
\text { discriminação de } \\
\text { melodias semelhantes, } \\
\text { alteração do pitch, ritmo } \\
\text { e memorização. } \\
\text { Análise estatística: } \\
\text { ANOVA }\end{array}$ & $\begin{array}{l}\text { Correlaciona os } \\
\text { benefícios de aulas de } \\
\text { música com o } \\
\text { desenvolvimento da } \\
\text { percepção auditiva e } \\
\text { musical. } \\
\text { Concluíram que } \\
\text { crianças que } \\
\text { participaram do } \\
\text { treinamento musical } \\
\text { eram mais rápidas e } \\
\text { precisas na percepção } \\
\text { musical, } \\
\text { independentemente } \\
\text { da sua condição de } \\
\text { audição. }\end{array}$ \\
\hline $\begin{array}{l}\text { Bedoin et } \\
\text { al., } 2018\end{array}$ & $\begin{array}{l}10 \text { crianças } \\
\text { usuárias IC } \\
\text { unilateral e } \\
\text { bilateral } \\
\text { com idade } \\
\text { entre } 5 \text { e } 10 \\
\text { anos. } \\
\text { Divididas } \\
\text { em dois } \\
\text { grupos para } \\
\text { avaliação. }\end{array}$ & $\begin{array}{l}\text { As crianças foram } \\
\text { expostas a } 16 \\
\text { semanas de } \\
\text { treinamento } \\
\text { morfossintático } \\
\text { (baseado no } \\
\text { processamento da } \\
\text { fala). } \\
8 \text { sessões com } \\
\text { intervenções } \\
\text { musicais } \\
\text { computadorizadas } \\
\text { (treinamento } \\
\text { rítmico) e } 8 \\
\text { sessões de } \\
\text { treinamento } \\
\text { morfossintático. }\end{array}$ & $\begin{array}{l}\text { Analisar o } \\
\text { desenvolvimento } \\
\text { linguístico (sintaxe) de } \\
\text { crianças usuárias de IC } \\
\text { por meio de atividades } \\
\text { rítmicas musicais. } \\
\text { Os testes de } \\
\text { desempenho no } \\
\text { processamento } \\
\text { gramatical, repetição de } \\
\text { não palavras, atenção e } \\
\text { memória foram } \\
\text { realizados antes e após } \\
\text { as intervenções. } \\
\text { Análise estatística: Teste } \\
\text { de Mann-Whitney }\end{array}$ & $\begin{array}{l}\text { Afim de analisar o } \\
\text { desenvolvimento } \\
\text { linguístico por meio } \\
\text { de atividades rítmicas } \\
\text { musicais, os autores } \\
\text { concluíram que as } \\
\text { atividades musicais } \\
\text { melhoraram o } \\
\text { processamento do } \\
\text { material de } \\
\text { treinamento sintático, } \\
\text { aumentando assim os } \\
\text { efeitos do } \\
\text { treinamento no } \\
\text { processamento da } \\
\text { gramática, bem como } \\
\text { processamento } \\
\text { fonológico e } \\
\text { sequenciamento de } \\
\text { sinais de fala. }\end{array}$ \\
\hline $\begin{array}{l}\text { Torppa, } \\
2018\end{array}$ & $\begin{array}{l}21 \text { crianças } \\
\text { usuárias de } \\
\text { IC, com }\end{array}$ & $\begin{array}{l}12 \text { crianças em } \\
\text { um grupo exposto } \\
\text { a intervenções } \\
\text { musicais, como }\end{array}$ & $\begin{array}{l}\text { Avaliar percepção } \\
\text { auditiva e percepção da } \\
\text { fala. }\end{array}$ & $\begin{array}{l}\text { Avaliou se percepção } \\
\text { auditiva e de fala } \\
\text { melhoraria em virtude }\end{array}$ \\
\hline
\end{tabular}




\begin{tabular}{|c|c|c|c|c|}
\hline & $\begin{array}{l}\text { idade de } 4 \text { a } \\
13 \text { anos. } \\
\text { Idade } \\
\text { auditiva dos } \\
\text { sujeitos não } \\
\text { equivalente. }\end{array}$ & $\begin{array}{l}\text { aulas de canto e } 9 \\
\text { que não estavam } \\
\text { passando pelas } \\
\text { intervenções. }\end{array}$ & $\begin{array}{l}\text { Foram utilizados testes } \\
\text { para avaliação da } \\
\text { percepção e do } \\
\text { reconhecimento de } \\
\text { palavras, timbre e } \\
\text { intensidade. } \\
\text { Análise estatística: teste } \\
\text { ANOVA de medidas } \\
\text { repetidas }\end{array}$ & $\begin{array}{l}\text { das intervenções } \\
\text { musicais. } \\
\text { Concluiu que a } \\
\text { percepção da fala em } \\
\text { crianças usuárias de } \\
\text { IC melhorou } \\
\text { principalmente } \\
\text { devido aos testes com } \\
\text { maiores intervalos de } \\
\text { mudança de notas. } \\
\text { Todas as crianças } \\
\text { tiveram melhora nas } \\
\text { habilidades de } \\
\text { linguagem. }\end{array}$ \\
\hline $\begin{array}{l}\text { Yang et al., } \\
2019\end{array}$ & $\begin{array}{l}28 \text { crianças } \\
\text { usuárias de } \\
\text { IC bilateral, } \\
\text { unilateral ou } \\
\text { com audição } \\
\text { normal com } \\
\text { idade entre } \\
7 \text { e } 13 \text { anos. } \\
\text { Idade } \\
\text { auditiva dos } \\
\text { sujeitos não } \\
\text { equivalente. } \\
\text { Divididos } \\
\text { em dois } \\
\text { grupos para } \\
\text { avaliação. }\end{array}$ & $\begin{array}{l}\text { As crianças } \\
\text { usuárias de IC } \\
\text { tiveram } 21 \text { meses } \\
\text { de treinamento } \\
\text { musical formal } \\
\text { antes de iniciarem } \\
\text { os ensaios de um } \\
\text { coral, durante } 2 \\
\text { semanas } \\
\text { ensaiando apenas } \\
\text { uma música no } \\
\text { período de } 3 \\
\text { horas semanais } \\
\text { mais } 1 \text { hora de } \\
\text { treino em casa. } \\
\text { As crianças com } \\
\text { audição normal } \\
\text { não tiveram } \\
\text { treino musical, só } \\
\text { o ensaio do coral. }\end{array}$ & $\begin{array}{l}\text { Avaliar a proficiência de } \\
\text { fala de crianças usuárias } \\
\text { de IC por meio da } \\
\text { participação das mesmas } \\
\text { em um coral. } \\
\text { Após as duas semanas } \\
\text { de ensaio, todas as } \\
\text { crianças do estudo } \\
\text { gravaram um arquivo } \\
\text { com a música ensaiada } \\
\text { somente com a linha } \\
\text { vocal sem } \\
\text { acompanhamento. } \\
\text { Os arquivos foram } \\
\text { submetidos a análises } \\
\text { acústicas e métricas } \\
\text { foram desenvolvidas } \\
\text { para analisar e } \\
\text { quantificar a precisão da } \\
\text { afinação e desempenho } \\
\text { musical. } \\
\text { Análise estatística - } \\
\text { Teste T. }\end{array}$ & $\begin{array}{l}\text { Avaliou se o } \\
\text { treinamento musical } \\
\text { formal pós } \\
\text { implantação } \\
\text { beneficiaria o } \\
\text { desenvolvimento da } \\
\text { oralidade das } \\
\text { crianças. } \\
\\
\text { Concluíram que } \\
\text { atividades musicais } \\
\text { bem dirigidas podem } \\
\text { ser estratégia eficaz } \\
\text { para desenvolvimento } \\
\text { da oralidade } \\
\text { incluindo o canto, de } \\
\text { usuários de IC pós } \\
\text { implantação. }\end{array}$ \\
\hline
\end{tabular}




\section{Quadro 6 - Quadro de estudos excluídos}

\begin{tabular}{|c|c|}
\hline Estudo & Motivo de exclusão \\
\hline Abdi et al., 2001 & $\begin{array}{l}\text { Heterogeneidade na amostragem (faixa etária muito ampla (5 a } 14 \\
\text { anos), viés por avaliar crianças usuárias de IC com idade auditiva } \\
\text { muito distante umas das outras. Sem análise estatística e não } \\
\text { randomizado }\end{array}$ \\
\hline Yucel et al., 2009 & $\begin{array}{l}\text { Heterogeneidade na amostragem (IC e outros dispositivos para } \\
\text { surdez), intervenção musical realizada pelos pais. Não } \\
\text { randomizado. }\end{array}$ \\
\hline Chen et al., 2010 & $\begin{array}{l}\text { Heterogeneidade na amostragem (faixa etária muito ampla (5 a } 14 \\
\text { anos), viés por avaliar crianças usuárias de IC com idade auditiva } \\
\text { muito distante umas das outras, avaliou crianças que já tinham } \\
\text { experiência com outras atividades musicais além da intervenção do } \\
\text { estudo. Sem análise estatística e não randomizado. }\end{array}$ \\
\hline Torppa et al., 2010 & $\begin{array}{l}\text { Heterogeneidade na amostragem (faixa etária muito ampla (4 a } 14 \\
\text { anos), viés por avaliar crianças usuárias de IC com idade auditiva } \\
\text { muito distante umas das outras e avaliou diversas abordagens } \\
\text { musicais totalmente diferentes. Sem análise estatística e não } \\
\text { randomizado. }\end{array}$ \\
\hline Rocca, 2012 & $\begin{array}{l}\text { Heterogeneidade na amostragem (faixa etária muito ampla (4 a } 14 \\
\text { anos), usuários de IC e outros dispositivos. Sem análise estatística } \\
\text { e não randomizado. }\end{array}$ \\
\hline $\begin{array}{l}\text { Innes-Brown et al., } \\
2013\end{array}$ & $\begin{array}{l}\text { Heterogeneidade na amostragem (crianças usuárias de IC e outros } \\
\text { dispositivos). Abordagem musical não é coerente (metodologia } \\
\text { Kodaly). Não randomizado. }\end{array}$ \\
\hline Fu et al., 2015 & $\begin{array}{l}\text { Viés por avaliar crianças usuárias de IC com idade auditiva muito } \\
\text { distante umas das outras e utilizou abordagem musical não coerente } \\
\text { (Computadorizada). Não randomizado. }\end{array}$ \\
\hline Petersen et al., 2015 & $\begin{array}{l}\text { Procedimento de intervenção heterogêneo. Diversas abordagens } \\
\text { musicais: computadorizadas, aulas mistas e aulas de canto. } \\
\text { diferença de idade auditiva dos participantes muito ampla e tempo } \\
\text { de abordagem do procedimento de intervenção curto. Não } \\
\text { randomizado. }\end{array}$ \\
\hline
\end{tabular}




\begin{tabular}{|l|l|}
\hline Rocca, 2015 & $\begin{array}{l}\text { Abordagem musical não coerente com a faixa etária. Bebes } \\
\text { expostos a melodias gravadas ou a voz dos pais. Sem análise } \\
\text { estatística e não randomizado. }\end{array}$ \\
\hline Good, et al., 2017 & $\begin{array}{l}\text { Heterogeneidade na amostragem (faixa etária muito ampla (6 a 15 } \\
\text { anos), Idade auditiva dos sujeitos não equivalente, aulas de música } \\
\text { ou arte visuais. Não randomizado. }\end{array}$ \\
\hline Hidalgo et al., 2017 & $\begin{array}{l}\text { Heterogeneidade na amostragem (crianças usuárias de IC e outros } \\
\text { dispositivos). Diversas abordagens musicais realizada por } \\
\text { fonoaudiólogo em terapia fonoaudiológica. Não randomizado. }\end{array}$ \\
\hline Polonenko et al., 2017 & $\begin{array}{l}\text { Heterogeneidade na amostragem (faixa etária muito ampla, 6 a 18 } \\
\text { anos e crianças usuárias de IC e outros dispositivos). Não } \\
\text { randomizado. }\end{array}$ \\
\hline Bedoin et al., 2018 & $\begin{array}{l}\text { Usuários de IC unilateral e bilateral. Idade auditiva ampla. } \\
\text { Abordagem musical computadorizada realizada por profissional } \\
\text { não capacitado para atividades musicais. Não randomizado. }\end{array}$ \\
\hline Yang et al., 2019 & $\begin{array}{l}\text { Amostra heterogênea com faixa etária muito ampla, 4 a 13 anos. } \\
\text { Idade auditiva dos sujeitos não equivalente. Não randomizado. } \\
\text { randomizado. }\end{array}$ \\
\hline Torppa, 2018 & \begin{tabular}{l} 
Ariancordagem mista e diferente para os sujeitos. Não \\
\hline
\end{tabular} \\
\hline
\end{tabular}

\section{DADOS E ANÁLISES}

Essa revisão não possui dados. 


\section{REFERÊNCIAS}

Abdi, S., Khalessi, M. H., Khorsandi, M., \& Gholami, B. (2001). Introducing music as a means of habilitation for children with cochlear implants. International Journal of Pediatric Otorhinolaryngology, 59(2), 105-113.

Bedoin, N., Besombes, A. M., Escande, É., Dumont, A., Lalitte, P., \& Tillmann, B. (2018). Boosting syntax training with temporally regular musical primes in children with cochlear implants. Annals of Physical and Rehabilitation Medicine, 61(6), 365-371.

Bevilacqua, M. C., \& Formigoni, G. M. P. (2003). Audiologia educacional: uma opção terapêutica para a criança deficiente auditiva. Pró-fono.

Bevilacqua, M. C., Martinez, M. A. N., Balen, S. A., Pupo, A. C., Reis, A. C. M. B., \& Frota, S. (2011). Tratado de audiologia. São Paulo: Santos, 49.

Brandalise, A. (2015). A aplicação terapêutica da música no tratamento de pessoas com implante coclear (IC): uma revisão sistemática. Revista Brasileira de Musicoterapia.

Campos, P. D., Alvarenga, K. D. F., Frederigue, N. B., Nascimento, L. T. D., Sameshima, K., Costa Filho, O. A., \& Bevilacqua, M. C. (2008). Habilidades de ordenação temporal em usuários de implante coclear multicanal. Revista Brasileira de Otorrinolaringologia, 74(6), 884-889.

Cason, N., Hidalgo, C., Isoard, F., Roman, S., \& Schön, D. (2015). Rhythmic priming enhances speech production abilities: Evidence from prelingually deaf children. Neuropsychology, 29(1), 102.

Chen, J. K. C., Chuang, A. Y. C., McMahon, C., Hsieh, J. C., Tung, T. H., \& Li, L. P. H. (2010). Music training improves pitch perception in prelingually deafened children with cochlear implants. Pediatrics, 125(4), e793-e800.

Chelune, G. J., \& Baer, R. A. (1986). Developmental norms for the Wisconsin Card Sorting test. Journal of clinical and experimental neuropsychology, 8(3), 219-228.

Ching, T. Y., Dillon, H., Day, J., Crowe, K., Close, L., Chisholm, K., \& Hopkins, T. (2009). Early language outcomes of children with cochlear implants: Interim findings of the NAL study on longitudinal outcomes of children. Cochlear implants international, 10(sup1), 28-32.

Cochrane Collaboration. (2008). Review Manager (RevMan). Version 5.0 [Computer software]. Copenhagen: The Nordic Cochrane Centre.

Coffey, E. B., Mogilever, N. B., \& Zatorre, R. J. (2017). Speech-in-noise perception in musicians: A review. Hearing research, 352, 49-69.

Dastgheib, S. S., Riyassi, M., Anvari, M., Niknejad, H. T., Hoseini, M., Rajati, M., \& Ghasemi, M. M. (2013). Music training program: a method based on language development and principles of neuroscience to optimize speech and language skills in hearing-impaired children. Iranian journal of otorhinolaryngology, 25(71), 91. 
Deeks, J. J., Higgins, J. P., Altman, D. G., \& Cochrane Statistical Methods Group. (2019). Analysing data and undertaking meta-analyses. Cochrane handbook for systematic reviews of interventions, 241-284.

Driscoll, V., Gfeller, K., Tan, X., See, R. L., Cheng, H. Y., \& Kanemitsu, M. (2015). Family involvement in music impacts participation of children with cochlear implants in music education and music activities. Cochlear implants international, 16(3), 137-146.

Follmann, D., Elliott, P., Suh, I. L., \& Cutler, J. (1992). Variance imputation for overviews of clinical trials with continuous response. Journal of clinical epidemiology, 45(7), 769-773.

Fu, Q. J. Galvin 3rd, JJ, Wang, X., Wu, J.-L., 2015. Benefits of music training in Mandarinspeaking pediatric cochlear implant users. J. Speech Lang. Hear. Res, 58.

Fuller, C. D., Galvin III, J. J., Maat, B., Başkent, D., \& Free, R. H. (2018). Comparison of two music training approaches on music and speech perception in cochlear implant users. Trends in hearing, 22, 2331216518765379.

Galvão, M. V. A. (2018). Musicoterapia e o implantado coclear: revisão sistemática. Revista InCantare $\mid$ Curitiba| v, 9(1), 1-108.

Gfeller, K. (2016). Music-based training for pediatric CI recipients: A systematic analysis of published studies. European Annals of Otorhinolaryngology, Head and Neck Diseases, 133, S50-S56.

Good, A., Gordon, K. A., Papsin, B. C., Nespoli, G., Hopyan, T., Peretz, I., \& Russo, F. A. (2017). Benefits of music training for perception of emotional speech prosody in deaf children with cochlear implants. Ear and Hearing, 38(4), 455.

Gordon, E. E., Rodrigues, H., Rodrigues, P. M., \& de Freitas, A. (2000). Teoria de aprendizagem musical para recém-nascidos e crianças em idade pré-escolar.

Gresham, F. M., \& Elliott, S. N. (1990). Social skills rating system: ManualUnited States: American Guidance Service.

Hidalgo, C., Falk, S., \& Schön, D. (2017). Speak on time! Effects of a musical rhythmic training on children with hearing loss. Hearing research, 351, 11-18.

Higgins, J. P., Thomas, J., Chandler, J., Cumpston, M., Li, T., Page, M. J., \& Welch, V. A. (Eds.). (2019). Cochrane handbook for systematic reviews of interventions. John Wiley \& Sons.

Innes-Brown, H., Marozeau, J. P., Storey, C. M., \& Blamey, P. J. (2013). Tone, rhythm, and timbre perception in school-age children using cochlear implants and hearing aids. Journal of the American Academy of Audiology, 24(9), 789-806.

Jiam, N. T., \& Limb, C. J. (2019). Rhythm processing in cochlear implant- mediated music perception. Annals of the New York Academy of Sciences, 1453(1), 22-28.

Koşaner, J., Kilinc, A., \& Deniz, M. (2012). Developing a music programme for preschool children with cochlear implants. Cochlear implants international, 13(4), 237-247. 
Lassaletta, L., Castro, A., Bastarrica, M., Pérez-Mora, R., Herrán, B., Sanz, L., ... \& Gavilán, J. (2008). Changes in listening habits and quality of musical sound after cochlear implantation. Otolaryngology_Head and Neck Surgery, 138(3), 363-367.

Latour, J., Abraira, V., \& Cabello, J. B. (1997). Investigation methods in clinical cardiology. IV. Clinical measurements in cardiology: validity and errors of measurements. Revista Española de Cardiología, 50(2), 117-128.

Lefebvre, C., Manheimer, E., \& Glanville, J. (2008). Searching for studies. Cochrane handbook for systematic reviews of interventions: Cochrane book series, 95-150.

Moret, A. L. M., Bevilacqua, M. C., \& Costa, O. A. (2007). Implante coclear: audição e linguagem em crianças deficientes auditivas pré-linguais. Pró-Fono Revista de Atualização Científica, 19(3), 295-304.

Nóbrega, M. D., Weckx, L. L., Juliano, Y., \& Novo, N. F. (1998). Aspectos diagnósticos e etiológicos da deficiência auditiva em crianças e adolescentes. Rev. paul. pediatr, 16(1), 28 43.

Pantev, C., Oostenveld, R., Engelien, A., Ross, B., Roberts, L. E., \& Hoke, M. (1998). Increased auditory cortical representation in musicians. Nature, 392(6678), 811-814.

Patel, A. D. (2003). Language, music, syntax and the brain. Nature neuroscience, 6(7), 674681.

Patel, A. D. (2011). Why would musical training benefit the neural encoding of speech? The OPERA hypothesis. Frontiers in psychology, 2, 142.

Patel, A. D. (2014). Can nonlinguistic musical training change the way the brain processes speech? The expanded OPERA hypothesis. Hearing research, 308, 98-108.

Pesnot Lerousseau, J., Hidalgo, C., \& Schön, D. (2020). Musical Training for Auditory Rehabilitation in Hearing Loss. Journal of Clinical Medicine, 9(4), 1058.

Petersen, B., Weed, E., Sandmann, P., Brattico, E., Hansen, M., Sørensen, S. D., \& Vuust, P. (2015). Brain responses to musical feature changes in adolescent cochlear implant users. Frontiers in human neuroscience, 9, 7.

Pinto, M. M., Raimundo, J. C., Samelli, A. G., Carvalho, A. C. M. D., Matas, C. G., Ferrari, G. M. D. S., ... \& Bento, R. F. (2012). Idade no diagnóstico e no início da intervenção de crianças deficientes auditivas em um serviço público de saúde auditiva brasileiro. Arquivos Internacionais de Otorrinolaringologia, 16(1), 44-49.

Polonenko, M. J., Giannantonio, S., Papsin, B. C., Marsella, P., \& Gordon, K. A. (2017). Music perception improves in children with bilateral cochlear implants or bimodal devices. The Journal of the Acoustical Society of America, 141(6), 4494-4507.

Rocca, C. (2012, November). A different musical perspective: improving outcomes in music through habilitation, education, and training for children with cochlear implants. In Seminars in Hearing (Vol. 33, No. 4, p. 425). 
Rocca, C. (2015). Developing the musical brain to boost early pre-verbal, communication and listening skills: The implications for musicality development pre-and post-cochlear implantation. It is not just about Nursery Rhymes!. Cochlear implants international, 16(sup3), S32-S38.

Rochette, F., Moussard, A., \& Bigand, E. (2014). Music lessons improve auditory perceptual and cognitive performance in deaf children. Frontiers in human neuroscience, 8, 488.

Teixeira, A. R., \& Garcez, V. R. C. (2011). Aparelho de amplificação sonora individual: componentes e características eletroacústicas. Bevilacqua MC, Martinez MAN, Balen AS, Pupo AC, Reis ACM, Frota S (organizadoras). Tratado de Audiologia. São Paulo: Santos.

Theunissen, M., \& Swanepoel, D. (2008). Early hearing detection and intervention services in the public health sector in South Africa. International Journal of Audiology, 47(sup1), S23S29.

Torppa, R., Faulkner, A., Huotilainen, M., Järvikivi, J., Lipsanen, J., Laasonen, M., \& Vainio, M. (2014). The perception of prosody and associated auditory cues in early-implanted children: The role of auditory working memory and musical activities. International Journal of Audiology, 53(3), 182-191.

Torppa, R., \& Huotilainen, M. (2019). Why and how music can be used to rehabilitate and develop speech and language skills in hearing-impaired children. Hearing research, 380, 108122.

Torppa, R., Faulkner, A., Kujala, T., Huotilainen, M., \& Lipsanen, J. (2018). Developmental links between speech perception in noise, singing, and cortical processing of music in children with cochlear implants. Music Perception: An Interdisciplinary Journal, 36(2), 156-174.

Torppa, R., Faulkner, A., Vainio, M., \& Järvikivi, J. (2010). Acquisition of focus by normal hearing and cochlear implanted children: the role of musical experience. In Proceedings of the 5 th international conference on speech prosody.

Vongpaisal, T., Caruso, D., \& Yuan, Z. (2016). Dance movements enhance song learning in deaf children with cochlear implants. Frontiers in psychology, 7, 835.

Wagner, R. K., Torgesen, J. K., Rashotte, C. A., \& Pearson, N. A. (1999). Comprehensive test of phonological processing: CTOPP. Austin, TX: Pro-ed.

Wilkerson, D. (2000). Current issues in rehabilitation outcome measurement: implications for audiological rehabilitation. Ear and hearing, 21(4 Suppl), 80S-88S.

Yang, J., Liang, Q., Chen, H., Liu, Y., \& Xu, L. (2019). Singing Proficiency of Members of a Choir Formed by Prelingually Deafened Children With Cochlear Implants. Journal of Speech, Language, and Hearing Research, 62(5), 1561-1573.

Yucel, E., Sennaroglu, G., \& Belgin, E. (2009). The family oriented musical training for children with cochlear implants: speech and musical perception results of two year followup. International Journal of Pediatric Otorhinolaryngology, 73(7), 1043-1052. 


\section{APÊNDICES}

\section{Apêndice 1 - Estratégias de Busca}

\section{CENTRAL, parte da Cochrane Library}

\#1 MeSH descritor Music, somente esse termo.

\#2 MeSH descritor Music Therapy, somente esse termo.

\#3 music*

\#4 MeSH descritor Pitch Perception, somente esse termo.

\#5 pitch*

\#6 rhythm*

\#7 harmon*

\#8 timbre*

\#9 (sing ou singing song* ou choral ou choir* ou orchestra*)

\#10 (music training* ou music education* ou music perception)

\#11 melodies

\#12 ((orff* ou suzuki*) (method* ou approach*ou system* ou technique*))

\#13 (\#1 OR \#2 OR \#3 OR \#4 OR \#5 OR \#6 OR \#7 OR \#8 OR \#9 OR \#10 OR \#11 OR \#12)

\#14 MeSH descritor Cochlear Implants, somente esse termo.

\#15 Hearing aids

\#16 Deaf

\#17 (\#1 AND \#14, \#2 AND \#14, \#4 AND \#14, \#10 AND \#14)

- Cochrane Central Register of Controlled Trials (CENTRAL) em 04/2020 (no período de 2015 até 2020). 


\section{PUBMED}

1 Music

2 Music Therapy

3 Pitch Perception

4 Music Education*

5 Music Training*

6 Music Perception*

7 Music activites*

8 Sing*

9 Cochlear Implants

10 Hearing loss*

11 Hearing aids*

12 Deaf*

13 (1 OR 2 OR 3 OR 4 OR 5 OR 6 OR 7 OR 8)

14 (9 AND 1, 9 AND 2, 9 AND 3, 9 AND 4, 9 NA 5, 9 AND 6, 9 AND 7)

15 Exp Clinical trial

16 Randomized controlled trial

17 Randomization

18 Single blind procedure

19 Double blind procedure

20 Crossover procedure

21 Placebo

22 Treatment outcome

23 Comparative study

24 (14 AND 15-23) 
- Biblioteca Nacional de Medicina (PubMed) em 03/2020 (no período de 1995 até abri1/2020);

\section{EMBASE}

1 Music

2 Music Therapy

3 Pitch Perception

4 Cochlear Implants

5 Music Education*

6 Music Training*

7 Music Perception*

8 Music Activites*

9 Exp Clinical trial

10 Randomized controlled trial

11 Randomization

12 Single blind procedure

13 Double blind procedure

14 Crossover procedure

15 Placebo

16 Treatment outcome

17 Comparative study

18 (4 AND 1-3/ 5-8)

19 (18 AND 9-17)

- Excerpta Medica dataBASE (EMBASE) em 04/2020 (no período de 2012 até 2018). 


\section{MEDLINE}

1 Music

2 Music Therapy

3 Pitch Perception

4 Cochlear Implants

5 Music Education*

6 Music Training*

7 Music Perception*

8 Music Activites*

9 randomized controlled trial

10 controlled clinical trial

12 placebo

13 drug therapy

14 randomly

15 trial

16 groups

$17 \mathrm{OR} / 9-16$

18 exp animals/ not humans

1917 NOT 18

\section{LILACS}

Music OR Music Therapy OR Music Training OR Music Education AND Cochlear Implants

- Literatura Latino Americana e do Caribe em Ciências da Saúde (LILACS) em 03/2020 (no período de 2012 até o ano de 2018). 


\section{SCIELO}

Music OR Music Therapy OR Music Training AND Cochlear Implants

Music OR Music Therapy OR Music Training AND Hearing Aids

- Biblioteca Eletrônica Científica Online (SciELO) em 03/2020 (no período de 2012 até 2018).

\section{CINAHL}

Music OR Music Therapy AND Cochlear Implants Or Hearing Aids

- Cumulative Index to Nursing and Allied Health Literature (CINAHL) em 04/2020 (no período de 2012).

\section{A\&HCI, SSCI e CPCI-SSH}

Tópico $=\left(\right.$ music $^{*}$ or music therapy* or music education* or music training* or pitch* or rhythm* or play* timbre* or sing*) AND Tópico= (cochlear implants* or hearing aids* or hearing loss* or deaf*) AND Tópico $=\left(\right.$ random* ${ }^{*}$ or control* or trial* or evaluat* or effectiveness or compar* or experiment* or treatment* or program* or intervention*)

- Arts and Humanities Citation Index (A\&HCI), Social Science Citation Index (SSCI) e Conference Proceedings Citation Index - Social Sciences and Humanities (CPCI-SSH) (Web of Knowledge) em 04/2020 (no período de 2009 até 2017).

\section{WHO -ICTPR}

Music OR Music Therapy AND Cochlear Implants

- WHO Institute for Conflict, Transition, and Peace Research (ICTPR) em 04/2020 (no período de 2017). www.who.int/ictrp/en/

\section{WorldCat}

Palavras-chave: Cochlear Implantes* AND Music*. Somente esses.

- The World's Largest Library Catalog (WORLDCAT) em 04/2020 (todos os anos disponíveis). www.worldcat.org 


\section{Apêndice 2}

\section{Quadro 7 - quadro de métodos não utilizados}

\begin{tabular}{|c|c|}
\hline $\begin{array}{l}\text { Gerenciamento } \\
\text { de dados }\end{array}$ & $\begin{array}{l}1 \text { autor da revisão (PMS) extrairia independentemente os dados dos } \\
\text { estudos que atenderam aos critérios de inclusão, utilizando um formulário } \\
\text { de extração padrão contendo: } \\
\text { 1. Estudo: informações sobre o(s) autor(es); ano de publicação; fonte; } \\
\text { país; e linguagem. } \\
\text { 2. Características do ambiente e dos participantes: critérios de } \\
\text { elegibilidade dos participantes; explicação dos procedimentos de } \\
\text { recrutamento; configuração (país, localização, clínico ou não clínico); } \\
\text { características demográficas da amostra. } \\
\text { 3. Amostragem: tamanhos de amostra para tratamento e controle; } \\
\text { alocação para tratamento e controle; explicação do método usado para } \\
\text { gerar a alocação. } \\
\text { 4. Projeto de pesquisa: tipo de projeto incluindo características principais, } \\
\text { como, seleção, atribuição aleatória e grupo de controle não equivalente. } \\
\text { 5. Dados da intervenção: natureza das intervenções: musicoterapia, } \\
\text { educação musical ou apreciação e percepção musical. } \\
\text { 6. Dados de resultados: resultados primários e secundários; medidas } \\
\text { utilizadas. } \\
\text { 7. Resultados: pós-intervenção e acompanhamento; número excluído da } \\
\text { análise; duração do acompanhamento; Métodos estatísticos; tipo de efeito } \\
\text { e dados necessários para cálculos do tamanho do efeito. }\end{array}$ \\
\hline $\begin{array}{l}\text { Avaliação do } \\
\text { risco de viés nos } \\
\text { estudos } \\
\text { incluídos }\end{array}$ & $\begin{array}{l}\text { Dois revisores avaliariam independentemente o risco de viés dentro de } \\
\text { cada, estudo incluído de acordo com as orientações do Manual Cochrane } \\
\text { para Revisões sistemáticas de intervenções (Higgins 2008). Os autores da } \\
\text { revisão também avaliariam o risco de viés dentro de cada estudo, por meio } \\
\text { das seguintes classificações: de baixo risco de viés, alto risco de viés e } \\
\text { risco pouco claro. } \\
\text { Geração de sequência } \\
\text { Descreveríamos em detalhes o método usado para gerar a sequência de } \\
\text { alocação de modo a avaliar se deveriam ser produzidos grupos }\end{array}$ \\
\hline
\end{tabular}




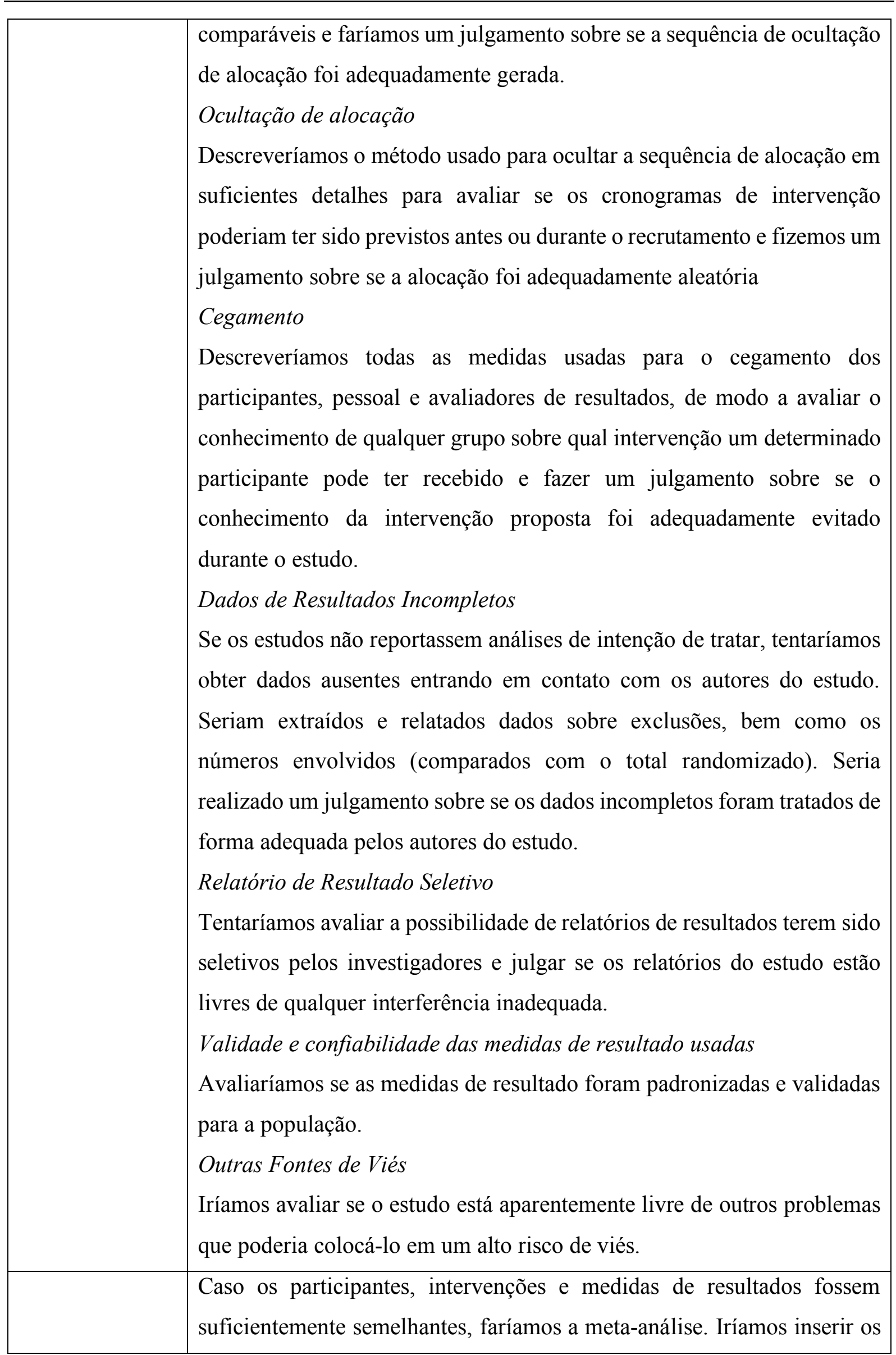




\begin{tabular}{|c|c|}
\hline $\begin{array}{l}\text { Medidas do } \\
\text { Efeito do } \\
\text { Tratamento }\end{array}$ & $\begin{array}{l}\text { dados em uma planilha do Excel e também no Review Manager } 5 \\
\text { (RevMan 2008). Uma mesma escala de classificação seria usada para } \\
\text { todos os estudos, agrupando os dados de forma que diferentes escalas de } \\
\text { avaliação seriam usadas para medir o mesmo resultado. }\end{array}$ \\
\hline $\begin{array}{l}\text { Unidade de } \\
\text { Problemas de } \\
\text { Análise }\end{array}$ & $\begin{array}{l}\text { Iríamos seguir as orientações sobre métodos estatísticos para } \\
\text { randomização descritos no Cochrane Handbook for Systematic Reviews } \\
\text { of Interventions (Higgins } 2008 \text {, Seção 16.3). seriam buscadas estimativas } \\
\text { diretas do efeito de uma análise que considera adequadamente o design } \\
\text { estudo; alternativamente, nós extrairíamos e calcularíamos estimativas de } \\
\text { efeito e seus erros padrão. Iriámos extrair essas informações de artigos } \\
\text { disponíveis, caso contrário entraremos em contato com os autores ou } \\
\text { usaríamos estimativas externas obtidas de estudos semelhantes. }\end{array}$ \\
\hline Dados Ausentes & $\begin{array}{l}\text { Entraríamos em contato com os autores originais para solicitar quaisquer } \\
\text { dados ausentes e informações, a fim de decidir se os dados ausentes } \\
\text { podem ou não estarem ausentes. Para dados dicotômicos, relataremos } \\
\text { dados ausentes e desistências para cada estudo incluído e também o } \\
\text { número de participantes incluídos na análise final, como uma proporção } \\
\text { de todos os participantes em cada estudo. } \\
\text { Para dados contínuos ausentes, forneceremos um resumo qualitativo. O } \\
\text { desvio-padrão das medidas de resultado deveriam ser relatados para cada } \\
\text { grupo em cada ensaio. Se estes não fossem fornecidos, iriamos imputar } \\
\text { desvios-padrão usando dados relevantes (por exemplo, desvios padrão ou } \\
\text { coeficientes de correlação) de outros estudos semelhantes (Follmann } \\
\text { 1992). }\end{array}$ \\
\hline \multirow[t]{2}{*}{$\begin{array}{c}\text { Avaliação de } \\
\text { Heterogeneidade }\end{array}$} & $\begin{array}{l}\text { Avaliaríamos a extensão da heterogeneidade usando os três métodos } \\
\text { sugeridos pelo Cochrane Handbook for Systematic Reviews of } \\
\text { Interventions (Deeks,2008): inspeção visual de forest plots, o teste Chi2 } \\
\text { (aumentando o nível de significância de } 0,10 \text { para evitar subestimar a } \\
\text { heterogeneidade) e usando a estatística I2 projetada para avaliar o impacto } \\
\text { da heterogeneidade na meta-análise. }\end{array}$ \\
\hline & $\begin{array}{l}\text { Iriámos desenhar gráficos em funil (tamanho do efeito versus erro padrão) } \\
\text { para avaliar o viés da publicação se estudos suficientes fossem } \\
\text { encontrados. A assimetria dos gráficos pode indicar viés de publicação, }\end{array}$ \\
\hline
\end{tabular}




\begin{tabular}{|c|c|}
\hline $\begin{array}{l}\text { Avaliação de } \\
\text { enviesamento de } \\
\text { relatórios }\end{array}$ & $\begin{array}{l}\text { embora também possam representar um resultado verdadeiro entre o } \\
\text { tamanho do ensaio e o tamanho do efeito. }\end{array}$ \\
\hline $\begin{array}{l}\text { Síntese de } \\
\text { Dados }\end{array}$ & $\begin{array}{l}\text { Realizaríamos meta-análises para combinar medidas de resultados } \\
\text { comparáveis entre os estudos. Usaríamos modelos de efeitos aleatórios, } \\
\text { porque estudos podem incluir tratamentos ou populações um tanto } \\
\text { diferentes. Seriam agrupadas as medidas de resultados por duração do } \\
\text { acompanhamento. }\end{array}$ \\
\hline $\begin{array}{c}\text { Análise de } \\
\text { subgrupo e } \\
\text { investigação de } \\
\text { heterogeneidade }\end{array}$ & $\begin{array}{l}\text { Era planejando realizar análises de subgrupos para explorar o possível } \\
\text { efeito diferencial da intervenção, dependendo dos seguintes fatores: } \\
\text { 1. Duração da formação musical: curta duração, média ou longa duração; } \\
\text { 2. Tipo de treinamento musical; } \\
\text { 3. Faixa etária dos participantes. }\end{array}$ \\
\hline $\begin{array}{l}\text { Análise } \\
\text { Sensitiva }\end{array}$ & $\begin{array}{l}\text { Iríamos conduzir as seguintes análises de sensibilidade. } \\
\text { 1. A remoção de estudos com inconsistências na definição, medição ou } \\
\text { relatórios de resultados (por exemplo, se o número de participantes } \\
\text { variaria no relatório ou se as medidas não foram tomadas em pontos de } \\
\text { tempo consistentes para todos os participantes); } \\
\text { 2. Alterar a forma como os valores são imputados para dados ausentes } \\
\text { (por exemplo, último valor transportado versus pontuação média para } \\
\text { valores ausentes); } \\
\text { 3. Reanalisar os dados usando diferentes abordagens estatísticas (por } \\
\text { exemplo, usando um modelo de efeito fixo em vez de um modelo de } \\
\text { efeitos aleatórios) (Higgins, 2008). }\end{array}$ \\
\hline
\end{tabular}




\section{Apêndice 3 - Critérios para a fase de seleção inicial}

1. Estudos primários (excluindo revisões narrativas, diretrizes, cartas, etc.).

2. Estudos em que os autores ofereceram alguma abordagem musical.

3. Em crianças e adolescentes usuários de implante coclear.

4. Independentemente do desenho do estudo (prospectivo, retrospectivo, ensaios clínicos randomizados, série de casos, relato de caso, etc.).

\section{TERMOS INDEXADOS}

\section{Medical Subject Headings (MeSH)}

*Music; *Music Therapy [education, training, perception]; *Pitch Perception; *Cochlear Implants.

$\underline{\text { MeSH check words }}$

Adolescent; Child; Humans. 
4.2 Estudo 2: Contributos da musicalização infantil no desenvolvimento das habilidades perceptivas, cognitivas e sociais em crianças com implante coclear

\section{REVISÃO DE LITERATURA}

\subsection{Música e Habilidades Perceptivas, Cognitivas e Sociais}

Desde os primórdios da sociedade, a música é considerada veículo de aprendizado e bem-estar, em que se observam elementos pessoais, subjetivos, criativos e emocionais. Ela é composta por vários elementos diferentes. Envolve discriminar uma melodia ou ritmo, também sentir emoções e gostar do som de uma determinada peça musical ou instrumento. No entanto, nenhum desses recursos pode descreve a entidade complexa que forma a música como um todo. Além da linguagem, a música é um dos dois principais sinais acústicos para a expressão da natureza humana.

$\mathrm{Na}$ literatura, diversos autores elaboraram suas análises sobre os efeitos biopsicosociais da música, mostrando que a música influencia na formação do indivíduo de forma global, pois, trabalha as emoções, desenvolve a sensibilidade, a percepção auditiva, a linguagem, a cognição, a sociabilidade (DE ALMEIDA SILVA, 2010; DASTGHEIB ET AL., 2013; GORDON ET AL., 2015; PATSCHEKE ET AL., 2018; GFELLER, 2016, FRANÇAFREITAS ET AL., 2017; TORPPA E HUOTILANEM, 2019; YANG ET AL., 2019; LEROUSSEAU ET AL., 2020) e as habilidades sociais e o desempenho escolar em crianças com desenvolvimento típico (SAID E ABRAMIDES, 2020).

Recentemente muitas pesquisas relacionadas à cognição musical são desenvolvidas por neurocientistas interessados em descobrir como o cérebro opera, quando está envolvido em atividades musicais, sejam estas de criação, de performance ou de apreciação (PATEL, 2003; MORENO E BILDEMAN, 2014; KERSTEN, 2017; TREHUB E WEISS, 2017; LEMAN ET A., 2018; BIRD ET AL., 2019; KHALIL ET AL., 2019; JACOBY ET AL., 2020).

A neurociência cognitiva tem a atenção prevalente ao estudo das funções mentais mais complexas, tais como a linguagem, e a memória, de forma que entender como o cérebro funciona, especialmente no que diz respeito aos aspectos cognitivos, possibilitando uma melhor compreensão de como se dá o processo de aprendizagem musical (CARVALHO, 2011; PATEL, 2011; CASAROTTO ET AL., 2017; TRIMBLE E HESDORFFER, 2017; HASLBECK E BASSLER, 2018; MORREALE ET AL., 2018; ZHANG, 2018; SCHELLENBERG, 2019, BASHWINER E BACON, 2020). 
Estudos mostram que o aprendizado musical é a única atividade que ativa os dois lados do cérebro simultaneamente, favorecendo as conexões entre os neurônios, incluindo os neurônios-espelho, que por meio da imitação são recrutados tanto na ação quanto na observação de uma atividade e interferem diretamente na plasticidade cerebral, no desenvolvimento de diversas habilidades, das funções executivas e da inteligência (ALTENMULLER, 2016; DALLA BELLA, 2016; SALLES E PAULA, 2016; SCHNAKERS ET AL., 2016; MIU E VUOSKOSKI, 2017; SWAMINATHAN ET AL., 2017; FERRARI E COUDÉ, 2018; LINNAVALLI ET AL., 2018; PANAIOTIDI, 2018; REYBROUCK, 2018; ZHU, 2018; KER E NELSON, 2019; SCHELLENBERG, 2019; ALTENMULLER E JAMES, 2020; ZHANG, 2020).

Habilidades musicais estão ligadas diretamente ao processamento auditivo de um indivíduo. O sistema auditivo é um dos sistemas mais complexos do nosso organismo e a audição é configurada como fator fundamental para o desenvolvimento global do mesmo. Assim, a perda auditiva permanente na infância impacta negativamente no desenvolvimento das habilidades auditivas, de fala, de linguagem, psicossociais e nos níveis de escolaridade da criança o que interfere decisivamente na sua qualidade de vida, uma vez que provoca isolamento social e familiar. A literatura aponta que a (re)habilitação auditiva por meio de diversas abordagens clínicas em usuários de Implante Coclear (IC), permite que o indivíduo retome o desenvolvimento das referidas habilidades (BEVILACQUA ET AL., 2011; TEIXEIRA E GARCES, 2011; VERDU E GOMES, 2016; DAS NEVES ET AL., 2019).

As experiências auditivas que a criança tem nos primeiros anos de vida são fundamentais para que ela se torne uma boa ouvinte. Para Gordon (2000) todo indivíduo possui uma aptidão musical inicial inata e quanto mais cedo se beneficiar de um ambiente musical rico, mais cedo sua aptidão irá aumentar, sendo assim, a aprendizagem musical pode e deve ser iniciada antes ou desde o nascimento da criança.

Além da percepção auditiva e musical, estudos enfatizam que crianças com implante coclear tem melhora das habilidades linguísticas, da percepção e produção da fala (ROCHETTE ET AL., 2014; CASON ET AL., 2015; BRUNS ET AL., 2016; GOOD ET AL., 2017; HIDALGO ET AL., 2017; BEDOIN, ET AL., 2018; FULLER ET AL., 2018; YANG ET AL., 2019). Música e linguagem necessitam de parâmetros acústicos para transmitir e decodificar informações, porém a música é um estímulo acusticamente mais complexo do que a linguagem, pois contém uma gama de características específicas e complexas. Devido a esta complexidade de características, supõe-se que por estimular mecanismos sensoriais e cognitivos relacionados ao processamento de linguagem, a música pode melhorar o processamento da fala (TORPPA E 
HUOTILAINEM, 2019).

De fato, como afirmam Greer e Ross (2004), a capacidade de ouvir é essencial para o desenvolvimento de outras capacidades verbais assim como outras diferentes dimensões do comportamento de falante. Para Skinner (1981) o comportamento verbal é entendido como um comportamento operante que é modelado e mantido - selecionado - por consequências mediadas, ou seja, aquelas que são produzidas por intermédio de uma segunda pessoa, a qual se denomina ouvinte. Deste modo, Skinner acentuou a dimensão social do comportamento verbal (MATOS, 1991) e sinalizou a importância das práticas culturais da comunidade verbal para o treinamento e a manutenção dos repertórios de ouvinte e falante (BAUM, 1999).

Said e Abramides (2020) apontam para o benefício do aprendizado musical na promoção das habilidades de vida englobando as habilidades sociais e escolares que devem ser utilizadas como fator de proteção para o desenvolvimento satisfatório da infância, pois uma vez que habilidades sociais são fatores essenciais para o pleno desenvolvimento da criança em idade escolar, as autoras consideram que o aprendizado musical pode contribuir tanto na avaliação quanto na promoção destas habilidades.

Gordon (2000) aponta que por intermédio da aprendizagem musical, as crianças passam a se conhecer melhor e também aos outros. A música torna capaz o desenvolvimento da imaginação e da criatividade audaz.

O campo das habilidades sociais vem sendo muito utilizado, não só na Psicologia, mas também de forma interdisciplinar, considerando que as habilidades sociais são comportamentos sociais necessários para construção de relações interpessoais saudáveis e produtivas (SAID E ABRAMIDES, 2020). A literatura aponta diversos estudos que comprovam os benefícios do treino de habilidades sociais para crianças em diversos contextos e desordens, incluindo problemas de comportamento e competência acadêmica (BENETTI ET AL., 2014; FALCÃO ET AL., 2016; VAN GROL ET AL., 2016; FERREIRA E MUNSTER, 2017, FRANÇAFREITAS ET AL., 2017; ROCHA E DEL PRETTE, 2017; DEUS E FAVA, 2019; ASSISFERNANDES, 2020; SAID E ABRAMIDES, 2020).

Vários estudos que mostram os efeitos da música no cérebro e consequentemente na cognição, percepção, comportamento e aprendizado infantil (GFELLER, 2016; SANTANA, 2017; CAMPOS ET AL., 2019; YANG ET AL., 2019; SAID E ABRAMIDES, 2019, 2020). Entretanto, estudos que investigam o impacto do aprendizado musical para o desenvolvimento das habilidades sociais e escolares em crianças usuárias de implante coclear são escassos. 


\subsection{Aprendizagem Musical}

Através do lúdico e por meio de canções, jogos, danças, exercícios de movimento, relaxamento, improvisação, prática instrumental são trabalhadas noções de ritmo, melodia, compasso, métrica, leitura musical, promovendo o desenvolvimento de aspectos psicológicos, cognitivos e motores, encontramos a primeira etapa da educação musical, a musicalização infantil (LOURO, 2012; BROOCK, 2013).

No campo da educação musical encontramos renomados educadores musicais que estudaram e desenvolveram suas metodologias de ensino. Para o presente estudo destacam-se: Carl Orff - defendia o aprendizado por habilidades. Segundo ele há um lugar para cada criança, e cada uma contribui de acordo com sua habilidade; Dalcroze - acreditava que processos corporais, ritmos e movimento eram a base da expressividade e pedagogia musical. Foi baseado nesses dois educadores que foram desenvolvidas as atividades para o procedimento de intervenção desse estudo. Como base para todas essas atividades, foi utilizada a teoria de ensino e aprendizagem musical de Edwin Gordon - desenvolveu uma teoria de aprendizagem musical, conhecida como Music Learning theory (MLT), que explica e descreve os caminhos pelos quais crianças e adultos aprendem música e é considerada a pesquisa mais longa realizada até então (GORDON, 2013, TORMIN, 2014; LOPES, 2019). Ela foi elaborada na década de 70 e é onde aparece pela primeira vez, o termo audiação (FREIRE, 2006).

Para que esse processo aconteça é necessário a combinação de três aspectos: o conhecimento sobre a aprendizagem sequencial da música, a aptidão musical e a audiação, pode-se dizer, portanto, que o objetivo da aprendizagem musical, de acordo com a MLT, é o desenvolvimento da audiação. Em relação a aprendizagem musical nos primeiros anos de vida, do nascimento até por volta dos sete anos, o caminho para o desenvolvimento dessa audiação foi chamado por Gordon de Audiação Preparatória (REYNOLDS ET AL., 2000; GORDON, 2015).

A MLT foi baseada e referenciada principalmente em Jerome Bruner (1915- 2016), um dos principais teóricos da psicologia da aprendizagem e da fundamentação teórica da corrente cognitivista.

Assim como a MLT, a teoria de aprendizagem e ensino de Bruner (1969) é uma teoria de descoberta, uma teoria que leva a criança ser agente do conhecimento, pois possibilita ela mesma ir descobrindo, criando e construindo o conhecimento. Para Bruner, a tarefa de ensinar determinado conteúdo a uma criança é a de representar a estrutura deste em termos da visualização que a criança tem das coisas. Portanto, a relevância no ensino para Bruner está na 
estrutura que a criança vai adquirindo por meio de uma sequência de aprendizagem apresentada. Esta sequência de aprendizagem se dá pelas etapas e estratégias de como a estrutura é apresentada à criança, de forma que ela esteja motivada a aprender. (TORMIN, 2018).

Além de Bruner, o psicólogo russo Vigotski (1896-1924), também possui suas teorias abrangendo o tema, e teve grande impacto para a consolidação da MLT.

É importante registrar a correspondência de pensamentos e concepções que se interrelacionam entre estes autores. O nexo entre Vigotski, Bruner e Gordon permite dizer que Bruner considerou muitos aspectos das concepções de Vigotski em seus estudos sobre desenvolvimento e aprendizagem e que Gordon recebeu influências e contribuições de Bruner na elaboração da teoria da aprendizagem musical (TORMIN, 2014).

A música é uma arte que se utiliza de uma linguagem. É linguagem, uma vez que utiliza um sistema de signos estabelecidos naturalmente ou por convenção, que transmite informações ou mensagens de um sistema (orgânico, social, sociológico) a outro. Existem paralelos entre a linguagem verbal e a musical. Ambas dependem, do ponto de vista neurofuncional das estruturas sensoriais responsáveis pela recepção e pelo processamento auditivo (fonemas, sons), visual (grafemas da leitura verbal e musical), da integridade funcional das regiões envolvidas com atenção e memória e das estruturas eferentes motoras responsáveis pelo encadeamento e pela organização temporal e motora necessárias para a fala e para a execução musical (MUZKAT ET AL., 2000).

Para Gordon (2003), a música não é uma linguagem pois não possui gramática, mas possui uma sintaxe que é a organização dos sons. Além disso, o cérebro aprende a música como uma linguagem, estrutura ela como uma linguagem e aprende contexto e sintaxe musicais, logo, pode ser considerada uma forma de comunicação e expressão social. Sendo assim, ter fluência dessa "linguagem" faz parte do desenvolvimento do homem enquanto ser social e não deve, portanto, ser privilégio de alguns (LOPES, 2019).

A aprendizagem musical pode acontecer por meio de dois fatores, da discriminação e da inferência. A aprendizagem por discriminação ocorre primeiro e é fundamental pois irá fornecer as competências necessárias, ou seja, a linguagem musical que será a base para que seja possível novas descobertas por si só. No entanto a aprendizagem por inferência acontece quando o aluno já está com a percepção musical de forma global mais trabalhada, e é capaz de se ensinar e se corrigir a partir dos conceitos que já adquiriu via discriminação, gerando uma fluência musical. Dentro desses dois modos existem diferentes níveis que podem se revisitar, pois elas ocorrem juntas, porém ora uma recebe maior ênfase e ora a outra (GORDON, 2015). 
Gordon desenvolveu dois modelos que estão relacionados aos estágios e tipos da aprendizagem musical: o modelo de audiação preparatória, que tem como foco o desenvolvimento de estruturas sintáticas através da imersão em um ambiente musicalmente apropriado e rico; o modelo de aprendizagem musical formal. A audiação preparatória é dividida em 3 tipos e 7 estágios:

1. Aculturação: a criança participa com pouca consciência do ambiente (1Absorção: a criança ouve e absorve os sons musicais do ambiente. 2-Resposta sem intenção: a criança se move e faz balbucios, mas sem relação com os sons musicais do ambiente. 3- Reposta com intenção: a criança tenta relacionar o movimento e o balbucio com os sons musicais do ambiente).

2. Imitação: a criança participa com pensamento consciente focado no ambiente (4- Saindo do egocentrismo: a criança percebe que seu movimento e balbucio não coincidem com os sons musicais do ambiente. 5- Decifrando o código: a criança imita com alguma precisão os sons musicais do ambiente, como padrões tonais e rítmicos).

3. Assimilação: a criança participa com o pensamento consciente focado nela mesma (6- Introspecção: a criança reconhece a falta de coordenação entre cantar, respirar e se mover. 7- Coordenação: a criança consegue cantar, respirar e se mover de forma coordenada) (GORDON 2008).

Para Gordon (2000) a criança precisa estar em condições de aprender e o educador precisa de uma forma de ensinar, assim como para Vygotsky o processo de aprendizagem acontece de forma colaborativo, ou seja, é uma ação conjunta, uma interação, entre educador e aluno.

\section{OBJETIVOS}

Investigar o efeito da Musicalização Infantil sobre o repertório das habilidades perceptivas, cognitivas e sociais em crianças com implante coclear entre 06 e 10 anos de idade. 


\section{MATERIAL E MÉTODOS}

\subsection{Tipo de estudo}

Este foi um estudo clínico randomizado que foi adotado por envolver a condição experimental permitindo múltiplas comparações a partir da avaliação de indicadores considerados importantes em interações sociais (variáveis dependentes) obtidos na préintervenção, durante e pós-intervenção (Musicalização infantil - variável independente) e de forma observacional.

Foi realizada a aleatorização na seleção dos participantes que se enquadravam nos critérios de inclusão do estudo (descritos abaixo). Este foi um estudo duplo-cego, no qual os profissionais (psicóloga, fonoaudióloga e educadoras externas a pesquisa) e os sujeitos envolvidos na coleta não sabiam o objetivo dos procedimentos e avaliações que foram utilizados.

\subsection{Participantes}

Para a realização do estudo foram selecionadas 10 crianças usuárias de Implante Coclear, residentes na cidade de Bauru, que são acompanhadas em terapia fonoaudiológica no CEDAU do HRAC/USP. Desta maneira, os dados necessários para o estabelecimento dos critérios de elegibilidade foram obtidos por meio do prontuário destes usuários nestes serviços.

O projeto, juntamente com o termo de aquiescência da Direção da Bravo Academia de Música autorizando a sua realização naquele estabelecimento, foi submetido à avaliação do Comitê de Ética em Pesquisa da Faculdade de Odontologia de Bauru FOB/USP, conforme Resolução CNS 466/12, e aprovado de acordo com o protocolo nº 2.820.891.

Foram selecionadas crianças conforme os seguintes critérios:

- Faixa etária entre 06 e 10 anos;

- Ambos os sexos;

- Com perda auditiva sensorioneural severa a profunda bilateral;

- Usuárias de implante coclear;

- Sem queixas relacionadas a problemas neurológicos e psiquiátricos;

- Nível intelectual dentro dos parâmetros de normalidade, avaliado por meio do teste Matrizes Progressivas de Raven (CPM) (RAVEN ET AL., 2018) e pelo profissional da área da Psicologia. O instrumento avalia a aptidão do raciocínio analógico (habilidade de deduzir relações entre objetos ou elementos) em crianças considerada como uma das principais 
componentes da inteligência geral (fator g). É constituída por 36 itens, divididos em 3 séries de 12, identificadas como: A, AB e B. Para Esquivel (1984), as CPM são um teste válido e preciso, com grande utilidade de uso em culturas diferentes e especialmente útil com crianças que possuem deficiências sensoriais e problemas de comunicação oral.

Em um primeiro momento foi realizada a apresentação do projeto e esclarecimentos de quaisquer dúvidas. As educadoras, a fonoaudióloga, a psicóloga e pais dos participantes selecionados para a pesquisa e dispostos a participar da mesma, assinaram o Termo de Consentimento (TCLE), e as crianças ao Termo de Assentimento Livre e Esclarecido (TALE), fornecendo assim concordância expressa para a realização dos procedimentos. É importante ressaltar que houve co-participação entre duas instituições para o presente estudo, o HRAC/USP e a Bravo Academia de Música.

\subsection{Caracterização da instituição}

O estudo foi realizado na escola Bravo Academia de Música, localizado na Avenida Nossa Senhora de Fátima, 19-89, Jardim América, município de Bauru, localizado no interior do estado de São Paulo.

A escola atende em torno de 250 alunos na faixa etária entre 08 meses a 80 anos. Também possui uma equipe de 23 Educadores musicais, um para cada área em questão: cordas friccionadas, cordas dedilhadas, piano, sopros, canto, musicalização infantil, bateria e musicoterapia. Três funcionários administrativos e uma Fonoaudióloga.

Os cursos podem ser coletivos ou individuais com aulas semanais. No formato coletivo existe um critério de formação da turma, respeitando a modalidade do curso escolhido, a faixa etária e o perfil do aluno. As aulas têm duração de 30 a 60 minutos.

O principal objetivo da Bravo Academia de Música é permitir maios acessibilidade ao aprendizado musical de qualidade, favorecer o desenvolvimento musical diferenciado e a inclusão social do aluno.

\subsection{Procedimento de intervenção e avaliações}

A Musicalização Infantil (educadoras externas a pesquisa e a avaliação psicológica (psicóloga externa a pesquisa) de cada participante foi realizada na Escola Bravo Academia de Música. 
A aula de musicalização tem duração de 60 minutos, divididos com atividades musicais lúdicas e dinâmicas. Foram realizadas aulas semanais (uma vez por semana), divididas em um semestre, totalizando treze aulas. Duas educadores foram responsáveis por ministrar as aulas. As duas sempre trabalhavam de forma conjunta durante as aulas.

A sala de aula onde foram realizadas as aulas de musicalização infantil estava dentro do padrão acústico com tempo de reverberação de $0,3 \mathrm{~s}$ para crianças com deficiência auditiva na em espaços $\leq 283 \mathrm{~m} 3$, conforme especificado em ANSI / ASA S12.60-2010 (IGLEHART, 2020).

As aulas têm o formato coletivo, sendo que as dez crianças do grupo experimental fizeram as atividades em conjunto, pertencendo à mesma turma. Caso algum participante do estudo (crianças e pais) viesse a se cansar ou se constranger, tanto nas atividades de musicalização quanto na aplicação de testes e questionários era solicitado o apoio dos profissionais das diferentes áreas aqui citadas para que não houvesse prejuízos em nenhuma área e de nenhuma forma para os mesmos.

Para prevenir tais situações, foi realizada previamente uma reunião onde houve uma avaliação diagnóstica dos envolvidos e uma exposição detalhada dos procedimentos os quais os sujeitos foram submetidos.

\section{Modelo de estrutura de aula}

Para o procedimento de intervenção desse estudo, foram selecionados três educadores e pesquisadores musicais, Orff, Dalcroze e Gordon. Os três possuem pontos em comum em suas abordagens, pois partem de um material já familiar à criança, valorizando o material sonoro que ela já conhece previamente e criando vínculos de associação entre este material e novas ideias musicais, defendem que a prática vem antes da teoria, enfatizam a importância do movimento corporal junto à música e valorizam o processo de aprendizagem mais do que o resultado musical propriamente dito.

O critério para seleção dos educadores em questão se dá pelo fato de que as abordagens musicais propostas por eles se complementam com alta eficácia, em uma população onde a idade cronológica não está equivalente a idade auditiva. 


\section{Modelo de estrutura de aula - Rotina}

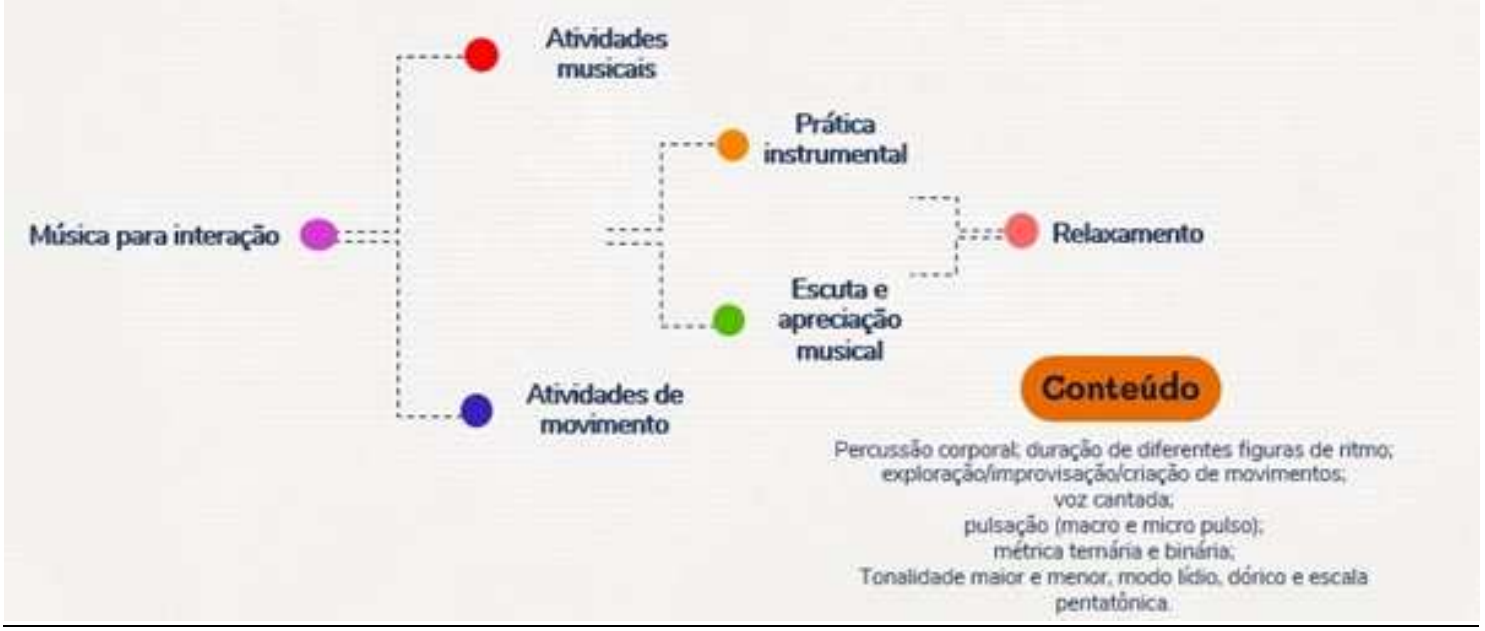

Figura 6: modelo de estrutura de aula

\subsection{Materiais e Instrumentos}

As habilidades sociais, dos alunos participantes da pesquisa, foram avaliadas por meio do Sistema de Avaliação de Habilidades Sociais (SSRS-BR) versão pais e professores e por meio do Inventário Multimídia de Habilidades Sociais Para Crianças.

Sistema de Avaliação de Habilidades Sociais (SSRS-BR): trata-se de uma escala produzida originalmente nos EUA (SSRS, GRESHAM E ELLIOTT, 1990) e validada para o contexto brasileiro por Del Prette, Bandeira Freitas e Del Prette (2016), com qualidades psicométricas já constatadas em termos de consistência interna e estabilidade temporal para crianças pré-escolares e de primeira à quarta série do Ensino Fundamental. Foram utilizadas as Versões P para professores e M para mães, contendo 57 e 55 itens, respectivamente, que avaliam a freqüência e importância das habilidades sociais e a freqüência de comportamentos problemáticos. O estudo nacional de validação do instrumento demonstrou que o SSRS-BR possui consistência interna satisfatória, aferida pelo alfa de Cronbach nas escalas de: habilidades sociais (estudantes $=0,78$; pais $=0,86$; professores $=0,94$ ); de comportamentos problemáticos (pais $=0,83$; professores $=0,91)$ e de competência acadêmica $($ alfa $=0,98) . O$ estudo também mostrou correlações positivas e significativas para todas as escalas, indicando estabilidade temporal (confiabilidade). Os percentis ponderados no SSRS permitem classificar as habilidades sociais e problemas e comportamento das crianças em: Baixa, escore abaixo de 
20, Média, entre 20 e 80, e Alta, acima de 80 . Foram utilizadas apenas as escalas de habilidades sociais e problemas de comportamento, já que avaliar a competência acadêmica não constituiu os objetivos dessa pesquisa.

Inventário Multimídia de Habilidades Sociais Para Crianças (IMHS): (DEL PRETTE; DEL PRETTE, 2005) com o objetivo de avaliar as habilidades sociais de crianças com idade entre sete e 12 anos, da primeira à quarta série do Ensino Fundamental. $\mathrm{O}$ instrumento avalia o desempenho social em diferentes situações (escola, família, cotidiano) por meio de 21 situações alvo, agrupados em quatro fatores:

Fator1 - Empatia e civilidade, Fator 2 - Assertividade de enfrentamento, Fator 3 Autocontrole, Fator 4 - Participação.

A partir da apresentação das situações são oferecidas à criança três possibilidades de reação: habilidosa, não-habilidosa passiva (internalizante) e não-habilidosa ativa (externalizante). A criança é solicitada a indicar sua resposta em escalas de frequência (Sempre, Às vezes ou Nunca) com que emite cada reação, a adequação (Certo, Mais ou Menos e Errado) que atribui a elas e a dificuldade (Fácil, difícil ou Mais ou Menos) em emitir a reação habilidosa. O IMHS também inclui a avaliação impressa, na forma de caderno, destinado ao professor que examina cada situação e as reações a ela associadas.

Teste de Classificação de Cartas de Wisconsin (WCST): (SILVA-FILHO, et al., 2007). Do ponto de vista do funcionamento cognitivo, foram selecionadas para avaliação as Funções Executivas considerando que são apontadas, pela literatura especializada, como centrais para a reabilitação auditiva. O WCST avalia as funções executivas, baseado na estimulação da flexibilidade de pensamento do sujeito, para gerar estratégias para solução de problemas com base no feedback do examinador. É um teste com cartas-estímulo que apresentam figuras que possuem três tipos de configuração: Cor, Forma e Número. As respostas são avaliadas baseadas em três dimensões, a saber: Correta-Incorreta, que indica se a associação que o sujeito realizou está certa; Ambígua-Não-ambígua, que diz que uma associação não é ambígua quando apenas uma característica da carta-resposta combina com a carta-estímulo; e Perseverativa-Nãoperseverativa, que diz que o princípio perseverante ocorre quando o sujeito, ao receber a informação de que o critério de associação já não está mais correto, não inibe sua tendência de persistir no padrão antigo.

Escala de Bem-estar e Envolvimento: (LAEVERS ET AL., 2005). Avalia o nível de envolvimento e bem-estar de uma criança durante uma atividade por meio de dez itens, sendo cinco de bem-estar e cinco de envolvimento, divididos em: 


\section{Bem-estar}

Muito baixo: Durante o episódio de observação, a criança mostra claramente sinais de desconforto, como, choramingando, soluçando, chorando, gritando, com aspecto abatido, triste, assustado ou alarmado, parecendo estar com raiva ou furiosa, evidencia tensão corporal: agitando os braços e/ou batendo com os pés no chão, contorcendo-se, partindo coisas ou magoando outros, sugando os dedos ou esfregando os olhos, não evidenciando reações ao ambiente, evitando o contacto, isolando-se, magoando-se a si própria: batendo com a própria cabeça, caindo deliberadamente no chão, etc. Baixo: A postura, expressão facial e ações indicam que a criança não se sente à vontade. Contudo, os sinais são menos explícitos do que aqueles indicados no nível 1 ou não estão expressos durante todo o período de observação. Moderado: A criança transmite uma impressão de "imobilidade", tem uma postura neutra Não existem sinais indicadores de tristeza ou prazer, conforto ou desconforto. A expressão facial e a postura demonstram pouca ou nenhuma emoção. Elevado: A criança mostra sinais de satisfação (ver nível 5). Contudo, os sinais demonstrativos de prazer não estão constantemente presentes com o mesmo grau de intensidade e Muito elevado: Durante todo o período de observação existem sinais claros de conforto, de que a criança se está a sentir bem, apreciando de forma plena, como, sentindo-se feliz e bem-disposta: sorrindo, chorando de alegria, sendo espontânea, sendo ela própria, sendo expressiva, falando para si própria, brincando com sons, murmurando, cantando, estando relaxada, não demonstrando sinais de stress, demonstrando abertura relativamente ao ambiente, demonstrando vivacidade, reagindo energicamente, demonstrando autoconfiança e segurança pessoal.

\section{Envolvimento}

Muito Baixo: A criança dificilmente está ativa, não está concentrada: olhar "vago" e "ausente", parecendo estar a "sonhar acordada", atitude ausente, passiva, atividade não orientada por objetivos, ações não intencionais, não produtivas, ausência de sinais de exploração e interesse ausência de atividade mental. Baixo: A criança demonstra algum grau de atividade, a qual é frequentemente interrompida, concentração limitada: olhar "vago" e "sonhador", vaguear sem objetivo, distrai-se com facilidade e a ação apenas conduz a resultados limitados. Moderado: A criança encontra-se ocupada durante todo o período da observação, mas sem estar realmente concentrada: ações rotineiras, atividades breves, motivação limitada, a criança não se dedica realmente, não se sente desafiada, a criança não ganha a partir de experiências de aprendizagem profundas, não está absorvida pela atividade, não usa plenamente as suas capacidades a atividade não desafia a imaginação e capacidade mental da criança. Elevado: Observam-se sinais claros de envolvimento, mas estes não estão sempre presentes na 
sua máxima expressão, como, em geral, a criança encontra-se absorvida pela atividade, durante a maior parte do tempo existe concentração real, mas a atenção é por vezes desviada, a criança sente-se desafiada, existe um certo grau de entusiasmo, utiliza as suas capacidades e utiliza a sua imaginação e capacidade mental e Muito Elevado: A atividade da criança não é interrompida e esta encontra-se completamente absorvida, como, concentração não interrompida, absorção pela atividade, a criança não está consciente da passagem do tempo, a criança está muito motivada, sente um apelo forte, não é possível distrair a criança, percepção alerta, atenção aos detalhes, precisão, uso constante de todas as suas capacidades e possibilidades, atividade mental forte: imaginação e capacidade mental estão a ser utilizadas na sua máxima possibilidade, ganha experiências novas, de natureza profunda e aprecia estar totalmente envolvida.

Para que houvesse uma análise de fatores musicais, foi realizado um diário de classe, de cada aula que foi preenchido pelas educadoras musicais, com o intuito de relatar os comportamentos e aspectos comportamentais, pedagógicos e musicais dos sujeitos. (ANEXO1).

\subsection{Procedimentos}

Pais e professores responderam ao questionário SSRS-BR, os questionários são autoaplicáveis e coube à psicóloga explicar detalhadamente a forma de respostas. A apuração e interpretação dos dados foi feita pela psicóloga com experiência no uso do questionário. A psicóloga também avaliou as crianças, no que se diz respeito as habilidades sociais por meio do IMHS, as funções executivas por meio do WSCT e a Inteligência por meio do teste de Raven.

As gravações das aulas foram avaliadas por três juízes (educadores musicais), pré e pós intervenção, por meio da escala de bem-estar e envolvimento.

As Educadoras Musicais envolvidas na pesquisa também avaliaram os sujeitos durante e após o término da coleta, por meio do diário de classe.

A aplicação dos instrumentos citados a cima foi realizada em quatro momentos distintos. Dois meses antes de iniciarmos o procedimento de intervenção (aulas de musicalização), ao início do procedimento (primeira semana de aula), na metade da coleta (dois meses após o início) e ao final da coleta (quatro meses após o início). Todas as avaliações foram realizadas em sala silenciosa, na Bravo Academia de Música. 
Os dados sociodemográficos (idade, gênero e escolaridade), a classificação socioeconômica e o tipo de perda auditiva, foram obtidos a partir do prontuário da criança utilizado pelo CEDAU.

\subsection{Forma de Análise dos Resultados}

Os dados foram analisados de forma descritiva e inferencial. Utilizou-se o software SPSS 25.0 e o software Sigmaplot 12.0.

A descrição das variáveis qualitativas nominais foi realizada por meio de frequência relativa e de frequência absoluta. A descrição das variáveis quantitativas e qualitativas ordinais foi realizada por meio de medidas de variabilidade (desvio-padrão), tendência central (média e mediana) e posição (mínimo, máximo, primeiro quartil e terceiro quartil).

Para comparação entre as múltiplas análises do grupo experimental foi realizado o Teste ANOVA para análise de variâncias de medidas repetidas.

A análise inferencial de comparação entre variáveis qualitativas nominais de dois grupos dependentes foi realizada com Teste de Wilcoxon, para essa análise foi considerada a mediana entre os juízes. A análise da confiabilidade inter-juízes para variáveis qualitativas ordinais foi realizada com o Teste Kappa de Fleiss.

Considerou-se um nível de significância de $5 \%(\mathrm{p}<0,05)$ em todas as análises inferenciais.

\section{RESULTADOS}

\subsection{Caracterização dos grupos analisados}

A amostra do presente estudo foi composta por 10 crianças com implante coclear, com idade média de 6 anos e 10 meses (Tabela 1). Foram mais frequentes os participantes de nível S.E. B2 $(n=4 ; 40 \%)$, de escola pública $(n=8 ; 80 \%)$, e com perda congênita $(n=7 ; 70 \%)$, conforme mostra a Tabela 2. 
Tabela 1 - Análise descritiva da variável quantitativa contínua idade da amostra

\begin{tabular}{cccccccc}
\hline Variável & Média & DP & Mínimo & Máximo & $\mathbf{1 Q}$ & Mediana & 3Q \\
\hline Idade & 6,90 & 1,29 & 6,00 & 9,00 & 6,00 & 6,00 & 8,25 \\
\hline
\end{tabular}

Análise descritiva

Legenda: $\mathrm{DP}=$ desvio padrão; $1 \mathrm{Q}=$ primeiro quartil; $3 \mathrm{Q}=$ terceiro quartil

Tabela 2 - Análise descritiva das variáveis qualitativas nominais nível S.E., escala e perda da amostra

\begin{tabular}{lcc}
\hline Variável e categorias & n & \% \\
\hline Nível S.E. & 3 & 30,00 \\
B1 & 4 & 40,00 \\
B2 & 3 & 30,00 \\
C & & \\
Escola & 2 & 20,00 \\
Privada & 8 & 80,00 \\
Pública & & \\
Perda Auditiva & 3 & 30 \\
Adquirida & 7 & 70 \\
Congênita & & \\
\hline Análise
\end{tabular}

Análise descritiva

Legenda: $\mathrm{n}=$ frequência absoluta; $\%=$ frequência relativa percentual

\subsection{Comparação Intragrupo}

A Tabela 3 aponta os valores de média, desvio padrão e significância das habilidades sociais do grupo experimental (GE) de acordo com as respostas do Sistema de Avaliação de Habilidades Sociais (SSRS-BR). Observando-se os valores referentes ao SSRS-BR, verificouse que há diferença estatisticamente significante quando comparados os resultados das avaliações intragrupo do GE de acordo com a visão dos pais no escore global (da primeira e segunda para a quarta avaliação) e nos fatores responsabilidade (da segunda para a quarta avaliação), desenvoltura social (da primeira para a terceira avaliação) e civilidade (da terceira para a quarta avaliação). Houve, portanto, um aumento na emissão de comportamentos habilidosos relacionados aos fatores 1,4 e 5 e que refletiram no escore global. $O$ mesmo não foi observado, em termos de significância para os fatores 2 e 3. 
Tabela 3 - Comparação das habilidades sociais na percepção dos pais, entre os resultados das quatro avaliações do grupo experimental.

\begin{tabular}{|c|c|c|c|c|c|c|c|c|c|c|}
\hline \multirow{2}{*}{$\begin{array}{c}\text { SSRS-BR } \\
\text { (Versão-M) }\end{array}$} & \multicolumn{4}{|c|}{ Média } & \multicolumn{4}{|c|}{ Desvio Padrão (Dp) } & \multirow[b]{2}{*}{$\mathbf{p}$} & \multirow{2}{*}{ post-hoc } \\
\hline & 1 & 2 & 3 & 4 & 1 & 2 & 3 & 4 & & \\
\hline Escore global & 27,20 & 27,60 & 30,20 & 32,90 & 8,77 & 8,96 & 9,64 & 10,73 & $0,001 *$ & $\begin{array}{c}1>4 \\
\mathrm{p}=0,001 * \\
2>4 \\
\mathrm{p}=0,001 *\end{array}$ \\
\hline $\begin{array}{c}\text { F1- } \\
\text { responsabilidade } \\
\end{array}$ & 5,00 & 4,50 & 5,50 & 6,00 & 1,25 & 1,18 & 1,18 & 1,94 & $0,023^{*}$ & $\begin{array}{c}2>4 \\
\mathrm{p}=0,018^{*}\end{array}$ \\
\hline $\begin{array}{c}\text { F2- } \\
\text { Autocontrole } \\
\end{array}$ & 5,40 & 4,80 & 5,20 & 6,10 & 0,70 & 1,81 & 1,87 & 1,91 & 0,108 & \\
\hline $\begin{array}{l}\text { F3- Afetividade/ } \\
\text { cooperação }\end{array}$ & 8,00 & 8,60 & 8,90 & 9,30 & 1,63 & 2,01 & 2,03 & 2,26 & 0,152 & \\
\hline $\begin{array}{c}\text { F4- } \\
\text { Desenvoltura social }\end{array}$ & 4,80 & 5,50 & 6,10 & 5,90 & 2,15 & 2,27 & 2,08 & 1,73 & $0,049 *$ & $\begin{array}{c}1>3 \\
\mathrm{p}=0,047 *\end{array}$ \\
\hline $\begin{array}{c}\text { F5- } \\
\text { Civilidade } \\
\end{array}$ & 6,00 & 6,10 & 5,70 & 6,90 & 6,00 & 6,10 & 5,70 & 6,90 & $0,032 *$ & $\begin{array}{c}3>4 \\
\mathrm{p}=0,025^{*}\end{array}$ \\
\hline
\end{tabular}

Análise de variância de medidas repetidas (teste ANOVA) e post-hoc (teste de Tukey)

A Tabela 4 aponta os valores de média, desvio padrão e significância dos problemas de comportamento do GE de acordo com as respostas do Sistema de Avaliação de Habilidades Sociais (SSRS-BR). Observando-se os valores referentes ao SSRS-BR, verificou-se que há diferença estatisticamente significante quando comparados os resultados das avaliações intragrupo do GE de acordo com a visão dos pais no escore global (da segunda para a quarta avaliação) e no fator externalizantes (da segunda para a quarta avaliação). Houve, portanto, uma redução na frequência de problemas de comportamento externalizantes e que refletiram no escore global. Para o F2 (internalizantes) não houve diferença e os escores se mantiveram numa faixa de classificação mediana (dentro da normalidade).

Tabela 4 - Comparação dos problemas de comportamento na percepção dos pais, entre os resultados das avaliações do grupo experimental.

\begin{tabular}{|c|c|c|c|c|c|c|c|c|c|c|}
\hline \multirow{2}{*}{$\begin{array}{c}\text { SSRS-BR } \\
\text { (Versão-M) }\end{array}$} & \multicolumn{4}{|c|}{ Média } & \multicolumn{4}{|c|}{ Desvio Padrão (Dp) } & \multirow{2}{*}{$\mathbf{P}$} & \multirow{2}{*}{ post-hoc } \\
\hline & 1 & 2 & 3 & 4 & 1 & 2 & 3 & 4 & & \\
\hline Escore global & 8,20 & 10,50 & 9,50 & 7,40 & 4,87 & 4,77 & 4,65 & 4,30 & $0,001 *$ & $\begin{array}{c}2>4 \\
\mathrm{p}=0,001 *\end{array}$ \\
\hline F1- externalizantes & 5,70 & 7,10 & 6,80 & 5,40 & 4,06 & 3,90 & 3,29 & 3,20 & $0,024 *$ & $\begin{array}{c}2>4 \\
\mathrm{p}=0,044^{*}\end{array}$ \\
\hline $\begin{array}{c}\text { F2- } \\
\text { internalizantes }\end{array}$ & 3,00 & 3,90 & 3,10 & 2,50 & 2,16 & 2,13 & 1,37 & 1,65 & 0,066 & \\
\hline
\end{tabular}

Análise de variância de medidas repetidas (teste ANOVA) e post-hoc (teste de Tukey)

A Tabela 5 aponta os valores de média, desvio padrão e significância das habilidades sociais do GE de acordo com as respostas do Sistema de Avaliação de Habilidades Sociais (SSRS-BR). Observando-se os valores referentes ao SSRS-BR, verificou-se que há diferença 
estatisticamente significante quando comparados os resultados das avaliações intragrupo do GE de acordo com a visão dos professores, no escore global (da primeira para a terceira e quarta avaliação e da e segunda para a quarta avaliação) e nos fatores autocontrole (da primeira, segunda e terceira para a quarta avaliação) assertividade/ desenvoltura social (da primeira para a quarta avaliação) e afetividade/cooperação (da primeira para a quarta avaliação). Houve, portanto, um aumento na emissão de comportamentos habilidosos relacionados a todos os fatores, exceto o fator 1 .

Tabela 5 - Comparação das habilidades sociais na percepção dos professores, entre os resultados das avaliações do grupo experimental.

\begin{tabular}{|c|c|c|c|c|c|c|c|c|c|c|}
\hline \multirow{2}{*}{$\begin{array}{c}\text { SSRS-BR } \\
\text { (Versão-P) }\end{array}$} & \multicolumn{4}{|c|}{ Média } & \multicolumn{4}{|c|}{ Desvio Padrão (Dp) } & \multirow{2}{*}{$\mathbf{P}$} & \multirow{2}{*}{ post-hoc } \\
\hline & 1 & 2 & 3 & 4 & 1 & 2 & 3 & 4 & & \\
\hline Escore global & 29,80 & 32,80 & 35,00 & 38,00 & 10,76 & 11,75 & 12,49 & 11,82 & $0,001 *$ & $\begin{array}{c}1>4 \\
\mathrm{p}=0,001 * \\
1>3 \\
\mathrm{p}=0,009 * \\
2>4 \\
\mathrm{p}=0,001 *\end{array}$ \\
\hline $\begin{array}{c}\text { F1- } \\
\text { responsabilidade }\end{array}$ & 9,00 & 10,20 & 10,00 & 10,90 & 2,75 & 2,39 & 2,94 & 2,28 & 0,071 & \\
\hline $\begin{array}{c}\text { F2- } \\
\text { Autocontrole }\end{array}$ & 9,20 & 10,60 & 10,60 & 12,40 & 2,94 & 3,10 & 3,37 & 2,76 & $0,001 *$ & $\begin{array}{c}1>4 \\
\mathrm{p}=0,001^{*} \\
2>4 \\
\mathrm{p}=0,025^{*} \\
3>4 \\
\mathrm{p}=0,025^{*}\end{array}$ \\
\hline $\begin{array}{l}\text { F3- assertividade/ } \\
\text { desenvoltura social }\end{array}$ & 7,30 & 7,90 & 8,40 & 9,10 & 2,11 & 1,97 & 2,22 & 1,60 & $0,026^{*}$ & $\begin{array}{c}1>4 \\
\mathrm{p}=0,019 *\end{array}$ \\
\hline $\begin{array}{c}\text { F4- } \\
\text { afetividade/ } \\
\text { cooperação }\end{array}$ & 4,40 & 4,40 & 5,40 & 5,70 & 1,58 & 1,58 & 1,58 & 1,58 & $0,003 *$ & $\begin{array}{c}1>4 \\
\mathrm{p}=0,013^{*}\end{array}$ \\
\hline
\end{tabular}

Análise de variância de medidas repetidas (teste ANOVA) e post-hoc (teste de Tukey)

A Tabela 6 aponta os valores de média, desvio padrão e significância dos problemas de comportamento do GE de acordo com as respostas do Sistema de Avaliação de Habilidades Sociais (SSRS-BR). Observando-se os valores referentes ao SSRS-BR, verificou-se que há diferença estatisticamente significante quando comparados os resultados das avaliações intragrupo do GE de acordo com a visão dos professores no escore global (da primeira para a terceira e quarta avaliação e da e segunda para a quarta avaliação) e nos fatores externalizantes (da primeira para a terceira e quarta avaliação) e hiperatividade (da primeira para a terceira e quarta avaliação). ). Houve, portanto, uma redução na frequência de problemas de comportamento externalizantes e hiperatividade que refletiram no escore global. 
Tabela 6 - Comparação dos problemas de comportamento na visão dos professores, entre as avaliações do grupo experimental.

\begin{tabular}{|c|c|c|c|c|c|c|c|c|c|c|}
\hline \multirow{2}{*}{$\begin{array}{c}\text { SSRS-BR } \\
(\text { Versão - P) }\end{array}$} & \multicolumn{4}{|c|}{ Média } & \multicolumn{4}{|c|}{ Desvio Padrão (Dp) } & \multirow{2}{*}{$\mathbf{P}$} & \multirow{2}{*}{ post-hoc } \\
\hline & 1 & 2 & 3 & 4 & 1 & 2 & 3 & 4 & & \\
\hline Escore global & 4,70 & 3,60 & 2,40 & 1,60 & 2,75 & 2,27 & 1,78 & 1,65 & $0,001 *$ & $\begin{array}{c}1>3 \\
\mathrm{p}=0,004^{*} \\
1>4 \\
\mathrm{p}=0,001^{*} \\
2>4 \\
\mathrm{p}=0,014^{*}\end{array}$ \\
\hline $\begin{array}{c}\text { F1- } \\
\text { externalizantes }\end{array}$ & 1,70 & 1,20 & 0,70 & 0,60 & 2,06 & 1,62 & 1,34 & 1,58 & $0,020 *$ & $\begin{array}{c}1>3 \\
\mathrm{p}=0,048^{*} \\
1>4 \\
\mathrm{p}=0,026^{*}\end{array}$ \\
\hline $\begin{array}{c}\text { F2- } \\
\text { hiperatividade }\end{array}$ & 3,00 & 2,20 & 1,70 & 1,30 & 1,89 & 1,81 & 1,57 & 1,64 & $0,008 *$ & $\begin{array}{c}1>3 \\
\mathrm{p}=0,047^{*} \\
1>4 \\
\mathrm{p}=0,006^{*}\end{array}$ \\
\hline $\begin{array}{c}\text { F3- } \\
\text { internalizantes }\end{array}$ & 1,00 & 1,20 & 0,80 & 0,70 & 1,56 & 1,69 & 1,48 & 1,57 & 0,356 & \\
\hline
\end{tabular}

Análise de variância de medidas repetidas (teste ANOVA) e post-hoc (teste de Tukey)

A Tabela 7 aponta os valores de média, desvio padrão e significância da competência acadêmica do GE de acordo com as respostas do Sistema de Avaliação de Habilidades Sociais (SSRS-BR). Observando-se os valores referentes ao SSRS-BR, verificou-se que há diferença estatisticamente significante quando comparados os resultados das avaliações intragrupo do GE de acordo com a visão dos professores no escore global (da primeira e segunda para a quarta avaliação). Tanto na percepção de pais quanto de professores os PC internalizantes se mantiveram dentro de uma classificação mediana (dentro da normalidade).

Tabela 7 - Comparação da competência acadêmica na percepção dos professores, entre os resultados das avaliações do grupo experimental.

\begin{tabular}{|c|c|c|c|c|c|c|c|c|c|c|}
\hline \multirow{2}{*}{$\begin{array}{c}\text { SSRS-BR } \\
\text { (Versão - P) }\end{array}$} & \multicolumn{4}{|c|}{ Média } & \multicolumn{4}{|c|}{ Desvio Padrão (Dp) } & \multirow[b]{2}{*}{$\mathbf{p}$} & \multirow{2}{*}{ post-hoc } \\
\hline & 1 & 2 & 3 & 4 & 1 & 2 & 3 & 4 & & \\
\hline Escore global & 30,50 & 31,30 & 33,60 & 35,50 & 10,76 & 10,88 & 11,08 & 11,23 & $0,001 *$ & $\begin{array}{c}1>4 \\
\mathrm{p}=0,001 * \\
2>4 \\
\mathrm{p}=0,007 *\end{array}$ \\
\hline
\end{tabular}

Análise de variância de medidas repetidas (teste ANOVA) e post-hoc (teste de Tukey)

A Tabela 8 aponta os valores de média, desvio padrão e significância da frequência de emissão do GE de acordo com as respostas do IMHS. Observando-se os valores referentes ao IMHS, verificou-se que há diferença estatisticamente significante quando comparados os resultados das avaliações intragrupo do GE de acordo com a análise da psicóloga nos fatores assertividade e enfrentamento - habilidoso (da primeira para a quarta avaliação), assertividade 
e enfrentamento - não habilidoso passivo (da segunda para a quarta avaliação) e participaçãonão habilidoso passivo (da primeira para a quarta avaliação). Houve, portanto, aumento na emissão de habilidades assertivas e redução de comportamento assertivo não habilidosopassivo e participação não habilidosa-passiva.

Tabela 8 - IMHS, entre os resultados das avaliações da frequência de emissão dos fatores do grupo experimental.

\begin{tabular}{|c|c|c|c|c|c|c|c|c|c|c|}
\hline \multirow{2}{*}{ IMHS } & \multicolumn{4}{|c|}{ Média } & \multicolumn{4}{|c|}{ Desvio Padrão (Dp) } & \multirow[b]{2}{*}{ p } & \multirow{2}{*}{ post-hoc } \\
\hline & 1 & 2 & 3 & 4 & 1 & 2 & 3 & 4 & & \\
\hline $\begin{array}{c}\text { Empatia e Civilidade - } \\
\text { Habilidoso }\end{array}$ & 1,51 & 1,54 & 1,73 & 1,59 & 0,46 & 0,40 & 0,28 & 0,25 & 0,346 & \\
\hline $\begin{array}{l}\text { Empatia e Civilidade - } \\
\text { Não Habilidoso Passivo }\end{array}$ & 0,65 & 0,54 & 0,82 & 0,56 & 0,47 & 0,45 & 0,64 & 0,70 & 0,514 & \\
\hline $\begin{array}{c}\text { Assertividade e } \\
\text { Enfrentamento- } \\
\text { Habilidoso } \\
\end{array}$ & 0,63 & 1,02 & 1,07 & 1,09 & 0,54 & 0,63 & 0,63 & 0,59 & $0,042 *$ & $\begin{array}{c}1>4 \\
\mathrm{p}=0,006^{*}\end{array}$ \\
\hline $\begin{array}{c}\text { Assertividade e } \\
\text { Enfrentamento- } \\
\text { Não Habilidoso Passivo }\end{array}$ & 0,74 & 0,78 & 0,51 & 0,40 & 0,47 & 0,27 & 0,23 & 0,28 & $0,020 *$ & $\begin{array}{c}2>4 \\
\mathrm{p}=0,035^{*}\end{array}$ \\
\hline $\begin{array}{c}\text { Assertividade e } \\
\text { Enfrentamento- } \\
\text { Não Habilidoso Ativo }\end{array}$ & 0,41 & 0,20 & 0,20 & 0,27 & 0,35 & 0,30 & 0,40 & 0,48 & 0,258 & \\
\hline Autocontrole - Habilidoso & 0,94 & 1,11 & 1,17 & 1,08 & 0,74 & 0,49 & 0,45 & 0,61 & 0,694 & \\
\hline $\begin{array}{c}\text { Autocontrole - Não } \\
\text { Habilidoso Passivo } \\
\end{array}$ & 0,58 & 0,69 & 0,61 & 0,47 & 0,56 & 0,48 & 0,44 & 0,32 & 0,797 & \\
\hline $\begin{array}{c}\text { Autocontrole - Não } \\
\text { Habilidoso Ativo }\end{array}$ & 0,28 & 0,31 & 0,31 & 0,28 & 0,23 & 0,30 & 0,30 & 0,34 & 0,977 & \\
\hline Participação - Habilidoso & 1,48 & 1,44 & 1,52 & 1,56 & 0,58 & 0,53 & 0,47 & 0,50 & 0,948 & \\
\hline $\begin{array}{l}\text { Participação- Não } \\
\text { Habilidoso Passivo } \\
\end{array}$ & 1,15 & 0,74 & 0,78 & 0,59 & 0,77 & 0,49 & 0,53 & 0,33 & $0,044 *$ & $\begin{array}{c}1>4 \\
p=0,033 *\end{array}$ \\
\hline $\begin{array}{c}\text { Participação - Não } \\
\text { Habilidoso Ativo }\end{array}$ & 0,22 & 0,30 & 0,26 & 0,26 & 0,33 & 0,48 & 0,52 & 0,46 & 0,938 & \\
\hline
\end{tabular}

Análise de variância de medidas repetidas (teste ANOVA) e post-hoc (teste de Tukey)

A Tabela 9 aponta os valores de média, desvio padrão e significância do percentil do GE de acordo com as respostas do WSCT. Observando-se os valores referentes ao WSCT, verificou-se que há diferença estatisticamente significante quando comparados os resultados das avaliações intragrupo do GE de acordo com a análise da psicóloga no percentil dos fatores, nível conceitual (da primeira para a segunda, terceira e quarta avaliação), categorias completadas (da primeira e segunda para a quarta avaliação), número de ensaios (da segunda para a quarta avaliação) e aprendendo a aprender (da segunda para a quarta avaliação). 
Tabela 9 - Comparação WSCT, entre os resultados das avaliações do grupo experimental.

\begin{tabular}{|c|c|c|c|c|c|c|c|c|c|c|}
\hline \multirow{2}{*}{ WSCT } & \multicolumn{4}{|c|}{ Média } & \multicolumn{4}{|c|}{ Desvio Padrão (Dp) } & \multirow[b]{2}{*}{$\mathbf{p}$} & \multirow{2}{*}{ post-hoc } \\
\hline & 1 & 2 & 3 & 4 & 1 & 2 & 3 & 4 & & \\
\hline $\begin{array}{l}\text { Número de } \\
\text { Ensaios }\end{array}$ & 125,00 & 117,22 & 116,89 & 117,78 & 9,00 & 21,40 & 18,27 & 14,10 & 0,469 & \\
\hline $\begin{array}{l}\text { Número de } \\
\text { Acertos }\end{array}$ & 68,67 & 77,78 & 80,89 & 82,89 & 27,88 & 7,71 & 10,48 & 9,32 & 0,291 & \\
\hline $\begin{array}{c}\text { Número de } \\
\text { Erros }\end{array}$ & 89,90 & 94,80 & 94,20 & 96,10 & 14,56 & 4,54 & 7,64 & 3,81 & 0,400 & \\
\hline $\begin{array}{c}\text { Respostas } \\
\text { Perseverativas }\end{array}$ & 43,00 & 47,20 & 46,90 & 43,40 & 26,51 & 13,63 & 7,19 & 16,94 & 0,901 & \\
\hline $\begin{array}{c}\text { Erros } \\
\text { Perseverativos } \\
\end{array}$ & 38,70 & 35,50 & 37,80 & 35,10 & 25,95 & 15,05 & 10,34 & 15,35 & 0,943 & \\
\hline $\begin{array}{c}\text { Erros Não } \\
\text { Perseverativos }\end{array}$ & 45,70 & 53,20 & 55,40 & 60,40 & 14,37 & 24,71 & 27,65 & 24,14 & 0,322 & \\
\hline $\begin{array}{c}\text { Nível } \\
\text { Conceitual }\end{array}$ & 38,44 & 66,11 & 68,67 & 73,11 & 20,92 & 4,43 & 14,22 & 13,75 & $0,001 *$ & $\begin{array}{c}1>2 \\
\mathrm{p}=0,005^{*} \\
1>3 \\
\mathrm{p}=0,002^{*} \\
1>4 \\
\mathrm{p}=0,001^{*}\end{array}$ \\
\hline $\begin{array}{l}\text { Categorias } \\
\text { Completadas }\end{array}$ & 30,50 & 31,30 & 33,60 & 35,50 & 10,76 & 10,88 & 11,08 & 11,23 & $0,001 *$ & $\begin{array}{c}1>4 \\
\mathrm{p}=0,001^{*} \\
2>4 \\
\mathrm{p}=0,007^{*}\end{array}$ \\
\hline $\begin{array}{c}\text { Número de } \\
\text { Ensaios }\end{array}$ & 27,20 & 27,60 & 30,20 & 32,90 & 8,77 & 8,96 & 9,64 & 10,73 & $0,001 *$ & $\begin{array}{c}2>4 \\
p=0,001 *\end{array}$ \\
\hline $\begin{array}{c}\text { Fracasso em } \\
\text { Manter o } \\
\text { Contexto }\end{array}$ & 12,60 & 15,00 & 14,00 & 14,00 & 5,58 & 3,16 & 4,22 & 4,22 & 0,649 & \\
\hline $\begin{array}{c}\text { Aprendendo a } \\
\text { Aprender }\end{array}$ & 8,20 & 10,50 & 9,50 & 7,40 & 4,87 & 4,77 & 4,65 & 4,30 & $0,001 *$ & $\begin{array}{c}2>4 \\
\mathrm{p}=0,001 *\end{array}$ \\
\hline
\end{tabular}

Análise de variância de medidas repetidas (teste ANOVA) e post-hoc (teste de Tukey)

\subsection{Análise dos Juízes}

As Tabelas 10 e 11 mostram os resultados das avaliações das gravações das aulas que foram analisadas por três juízes (educadores musicais) em relação a escala de bem-estar e envolvimento.

Para a análise do valor de confiabilidade interjuízes de 0,594 (Tabela 10) foi realizado o cálculo do Kappa de Fleiss.

Tabela 10 - Confiabilidade interjuízes para a escala de bem-estar e envolvimento

\begin{tabular}{lccccc}
\hline & Kappa de Fleiss & $\mathbf{Z}$ & $\mathbf{p}$-valor & Limite inferior IC 95\% & Limite superior IC 95\% \\
\hline Interjuízes & 0,594 & 8,039 & $<0,001^{*}$ & 0,449 & 0,739 \\
\hline
\end{tabular}

Kappa de Fleiss 
Para a análise de comparação da variável da escala de bem-estar e envolvimento pré e pós intervenção foi considerado o valor da mediana entre os três juízes, em ambos os momentos de avaliação. Observa-se na Tabela 11 que houve um aumento significativo no valor no momento pós intervenção dos sujeitos $(\mathrm{p}=0,007)$.

Tabela 11 - Comparação da variável escala de bem-estar e envolvimento pré e pós intervenção da amostra

\begin{tabular}{cccccccccc}
\hline Variável & Média & DP & Mínimo & Máximo & $\mathbf{1 Q}$ & Mediana & $\mathbf{3 Q}$ & $\mathbf{Z}$ & $\begin{array}{c}\mathbf{p}- \\
\text { valor }\end{array}$ \\
\hline $\begin{array}{c}\text { Escala Bem-estar } \\
\text { pré (mediana) }\end{array}$ & 2,70 & 1,25 & 1,00 & 5,00 & 1,75 & 3,00 & 3,25 & & \\
$\begin{array}{c}\text { Escala Bem-estar } \\
\text { pós (mediana) }\end{array}$ & 5,00 & 0,00 & 5,00 & 5,00 & 5,00 & 5,00 & 5,00 & & \\
\hline
\end{tabular}

Teste de Wilcoxon

Legenda: $\mathrm{DP}=$ desvio padrão; $1 \mathrm{Q}=$ primeiro quartil; $3 \mathrm{Q}=$ terceiro quartil

\section{DISCUSSÃO}

A faixa etária escolhida para esse estudo (Tabela 1) se baseou em estudos que apontam que essa é a melhor fase da vida para o neurodesenvolvimento da criança e de suas funções cognitivas. Pensando nesses fatores, é possível relacionar o desenvolvimento infantil diretamente às habilidades perceptivas, cognitivas e sociais, uma vez que estudos da literatura analisada, como o de Said e Abramides (2019) apontam que essa é uma fase propícia para o desenvolvimento do aprendizado, da coordenação motora, da linguagem, do raciocínio lógico, da memória, da sensibilidade, da personalidade e da formação global do indivíduo. Muzkat (2016), aponta como a música tem se mostrado importante fator para o neurodesenvolvimento infantil, indicando que tais habilidades começam a ser adquiridas e são mais bem desenvolvidas na infância, por meio de diferentes processos de aprendizagem, como, pessoas próximas, modelagem social e esquemas de reforçamento.

Além disso, escolha de tal população para o presente estudo (Tabela 2) se deu pelo fato de que existem inúmeros estudos que comprovam os benefícios de atividades musicais para crianças usuárias de implante coclear (INNES-BROWN ET AL., 2013; GFELLER, 2016; ARAÚJO ET AL.,2017; PETERSEN ET AL., 2015; POLONENKO ET AL., 2017). Entretanto, não existem estudos clínicos randomizados que abordem atividades musicais de forma coerente, seja em relação a abordagem musical escolhida, heterogeneidade da amostra, equipe 
de estudo sem músicos ou estudos sem rigor científico, conforme apontado pela literatura (GFELLER, 2016; TORPPA E HUOTILANEM, 2019; LEROUSSEAU, 2020).

Nas Tabelas 3 e 5 verificamos que houve diferenças estatisticamente significante na visão dos pais e professores quanto ao incremento do repertório de habilidades sociais das crianças expostas à musicalização, nos fatores responsabilidade, desenvoltura social, civilidade, autocontrole, assertividade e desenvoltura social e afetividade e cooperação. Houve convergência entre as respostas de pais e professores, quanto ao fator desenvoltura social e divergência quanto aos fatores responsabilidade, autocontrole e afetividade e cooperação. Ou seja, os mesmos fatores em contextos diferentes - doméstico e escolar- mostram-se heterogêneos por envolver percepções diferentes a partir de contingências ambientais específicas que afetam o desempenho social da criança. De qualquer maneira, a promoção do repertório de HS destas crianças foi relevante o que corrobora estudo anterior das pesquisadoras (SAID E ABRAMIDES, 2020) que evidenciou efeito positivo do aprendizado musical sobre o repertório de habilidades sociais e acadêmicas de crianças com desenvolvimento típico, utilizando o mesmo instrumento (SSRS-BR) uma vez que tal aprendizado além de estabelecer interação e comunicação com professor e com seus pares requer a manutenção de disciplina, foco atencional, seguir regras, ter disciplina acionando o sistema de controle da atenção o desenvolvimento do autocontrole, responsabilidade, afetividade, cooperação, permitindo a concentração em uma determinada tarefa e ignorando fatores distratores que favorecem as classes de HS investigadas.

Neste estudo, também foi realizada a autoavaliação da criança sobre suas HS em vários contextos que apontou (Tabela 8) o aumento na frequência de habilidades assertivas e redução de comportamento assertivo não habilidoso-passivo e redução de participação não habilidosapassiva. De fato, estudo de Abramides (2010) também caracterizou o comportamento não habilidoso-passivo de participação em crianças com deficiência auditiva quando comparada com crianças com outros distúrbios de comunicação (linguagem, fala e voz) não decorrentes de problemas sensoriais indicando dificuldade na interação da criança com DA com pares e professores com potencial impacto negativo para seu desenvolvimento e aprendizagem. Podese afirmar que as avaliações multimodais de HS (pais, professores e criança) adotadas no presente estudo dão maior robustez ao dado sobre papel promotor da aprendizagem musical sobre o comportamento habilidoso das crianças com IC. Além disso, o cérebro aprende a música como uma "linguagem", logo, pode ser considerada uma forma de comunicação e expressão social (LOPES, 2019). Tais elementos favorecem a participação na atividade proposta, resultando no desenvolvimento de diversas habilidades sociais 
O estudo apontou efeitos positivos da musicalização sobre o repertorio de HS e redução dos problemas de comportamento do tipo externalizante e hiperatividade das crianças (Tabelas 4 e 6). De fato, a literatura vem apontando que crianças com problemas externalizantes/agressividade foram avaliadas como menos habilidosas socialmente (LEME E BOLSONI-SILVA, 2010A, 2010B). Os comportamentos externalizantes tem curso e prognóstico menos favoráveis, especialmente os comportamentos de agressividade, impulsividade e tendências antissociais, que são mais frequentes na infância (BENETTI ET AL.,2014), porém se a criança usar das habilidades sociais para obter atenção e resolver problemas, pode reduzir a probabilidade de apresentar tais problemas de comportamento (FREITAS, 2016) sendo as HS tomadas como comportamentos concorrentes com comportamentos problemáticos. Assim, tais efeitos vão ao encontro do que Schwartz (2017) coloca sobre que há evidências que sugerem que o aprendizado musical pode ser uma estratégia eficaz para aumentar o envolvimento e o desempenho nas tarefas e diminuir os problemas de comportamento.

Dentro do sistema de avaliação de habilidades sociais (SSRS) na versão professores temos a avaliação da competência acadêmica que apontou diferença estatisticamente significante (Tabela 7), o que corrobora estudo anterior dos pesquisadores (SAID E ABRAMIDES, 2020) realizado em crianças com desenvolvimento típico. As autoras sustentam que quando pensamos em aprendizagem (entre elas a musical) como uma atividade de longo prazo que permite estimular as múltiplas conexões, raciocínios e inteligências da criança ao ativar sistemas cerebrais, como, controle de atenção, motor, memória, ordenação espacial entre outros.

Considerando o incremento do repertório de HS e competência acadêmica e a redução de PC-externalizantes, faz-se necessário analisar os dados à luz dos componentes da estruturação da intervenção (aprendizagem musical) proposta no presente estudo. Ela tem como base um modelo de orientação informal estruturada baseada na MLT que contempla aspectos importantes para a aprendizagem: interação entre professor e criança, criança com seus pares, o que favorece que as crianças conheçam melhor a si mesmas e aos outros (GORDON, 2000), aprendizagem colaborativa (GORDON, 2008), com base na discriminação e na inferência (GORDON, 2015) favorecendo o processo do desenvolvimento do pensamento intuitivo (TORMIN, 2014), o autocontrole, foco atencional e comunicação, seja ela verbal ou não-verbal (SAID E ABRAMIDES, 2020).

Gordon (2008) enfatiza que a aptidão musical é inata, mas afetada pela qualidade do ambiente em que a criança está inserida, sendo assim a interação professor-criança o eixo 
principal de condução na MLT. De fato, a interação humana é fundamental para que a ocorra a aprendizagem e ela acontece através da voz, do contato visual e dos movimentos propostos (RODRIGUES, 2000) nas atividades musicais que foram realizadas, por meio da abordagem Orff, que defendia que qualquer pessoa pode fazer música pois enfatizava o uso de sons e gestos corporais para expressar o ritmo e a voz como primeiro e mais natural dos instrumentos, e Dalcroze que acreditava que processos corporais, ritmos e movimento eram a base para o aprendizado musical.

A MLT também favorece a comunicação verbal e não-verbal. Para Vygotsky a linguagem tem papel fundamental no desenvolvimento humano, pois é imprescindível para a formação do pensamento (TORMIN, 2014); ela integra as funções psíquicas superiores, juntamente com o pensamento e a memória, e a sua apropriação resulta de um processo de internalização de processos externos a partir da mediação do outro (social). O que também é apontado no referencial skinneriano que acentua a dimensão social do comportamento verbal (MATOS, 1991) e sinaliza a importância das práticas culturais da comunidade verbal para o treinamento e a manutenção dos repertórios de ouvinte e falante (BAUM, 1999) o que foi verificado a partir da intervenção no presente estudo.

Dentre as funções cognitivas, o estudo selecionou avaliar as funções executivas (Teste Wisconsin), e como mostra a Tabela 9, houve diferença estatisticamente significante pré e pósintervenção nos aspectos aprender a aprender, diminuição de erros perseverativos e capacidade categorial). Estudo de Figueras, Edwards e Langdon (2008) apontaram que a habilidade de linguagem foi significativamente associada positivamente com FE em crianças com IC quando comparadas a crianças ouvintes, resultado esse corroborado por ( KRONENBERGER ET AL., 2014) em 64 sujeitos, entre sete a 27 anos de idade avaliados em três domínios: memória de trabalho, velocidade de fluência e concentração de inibição uma vez que o funcionamento executivo (FE) pode influenciar o desenvolvimento das habilidades de fala e linguagem em crianças surdas após o IC de várias maneiras que diferem da audição normal, mas também as habilidades e experiências, da linguagem falada também podem exercer efeitos recíprocos no desenvolvimento da FE. A título de esclarecimento, tais resultados não foram confirmados pelo presente estudo que não apontou desempenho deficitário $(\mathrm{P}<1)$ das $\mathrm{FE}$ em nenhum participante desde a primeira avaliação, o que pode ser justificado pelo menor número amostral e diversidade metodológica. Entretanto, há um consenso entre os autores referenciados quanto à necessidade de incluir as FE nos protocolos de avaliação e intervenção terapêutica de crianças com deficiência auditiva. 
Importante ressaltar que a melhora de desempenho no teste Wisconsin pode ter tido o efeito do fator aprendizagem ocorrida pela exposição e realização do teste em várias sondagens, muito embora tenha havido uma estabilidade nas linhas de base (avaliações nas duas primeiras sondagens da intervenção), exceto em um participante. Ou seja, os resultados foram incrementados apenas após a intervenção o que permite sustentar o efeito positivo da musicalização sobre as funções executivas.

Um aspecto importante sobre as funções executivas é que elas permitem ao indivíduo interagir no mundo de maneira intencional e formular um plano de ação que se baseia em experiências prévias e demandas do ambiente atual e, assim sendo, déficits sociais e comunicativos podem influenciar diretamente a qualidade das relações sociais e diminuir significativamente as oportunidades de aprendizado e crescimento social (SALLES E PAULA, 2016) indicando que estas ações precisam ser flexíveis e adaptativas e, por vezes, monitoradas em suas várias etapas de execução (LINNAVALLI ET AL., 2018).

Como dito anteriormente a estruturação de intervenção por meio da MLT engloba processos subjacentes os quais fomentam a capacidade de adaptação do indivíduo às mudanças de estímulos, o que é uma característica da plasticidade cerebral, que requer a interdependência das funções dos dois hemisférios cerebrais provocando interações neurais que resultam nas reações humanas ao estímulo musical, mostrando como o cérebro integra tarefas perceptuais e comportamentais complexas. Swaminathan e Schellenberg (2018) apontam que a música tem o modelo perfeito para investigar a plasticidade cerebral e a transferência de aprendizagem, por meio de atividades musicais comparadas a não musicais. Por fatores já citados no presente estudo, tal apontamento não é tão simples pois são escassos os estudos que utilizem um modelo de abordagem musical coerente ou que tenha um rigor científico dentro do estudo. Porém, ao pensarmos que a música é uma arte que se utiliza de uma linguagem. É linguagem, uma vez que utiliza um sistema de signos estabelecidos naturalmente ou por convenção, que transmite informações ou mensagens de um sistema (orgânico, social, sociológico) a outro, podemos afirmar que existem paralelos entre a linguagem verbal e a musical. Ambas dependem, do ponto de vista neurofuncional das estruturas sensoriais responsáveis pela recepção e pelo processamento auditivo (fonemas, sons), visual (grafemas da leitura verbal e musical), da integridade funcional das regiões envolvidas com atenção e memória e das estruturas eferentes motoras responsáveis pelo encadeamento e pela organização temporal e motora necessárias para a fala e para a execução musical (MUZKAT ET AL., 2000),

Existe uma associação entre a prática musical e o processamento cortical. Ao relacionarmos funções executivas, como a memória de trabalho, na codificação neural de sons 
complexos, na análise da prosódia e na consciência fonológica, especificamente em relação à linguagem (MORENO E BILDEMAN, 2014) percebemos que o treinamento musical é capaz de modificar circuitos de processamento de fala, com a chamada hipótese OPERA. A sigla refere-se a cinco aspectos fundamentais para que o treino musical induza a neuroplasticidade, influenciando em mecanismos relacionados à fala: Overlap, Precision, Emotion, Repetition e Attention (PATEL, 2011).

Overlap indica a sobreposição de redes neurais na codificação de características acústicas comuns à música e fala como, por exemplo, a frequência. Da mesma forma como acontece na aquisição da linguagem: ouvir, falar, pensar, ler e escrever, a aquisição da música se dá de maneira semelhante: ouvir, cantar, audiar, ler e escrever. O termo audiação é a base da aptidão musical e difere da audição interior e escuta. De acordo com a MLT, ela é o objetivo da aprendizagem musical. Essa teoria apresenta a música de acordo com uma estrutura sequencial de desenvolvimento, na qual os processos cognitivos-musicais são observados. Para Gordon, todo ser humano também nasce com uma aptidão musical inata, mas será o ambiente que também fará a diferença para que essa aptidão seja potencializada ou não (GORDON, 2003).

Precision indica que tanto na execução de tarefas musicais quanto na compreensão e produção de fala, é necessário que o indivíduo processe características acústicas. Por exemplo, entonação de sílabas e atingir a nota (altura) adequada. Para que a prática musical exerça influência na codificação neural da fala, é fundamental que a execução se imponha ao sistema nervoso, sendo maior que a compreensão. É importante ressaltar aqui a questão "voz de peito" e "voz de cabeça" para a população estudada. A voz de peito é a voz que sai naturalmente de nós, na nossa tessitura vocal. A voz de cabeça é o ajuste que fazemos para conseguir alcançar uma determinada altura, ou seja, afinar uma nota. Ao considerarmos a idade auditiva dos sujeitos aqui estudados, sabíamos que esse seria um fator determinante, pois conforme Gordon (2008) elenca os 3 tipos e 4 estágios da audiação preparatória, percebemos que as crianças do presente estudo estavam no segundo tipo e quarto estágio, que é quando uma criança tenta corrigir o som que está emitindo. Quando isso ocorre ela está saindo da etapa chamada de egocentrismo, é ali que a criança percebe suas dificuldades musicais, como não conseguir afinar. Essa é a etapa principal da audiação preparatória em relação a aspectos musicais.

Emotion indica a produção de emoções positivas, pois a emoção é uma função mental superior. Para Vygotsky a aprendizagem acontece quando essa interação existe com o objetivo de levar a criança para a transição de processos inferiores em superiores, ou seja, o interpsicológico se tornando intrapsicológico. Para Gordon o educador também tem esse papel, 
deve-se levar em consideração as vivências musicais que a criança já tem internalizada para atingir novas concepções e estruturas musicais. Portanto, a mediação do adulto é imprescindível para estimular a construção de estruturas sociais e mentais superiores, que serão a base para o desenvolvimento afetivo, cognitivo, psicológico, motor e social (TORMIN, 2018).

Repetition - A oportunidade de melhorar aptidões com a repetição. Mas, como e quando a aprendizagem acontece? Para Vygotsky depende do desenvolvimento das funções psíquicas, ou seja, o que a criança já alcançou (zona de desenvolvimento real- ZDR) e o que a criança ainda não alcançou (zona de desenvolvimento próximo - ZDP), mas é capaz de realizar através da mediação de alguém mais experiente. Portanto, o educador deve provocar ações que alcancem a ZDP, potencializando o processo de aprendizagem da criança (TORMIN, 2014). Gordon (2008) também defende que o educador deve ser um guia para ajudar a criança a desenvolver sua aptidão, considerando a etapa da aprendizagem musical em que a criança se encontra para poder potencializar e ajudá-la a atingir a próxima. Quanto mais cedo esse processo for iniciado e mediado pelo adulto, seja através de uma educação musical não estruturada ou estruturada, melhor serão as bases musicais que a criança irá formar.

Attention indica a atenção focada responsável pelo direcionamento e distribuição da energia mental dentro do cérebro. É esse controle de atenção que mantém a criança concentrada, permitindo que dê atenção exclusiva a uma determinada tarefa e ignore as distrações. Um aspecto muito importante em música é que, tanto em sua percepção como principalmente em sua produção, ela promove interações auditivo motoras no cérebro de quem escuta e de quem executa. São elas: Feedback - Capacidade do indivíduo de prever eventos. Ao perceber a regularidade rítmica da música (estímulo auditivo) e consegue prever e sincronizar o movimento dos pés com ela (resultado motor), e Feedfoward - Capacidade relacionada a quem faz música, pois realiza alterações no processo motor através da audição de um estímulo sonoro. Por exemplo, um violinista que toca uma nota sem a afinação estar precisa e consegue através do resultado sonoro alterar a posição dos dedos (MORREALE ET AL., 2018). Essa capacidade auditiva motora acontece por meio do neurodesenvolvimento, e cria condições favoráveis para promover a plasticidade em redes neurais que codificam características acústicas. Por esses fatores, podemos concluir que a estrutura de intervenção abordada no presente estudo induz a neuroplasticidade.

As habilidades perceptivas em crianças com IC vem sendo amplamente estudadas nos últimos anos. Habilidades musicais estão ligadas diretamente ao processamento auditivo de um indivíduo. Para Gfeller (2016), os benefícios do treino musical são baseados, em parte, na sobreposição de redes cerebrais que processam características acústicas importantes como a 
música e voz. Enquanto fala e música podem compartilhar as redes neurais, alguns estudos sugerem que ouvir ou fazer música pode ter benefícios particulares no desenvolvimento de processos eficientes e auditivos mais robustos. Os efeitos da música sobre o cérebro humano parece ser muito promissor e terapêutico em vários tipos de desordens e condições, incluindo implante coclear (DASTGHEIB ET AL., 2013).

A escolha da musicalização infantil (primeira etapa da educação musical) como procedimento de intervenção se deu pelo fato de que ela abrange os elementos básicos da música e trabalha fatores sensitivos, cognitivos, perceptivos, motores, sociais e de linguagem, por meio de uma abordagem lúdica (LOURO, 2012; BROOK, 2013) sendo as atividades estruturadas com base nos seguintes educadores musicais: Orff, que defende o aprendizado musical por meio de habilidades, onde qualquer um pode fazer música, Dalcroze, que ressalta a importância do movimento junto à música e Gordon.

Gordon é a base do procedimento de intervenção, pois é o único que desenvolveu uma teoria de ensino e aprendizagem musical por meio de uma abordagem diferenciada, que são as atividades de aprendizagem sequenciada (learning sequence activities). A base da MLT não é sobre como se ensinar música, mas como ela é aprendida. A partir dela o educador irá desenvolver a sua metodologia de ensino e atividades que irá utilizar em sala de aula.

A atividade musical mobiliza amplas áreas cerebrais, tanto as filogeneticamente mais novas, conhecidas como neocórtex, como os sistemas mais antigos e primitivos como o chamado cérebro reptiliano que envolve o cerebelo, áreas do tronco cerebral e a amígdala cerebral. O primeiro estágio é chamado senso-percepção musical, e se dá nas áreas de projeção localizadas no lobo temporal, aonde se encontra o córtex auditivo ou área auditiva primária responsável pela decodificação da altura, timbre e ritmo. Tal área conecta-se com o restante do cérebro em circuitos de ida e volta, com áreas da memória como o hipocampo que reconhece a familiaridade dos elementos temáticos e rítmicos, bem como com as áreas de regulação motora e emocional como o cerebelo e a amígdala, que atribuem um valor emocional à experiência sonora, e no núcleo accumbens, relacionado ao sentido de prazer e recompensa (MUZKAT, 2015).

Pode-se relacionar o primeiro estágio da senso-percepção musical (MUZKAT, 2015) com os estágios da aculturação, descritos por Gordon (2008). A interação do educador musical com a criança é fundamental para identificar qual etapa da Audiação Preparatória essa criança se encontra e, é a partir dessa relação que o educador poderá potencializar para que a criança se desenvolva para atingir os estágios seguintes. É durante a Audiação Preparatória que acontece 
o aprendizado por discriminação, ou seja, é nessa etapa que a criança irá adquirir "vocabulário musical" para, posteriormente, ser capaz de fazer inferências.

As crianças entraram no presente estudo no estágio 1 da audiação preparatória (aculturação), e saíram no estágio 4 (imitação), etapa na qual a criança está saindo do egocentrismo. O trabalho musical foi baseado no início de padrões tonais e rítmicos, reconhecimento e identificação do centro tonal e macropulso. Em virtude desses fatores nasce o seguinte questionamento, como uma criança que não tem a idade cronológica equivalente a auditiva e não ouve de forma acústica é capaz de fazer isso em tão pouco tempo?

A MLT é a única teoria musical existente que apresenta a música de forma estrutura e sequenciada, trabalhando o "todo - parte - todo". O todo pode ser comparado a frase. Ele é o contexto musical (melódico, rítmico, em qualquer tonalidade e métrica) apresentado a criança. A parte pode ser compara as palavras. São os conteúdos que são enfatizados do todo (padrões rítmicos ou melódicos). Sempre são trabalhados pelo menos três sons para que haja contexto melódico ou duas pulsações em qualquer métrica, para que haja contexto rítmico, e isso faça sentido para a criança. Ao retornar para o todo espera-se que as crianças sejam capazes de audiar as partes que foram expostas minuciosamente, fazendo com que o todo saia fluente.

Muitos usuários de IC consideram a compreensão da linguagem satisfatória, mas a percepção musical geralmente é considerada difícil. No entanto, a música contém diferentes dimensões que podem ser acessíveis de formas diferentes (BRUNS ET AL., 2016). Assim como a linguagem, a música possui elementos perceptivos organizados em sequências que são estruturadas hierarquicamente (PATEL, 2003). Semelhante à linguagem, a música também pode ser descrita como tendo uma sintaxe estruturada com gramática própria (LEROUSSEAU, 2020). Isso justifica a eficácia das abordagens musicais estruturadas. Ao apresentarmos uma abordagem musical para um indivíduo que nunca teve acesso ao aprendizado musical, deve-se pensar qual sentido aquilo irá fazer para ele. Inúmeras abordagens trabalham elementos musicais de forma "solta" e acabam não tendo um benefício cognitivo musical como quando trabalhado de forma estruturada.

A Tabela 11 nos aponta que a análise das aulas (gravação) que foi realizada por três educadores musicais (juízes) apontou diferença estatisticamente significante após o período de intervenção. Inúmeros são os fatores que fazem com que a musicalização apresente um resultado positivo, porém, no presente estudo, é possível corroborar que as melhoras das habilidades perceptivas, cognitivas e sociais apresentadas pelas crianças foram potencializadas. Em um primeiro momento por meio da organização e escolha das abordagens musicais (educadores: Orff, Dalcroze e Gordon) que iriam embasar o procedimento de intervenção para 
a população aqui estudada (IC). E em um segundo momento através da mediação do educador musical, do ambiente físico e interativo, das contingências estabelecidas e da interdisciplinaridade que embasa o procedimento das aulas de musicalização. Portanto as aulas de musicalização infantil, quando bem embasadas e estruturadas, além de serem musicalmente ricas e completas, acabam contribuindo para outros aspectos, como, o desenvolvimento perceptivo, cognitivo, social e emocional da criança, pois essa abordagem embasada na MLT permite o fazer musical ao vivo, além da interação direcionada e individualizada, através de uma estrutura sequenciada e coerente para o desenvolvimento da aquisição da linguagem musical e do desenvolvimento global da criança (FREIRE, 2005; TORMIN, 2015; LOPES, 2019).

Portanto, a MLT pode ser considerada como a única teoria musical existente que apresenta a música de forma estrutura e sequenciada, sendo assim, é possível corroborar que as melhoras, em níveis perceptivos, cognitivos e sociais apresentadas pelas crianças foram potencializadas através das aulas de musicalização. Portanto, as aulas que seguem a perspectiva da MLT, além de serem musicalmente ricas e completas, tendo em vista que a criança é exposta a diversas métricas e tonalidades, acabam contribuindo para outros aspectos do desenvolvimento cognitivo, social, emocional e afetivo da criança, pois essa teoria permite o fazer musical ao vivo, além da interação direcionada e individualizada, através de uma estrutura sequenciada e coerente para o desenvolvimento da aquisição da linguagem musical e do desenvolvimento global da criança (FREIRE, 2005; TORMIN, 2015; LOPES, 2019).

Com base no exposto, novos estudos podem ser conduzidos por meio da replicação metodológica ampliando dados e análises que permitam, cada vez mais, a prática do ensino musical baseado em evidências.

\section{CONCLUSÃO}

Considerando que o delineamento do estudo permitiu verificar, por meio de sondagens múltiplas, uma estabilidade nas linhas de base (pré-intervenção) e mudança somente durante e após a intervenção, há evidências que crianças usuárias de implante coclear expostas à Musicalização Infantil, apresentam melhora no repertório de habilidades cognitivas (funções executivas), sociais (responsabilidade, afetividade, cooperação, assertividade, desenvoltura social, civilidade, autocontrole, enfrentamento e participação), competência acadêmica bem como dos problemas de comportamento externalizantes, hiperatividade e dos níveis de bemestar e envolvimento. 


\section{REFERÊNCIAS}

Altenmüller, E. (2016). Music as a driver for brain plasticity. Clinical Neurophysiology, 127(3), e22.

Altenmüller, E., \& James, C. E. (2020). The impact of music interventions on motor rehabilitation following stroke in elderly. In Music and the Aging Brain (pp. 407-432). Academic Press.

Assis-Fernandes, R. P., \& Bolsoni-Silva, A. T. (2020). Habilidades Sociais Educativas e Repertório de Crianças Diferenciadas Por Comportamento e Sexo. Paidéia (Ribeirão Preto), 30.

Bashwiner, D., \& Bacon, D. (2020). Neuroscience: Music and the Brain.

Baum, W. (1999). Compreender o behaviorismo: ciência, comportamento e cultura. (M. T. A. Silva, Trad.) 2. ed. Porto Alegre: Artmed. (Trabalho original publicado em 1994).

Benetti, I. C., Gisard, E., \& da Silva, L. M. (2014). A percepção do professor sobre os efeitos da música no comportamento dos alunos. Estudos e Pesquisas em Psicologia, 14(2), 474-496.

Berta F. et Al. (2008). Executive Function and Language in Deaf Children, The Journal of Deaf Studies and Deaf Education, Volume 13 (3). Summer.362-377.

Bevilacqua, M. C., Martinez, M. A. N., Balen, S. A., Pupo, A. C., Reis, A. C. M. B., \& Frota, S. (2011). Tratado de audiologia. São Paulo: Santos, 49.

Bird, L. J., Jackson, G. D., \& Wilson, S. J. (2019). Music training is neuroprotective for verbal cognition in focal epilepsy. Brain, 142(7), 1973-1987.

Bedoin, N., Besombes, A. M., Escande, É., Dumont, A., Lalitte, P., \& Tillmann, B. (2018). Boosting syntax training with temporally regular musical primes in children with cochlear implants. Annals of Physical and Rehabilitation Medicine, 61(6), 365-371.

Brasil. (2014). Portaria GM/MS No 2.776, de 18 de dezembro de 2014 - Diretrizes gerais para a atenção especializada as pessoas com deficiência auditiva no sistema único de saúde (SUS): Ministério da Saúde. Secretaria de Atenção à Saúde.

Bruns, L., Mürbe, D., \& Hahne, A. (2016). Understanding music with cochlear implants. Scientific reports, 6, 32026.

Broock, A. M. V.(2013). Crianças na Universidade? Campinas, SP: Papirus. 142-166.

Casarotto, F. D., de Vargas, L. D. S., \& Mello-Carpes, P. B. (2017). Música e seus efeitos sobre o cérebro: uma abordagem da neurociência junto a escolares. Revista ELO-Diálogos em Extensão, 6(02).

Cason, N., Hidalgo, C., Isoard, F., Roman, S., \& Schön, D. (2015). Rhythmic priming enhances speech production abilities: Evidence from prelingually deaf children. Neuropsychology, 29(1), 102. 
Carvalho, F. A. H. (2011). Neurociências e educação: uma articulação necessária na formação docente. Trabalho, Educação e Saúde, 8(3), 537-550.

Dalla Bella, S. (2016). Music and brain plasticity. The Oxford handbook of music psychology, 325-342.

das Neves, A. J., Almeida-Verdu, A. C. M., do Nascimento Silva, L. T., \& Moret, A. L. M. (2019). Ensino baseado em equivalência e produção de sentenças em crianças com implante coclear. Revista Brasileira de Análise do Comportamento, 15(1).

Dastgheib, S. S., Riyassi, M., Anvari, M., Niknejad, H. T., Hoseini, M., Rajati, M., \& Ghasemi, M. M. (2013). Music training program: a method based on language development and principles of neuroscience to optimize speech and language skills in hearing-impaired children. Iranian journal of otorhinolaryngology, 25(71), 91.

De Almeida Silva, A. E. (2010). III encontro de educação musical da UNICAMP. Musicalização para Bebês: A importância da Educação Musical em Creches e Pré Escolas. Educação musical da UNICAMP.72-73.

Del Prette, Z. A. P. (2005). Sistema multimídia de habilidades sociais para crianças (SMHSCDEL-PRETTE) e Inventário multimídia de habilidades sociais para crianças (IMHSC-DELPRETTE).

Deus, A. C. D., \& Fava, D. C. (2019). Desenvolvendo civilidade e empatia na infância por meio da música. Revista Brasileira de Terapias Cognitivas, 15(2), 120-125.

Falcão, A. P., Bolsoni-Silva, A. T., Magri, N., \& Moretto, L. A. (2016). PROMOVECrianças: efeitos de um treino em habilidades sociais para crianças com problemas de comportamento. Estudos e Pesquisas em Psicologia, 16(2), 590-612.

Ferreira, E. F., \& Munster, M. D. A. V. (2017). Avaliação das Habilidades Sociais de Crianças com Deficiência Intelectual sob a Perspectiva dos Professores1. Revista Brasileira de Educação Especial, 23(1), 97-110.

França-Freitas, M. L. P. D., Prette, A. D., \& Del Prette, Z. A. (2017). Habilidades sociais e bem-estar subjetivo de crianças dotadas e talentosas. Psico-USF, 22(1), 1-12.

Ferrari, P. F., \& Coudé, G. (2018). Mirror neurons, embodied emotions, and empathy. In Neuronal correlates of empathy (pp. 67-77). Academic Press.

Freire, R. D. (2006). Contribuições de Bruner e Gagné para a Teoria da Aprendizagem Musical de Edwin Gordon. Anais do XVI Encontro Nacional da ANPPOM, 1.

Fuller, C. D., Galvin III, J. J., Maat, B., Başkent, D., \& Free, R. H. (2018). Comparison of two music training approaches on music and speech perception in cochlear implant users. Trends in hearing, 22, 2331216518765379. 
Gfeller, K. (2016). Music-based training for pediatric CI recipients: A systematic analysis of published studies. European Annals of Otorhinolaryngology, Head and Neck Diseases, 133, S50-S56.

Good, A., Gordon, K. A., Papsin, B. C., Nespoli, G., Hopyan, T., Peretz, I., \& Russo, F. A. (2017). Benefits of music training for perception of emotional speech prosody in deaf children with cochlear implants. Ear and Hearing, 38(4), 455.

Gordon E. (2000). Teoria da Aprendizagem Musical Para Recém Nascidos e Crianças em Idade Pré-Escolar. Lisboa: Fundação Calouste Gulbenkian.

Gordon, E. E. (2008). Teoria de aprendizagem musical para recém-nascidos e crianças em idade pré-escolar. Lisboa: Fundação Calouste Gulbenkian.

Gordon E. (2013). Quick and Easy Instroductions. Chigado: GIA Publications.

Gordon, R. L., Fehd, H. M., \& McCandliss, B. D. (2015). Does music training enhance literacy skills? A meta-analysis. Frontiers in psychology, 6, 1777.

Greer. R. D. \& Ross, D. E. (2004). Verbal behavior analysis: Research in the induction and expansion of complex verbal behavior. Journal of Early Intensive Behavioral Interventions, I. $2,141-165$

Gresham, F. M., \& Elliott, S. N. (1990). Social skills rating system: Manual. American Guidance Service.

Gresham, F. M., \& Elliott, S. N. (2016). Inventário de Habilidades sociais, problemas de comportamento e competência acadêmica para crianças: SSRS manual de aplicação, Apuração e Interpretação [DEL PRETTE, ZAP; FREITAS, LC; BANDEIRA, M.; DEL PRETTE, A. autores da adaptação e padronização brasileira].

Haslbeck, F. B., \& Bassler, D. (2018). Music from the very beginning-a neuroscience-based framework for music as therapy for preterm infants and their parents. Frontiers in Behavioral Neuroscience, 12, 112.

Hidalgo, C., Falk, S., \& Schön, D. (2017). Speak on time! Effects of a musical rhythmic training on children with hearing loss. Hearing research, 351, 11-18.

Iglehart, F. (2020). Speech Perception in Classroom Acoustics by Children With Hearing Loss and Wearing Hearing Aids. American Journal of Audiology, 29(1), 6-17.

Jacoby, N., Margulis, E. H., Clayton, M., Hannon, E., Honing, H., Iversen, J., ... \& Perlman, M. (2020). Cross-cultural work in music cognition: Challenges, insights, and recommendations. Music Perception, 37(3), 185-195.

Khalil, A., Minces, V. H., Iversen, J., Musacchia, G., Zhao, T. C., \& Chiba, A. A. (2019). Music, cognition and education. Developing Minds in the Digital Age, 167-176.

Ker, J., \& Nelson, S. (2019). The Effects of Musical Training on Brain Plasticity and Cognitive Processes. Jr Neuro Psych and Brain Res: JNPBR, 127. 
Kersten, L. (2017). Extended music cognition. Philosophical Psychology, 30(8), 1078-1103.

Kronenberger, W. G., Colson, B. G., Henning, S. C., \& Pisoni, D. B. (2014). Executive functioning and speech-language skills following long-term use of cochlear implants. Journal of deaf studies and deaf education, 19(4), 456-470.

Laevers, F. (2005). Well-being and Involvement in care settings. A process-oriented Selfevaluation Instrument (SIC's).

Leman, M., Maes, P. J., Nijs, L., \& Van Dyck, E. (2018). What is embodied music cognition?. In Springer handbook of systematic musicology (pp. 747-760). Springer, Berlin, Heidelberg.

Lerousseau, J., Hidalgo, C., \& Schön, D. (2020). Musical Training for Auditory Rehabilitation in Hearing Loss. Journal of Clinical Medicine, 9(4), 1058.

Linnavalli, T., Putkinen, V., Lipsanen, J., Huotilainen, M., \& Tervaniemi, M. (2018). Music playschool enhances children's linguistic skills. Scientific reports, 8(1), 1-10.

\section{Lopes, E., \& Montaña, J. D. L. (2019). PARA UNA DIDÁCTICA DE LA IMPROVISACIÓN Y CREATIVIDAD MUSICAL. MONTAÑA.}

Louro, V. (2012). Fundamentos da aprendizagem musical da pessoa com deficiência. São Paulo: Editora Som.

Matos, M. A. (1991). As categorias formais de comportamento verbal em Skinner. Anais da XXI Reunião Anual da Sociedade de Psicologia de Ribeirão Preto, Ribeirão Preto, São Paulo, Brasil, 333-341, Retirado em: < http://www.itcrcampinas.com.br/pdf/outros/as_categorias_formais_de_ comportamento_verbal.PDF>. (Acessado em $17 / 12 / 2013$ ).

Miu, A. C., \& Vuoskoski, J. (2017). The social side of music listening: Empathy and contagion in music-induced emotions. SEMPRE Studies in the Psychology of Music An Ashgate.

Monteiro, M. F. R. B., Acampora, B. I., \& Ferreira, S. (2019). A música como potencializadora das emoções e da aprendizagem: o viés da neurociência. Esta obra é licenciada por uma Licença Creative Commons: by-nc-nd. Direitos para esta edição cedidos à Pimenta Cultural pelo autor para esta obra. Qualquer parte ou a totalidade do conteúdo desta publicação pode ser reproduzida ou compartilhada. O conteúdo publicado é de inteira responsabilidade do autor, não representando a posição oficial da Pimenta Cultural., 154.

Moreno, S., \& Bidelman, G. M. (2014). Examining neural plasticity and cognitive benefit through the unique lens of musical training. Hearing research, 308, 84-97.

Morreale, F., Armitage, J., \& McPherson, A. (2018). Effect of instrument structure alterations on violin performance. Frontiers in psychology, 9, 2436.

Muszkat, M. ET AL. (2000). Música e neurociências. Rev Neurociências, v. 8(2). 70-75. 
Neves, M. A. P., \& Souza, V. L. T. D. (2018). Música e psicologia na escola: mobilizando afetos na classe de recuperação. Psicologia Escolar e Educacional, 22(1), 17-25.

Panaiotidi, E. (2018). Emotional Contagion and Music. Psychology. Journal of Higher School of Economics, 15(1), 145-163.

Patel, A. D. (2003). Language, music, syntax and the brain. Nature neuroscience, 6(7), 674681.

Patel, A. D. (2011). Why would musical training benefit the neural encoding of speech? The OPERA hypothesis. Frontiers in psychology, 2, 142.

Patscheke, H., Degé, F., \& Schwarzer, G. (2019). The effects of training in rhythm and pitch on phonological awareness in four-to six-year-old children. Psychology of Music, 47(3), 376391.

Raven, J.; Raven, J. C.; Court, J. H. (2018). CPM Raven - Matrizes Progressivas Coloridas de Raven - Manual. 1 ed. Pearson Clinical Brasil: São Paulo.

Reybrouck, M., Vuust, P., \& Brattico, E. (2018). Music and brain plasticity: how sounds trigger neurogenerative adaptations. Neuroplasticity: Insights of Neural Reorganization, 85103.

Reynolds, F. (2000). Managing depression through needlecraft creative activities: A qualitative study.

Rocha, M. M., \& Del Prette, Z. A. P. (2017). Habilidades sociais educativas para mães de crianças com TDAH e a inclusão escolar. Psicologia Argumento, 28(60).

Rochette, F., Moussard, A., \& Bigand, E. (2014). Music lessons improve auditory perceptual and cognitive performance in deaf children. Frontiers in human neuroscience, 8, 488.

Rodrigues, R. M. (2019). Música e emoção: um estudo exploratório sobre o estabelecimento de ralações condicionais com estímulos musicais em crianças usuárias de implante coclear.

Said, P. M., \& Abramides, D. V. M. (2019). Educação musical e habilidades sociais. Educação musical e habilidades sociais, 1-388.

Said, P. M., \& Abramides, D. V. M. (2020). Effect of music education on the promotion of school performance in children. In CoDAS (Vol. 32, No. 1). Sociedade Brasileira de Fonoaudiologia.

Salles, J. F. D., \& Paula, F. V. D. (2016). Compreensão da leitura textual e sua relação com as funções executivas. Educar em Revista, (62), 53-67.

Santana, M. D. F. D. (2017). As contribuições da música na educação infantil.

Schnakers, C., Magee, W. L., \& Harris, B. (2016). Sensory stimulation and music therapy programs for treating disorders of consciousness. Frontiers in Psychology, 7, 297. 
Schellenberg, E. G. (2019). Correlation= causation? Music training, psychology, and neuroscience. Psychology of Aesthetics, Creativity, and the Arts.

Silva, A. L. M., de Anchieta, M. H. M., Ferreira, M. A., \& Tavares, I. C. L. (2020). A relação entre comportamento social em adolescentes e música: uma revisão sistemática. Journal of Health \& Biological Sciences, 8(1), 1-7.

Silva Filho, J. H. D. (2007). Validade e normas do Wisconsin Card Sorting Test em adultos da região de Ribeirão Preto (Doctoral dissertation, Universidade de São Paulo).

Skinner, B. F. (1981). Selection by consequences. Science, 213(4507), 501-504

Swaminathan, S., Schellenberg, E. G., \& Khalil, S. (2017). Revisiting the association between music lessons and intelligence: Training effects or music aptitude?. Intelligence, 62, 119-124.

Swaminathan, S., \& Schellenberg, E. G. (2018). Music training and cognitive abilities: associations, causes, and consequences. The Oxford handbook of music and the brain. New York, NY: Oxford University Press. http://dx. doi.org/10.1093/oxfordhb/9780198804123.013, 26.

Teixeira, A. R., \& Garcez, V. R. C. (2011). Aparelho de amplificação sonora individual: componentes e características eletroacústicas. Bevilacqua MC, Martinez MAN, Balen AS, Pupo AC, Reis ACM, Frota S (organizadoras). Tratado de Audiologia. São Paulo: Santos.

Tormin, M. C. (2014). Dubabi Du: uma proposta de formação e intervenção musical na creche (Doctoral dissertation, Universidade de São Paulo).

Tormin, M. C., \& Kishimoto, T. M. (2018). Formação de professores e musicalização nas creches/Teacher training and musicalization in nurseries. Educação em Foco, 21(34), 147169.

Torppa, R., \& Huotilainen, M. (2019). Why and how music can be used to rehabilitate and develop speech and language skills in hearing-impaired children. Hearing research, 380, 108122.

Trehub, S. E., \& Weiss, M. W. (2017). Music Cognition: Developmental and Multimodal Perspectives. In The Routledge Companion to Music Cognition (pp. 403-414). Routledge.

Trimble, M., \& Hesdorffer, D. (2017). Music and the brain: the neuroscience of music and musical appreciation. BJPsych international, 14(2), 28-31.

Van Grol, L. D. S., \& Andretta, I. (2016). Habilidades Sociais e Variáveis Sociodemográfi cas em Crianças com Idade Escolar: Um Estudo Descritivo. Temas em Psicologia, 24(3), 11291138.

Verdu, A. C. M. A., \& Gomes, F. P. (2016). Precisão da fala em nomeação de figuras após formação de classes de equivalência em crianças com implante coclear. Perspectivas em análise do comportamento, 7(2), 274-287. 
Wazlawick, P. (2017). Vivências em contextos coletivos e singulares onde a música entra em ressonância com as emoções. Psicologia Argumento, 24(47), 73-83.

Yang, J., Liang, Q., Chen, H., Liu, Y., \& Xu, L. (2019). Singing Proficiency of Members of a Choir Formed by Prelingually Deafened Children With Cochlear Implants. Journal of Speech, Language, and Hearing Research, 62(5), 1561-1573.

Zhang, Y. (2018). Enlightenment on Vocal Music Classroom Teaching from the Perspective of Neuroscience. NeuroQuantology, 16(6).

Zhang, S. (2020). The Positive Influence of Music on the Human Brain. Journal of Behavioral and Brain Science, 10(1), 95-104.

Zhu, Y. (2018). Influence of Music Training on the Plasticity of the Brain. NeuroQuantology, 16(5). 


\section{ANEXOS}

\section{Anexo 1 - Diários das Aulas}

\section{$\underline{1^{\mathrm{a}} \text { AULA }}$}

Atividade interativa e de apreciação musical para pais, alunos e educadoras se conhecerem, estabelecerem regras e tirarem dúvidas.

- Presentes: Sujeito 1; Sujeito 2; Sujeito 3; Sujeito 4; Sujeito 5; Sujeito 6; Sujeito 7; Sujeito 8; Sujeito 9; Sujeito 10.

- Comentários: Os sujeitos estavam muito eufóricos e com dificuldade em se controlarem. Pais e educadoras tentaram controlar a situação, porém, as crianças presentaram bastante dificuldade em seguir as regras, ouvir sobre as atividades e se concentrarem.

\section{$\underline{2^{\mathrm{a}} \text { AULA }}$}

- Conteúdo:

$\checkmark$ Percussão corporal;

$\checkmark$ Duração das figuras de ritmo (semibreve/mínima pontuada/mínima/semínima; com referência de semibreve $=4$ );

$\checkmark$ Dança;

$\checkmark$ Improviso e criação de sons com o corpo.

- Atividades:

$\checkmark$ Apresentação da professora e alunos;

$\checkmark$ MÚSICA FUNGA ALAFIA (grupo/dupla);

$\checkmark$ Assinatura do nome com percussão corporal;

$\checkmark$ Palitos rítmicos (Dalcroze) - contagem 4, 3, 2 e 1 tempo; sempre batendo no 1 (movimento plástico);

$\checkmark$ Massagem em trem;

$\checkmark$ Música tchau;

$\checkmark$ Tchau.

- Presentes: Sujeito 1; Sujeito 2; Sujeito 3; Sujeito 4; Sujeito 5; Sujeito 6; Sujeito 7; Sujeito 8; Sujeito 10. 
- Comentários: Os meninos estavam muito eufóricos e apresentaram bastante dificuldade em seguir regras, ouvir sobre as atividades e controlar o corpo. Apresentaram também um comportamento desafiador perante as professoras, até mesmo porque a partir dessa aula não haveria mais a presença dos pais. Devido a isso, nenhuma proposta de aula foi feita. As meninas tentaram realizar as atividades, mas não conseguiram por causa do barulho. O Sujeito 1 foi o aluno que apresentou maior comportamento desafiador, contrariando todas as regras e pedidos das professoras e também por ter um perfil de liderança. Os Sujeitos 4, 5 e 6 seguiram o modelo do sujeito 1 que estava bastante incomodado com o barulho e optou em não participar.

\section{$\underline{3^{\mathrm{a}} \text { AULA }}$}

\section{- Conteúdo (idem aula 1)}

$\checkmark$ Percussão corporal;

$\checkmark$ Duração das figuras de ritmo (semibreve/mínima pontuada/mínima/semínima; com referência de semibreve $=4$ );

$\checkmark$ Dança;

$\checkmark$ Improviso e criação de sons com o corpo.

\section{- Atividades:}

$\checkmark$ Apresentação da professora e alunos;

$\checkmark$ MÚSICA FUNGA ALAFIA (grupo/dupla);

$\checkmark$ Assinatura do nome com percussão corporal;

$\checkmark$ Palitos rítmicos (Dalcroze) - contagem 4, 3, 2 e 1 tempo; sempre batendo no 1 (movimento plástico);

$\checkmark$ Massagem em trem;

$\checkmark$ Música tchau;

$\checkmark$ Tchau.

- Presentes: Sujeito 2; Sujeito 3; Sujeito 4; Sujeito 5; Sujeito 6; Sujeito 7; Sujeito 8.

- Comentários: Nessa aula as crianças entraram menos agitadas e conseguimos realizar a proposta da música Funga Alafia, tanto os meninos quanto as meninas se envolveram e os alunos 2, 4, 5, 6 e 8 tentaram cantar. Os alunos 3,5 e 7 também tentaram, mas apresentaram uma dificuldade maior na oralidade e também na coordenação motora para cantar/dançar. O Sujeito 2 apresenta uma musicalidade, oralidade e coordenação 
motora muito boas. $\mathrm{Na}$ atividade da assinatura de nome com percussão corporal as crianças ficaram bastante envolvidas, especialmente o Sujeito 7. Quando entregamos os palitos rítmicos o mesmo aluno quis tocar e cantar a música Pula Fogueira. Na atividade da duração das figuras de ritmo os sujeitos 6 e 7 apresentaram maior dificuldade para marcar a duração da figura, o sujeito 7 teve dificuldades em esperar para tocar o metalofone e conseguir esperar a sua vez. Todos os alunos tiveram dificuldades para tocar o metalofone nas durações de tempo solicitadas.

\section{$\underline{4^{\mathrm{a}} \mathrm{AULA}}$}

\section{- Conteúdo:}

$\checkmark$ Percussão corporal;

$\checkmark$ Duração das figuras de ritmo (semibreve/mínima pontuada/mínima/semínima; com referência de semibreve $=4$ );

$\checkmark$ Dança;

$\checkmark$ Improviso e criação de sons com o corpo.

\section{- Atividades:}

$\checkmark$ MÚSICA FUNGA ALAFIA (grupo/dupla);

$\checkmark$ Criar sequência utilizando palma/estalo/peito (percussão corporal) - Keith Terry;

$\checkmark 3$ Golpecitos:

- Movimentos fluidos e nos 3 golpecitos andar;

- Movimentos fluidos e golpear o palito 3x nos três últimos tempos do compasso.

$\checkmark$ Borboletinha:

- palma no final da frase;

- apenas bater palma no ritmo das palavras.

Escravos de Jó (passando saquinhos de psicomotricidade na pulsação);

Massagem em círculo com bolinha;

Música tchau;

Tchau.

- Presentes: Sujeito 1.; Sujeito 2; Sujeito 3; Sujeito 4; Sujeito 5; Sujeito 6; Sujeito 8; Sujeito 9. 
- Comentários: Começamos a aula com a música de integração Funga Alafia utilizando uma forma de dançar diferente. O sujeito 9 se mostrou bastante tímido e com difículdade de coordenação motora, porém se esforçou em fazer as atividades. Na segunda atividade, fizemos uma sequência rítmica utilizando percussão corporal para os alunos realizarem, posteriormente cada aluno criou a sua sequência, nessa atividade os alunos ficaram interessados e foram muito participativos, os sujeitos 4 e principalmente o 1 tiveram dificuldades para controlar o corpo e ficar no lugar, porém participaram. Na atividade dos 3 golpecitos eles conseguiram esperar o momento certo de fazer o estalo dos dedos marcando as 3 últimas semínimas, na repetição com os palitos rítmicos os sujeitos 4 e 6 tiveram mais dificuldade de concentração e controle, tocando muitas vezes nas 4 semínimas (macrotempo/pulsação). Na atividade "Escravós de Jó” as crianças passaram os saquinhos de psicomotricidade, mas sem manter a pulsação/macrotempo da música, o sujeito 2 cantou um pedaço da música sozinho utilizando a voz de cabeça e o sujeito 1 não seguiu as regras da atividade. A atividade "Borboletinha" trabalhou com o ritmo das palavras usando a percussão corporal, após cantarmos a música o sujeito 4 quis cantar sozinho, na última repetição fizemos andando, cantando e tocando a percussão corporal, as meninas realizaram a atividade, porém os meninos tiveram dificuldades em concentração e controle. O sujeito 1 continuou com o comportamento desafiador e de liderança na aula, mas, com menos intensidade. Todos participaram do relaxamento em círculo.

\section{$\underline{5^{\mathrm{a}} \text { AULA }}$}

\section{- Conteúdo:}

$\checkmark$ Percussão corporal;

$\checkmark$ Frase musical;

$\checkmark$ Macropulso;

$\checkmark$ Dança;

$\checkmark$ Escuta e apreciação musical;

$\checkmark$ Prática instrumental (xilofone).

\section{- Atividades:}

$\checkmark$ MÚSICA FUNGA ALAFIA;

$\checkmark$ MÚSICA THE LONGER THE FASTER;

$\checkmark$ MÚSICA PÓ DE CAFÉ; 
$\checkmark$ Massagem em círculo com a bolinha;

$\checkmark$ Música do Tchau.

- Presentes: Sujeito 1; Sujeito 2; Sujeito 4; Sujeito 6; Sujeito 7; Sujeito 8; Sujeito 9.

- Comentários: Começamos a aula com a música de integração Funga Alafia e todas as crianças participaram. Os Sujeitos 4 e 6 apresentaram uma melhora na coordenação motora entre dançar e tentar cantar. A educadora 2 dividiu a turma e pediu para os meninos cantarem e depois as meninas, os três meninos tentaram cantar e quem se destacou foi o sujeito 7, pois apresentou grande interesse. Apesar de eles ainda usarem a voz de peito (fala) (isso faz parte da etapa da imitação) demonstraram uma melhora. Já os sujeitos 2 e 8 apresentaram uma grande desenvoltura musical e usaram a voz de cabeça (cantar) na vez deles. Para mudar de atividade, os meninos já tiveram mais controle e sentaram, respeitando o momento de ouvir a música e as instruções, apenas o Sujeito 1 ficou mais ativo e teve maiores dificuldades em esperar a hora de pegar o instrumento, já os sujeitos 4, 6 e 7 observaram as professoras e tentaram imitar as instruções e movimentos da dança. Quando a segunda atividade iniciou, os alunos deveriam tocar no momento certo, então isso exigia um controle inibitório para realizar a atividade. As meninas demonstraram maior controle e conseguiram tocar nos momentos "certos". O sujeito 7 estava muito concentrado e, apesar de não tocar nos momentos "certos" estava marcando o macropulso da música corretamente. O sujeito 6, apesar de ainda não ter o controle e coordenação para realizar o movimento no momento "certo" tentou reproduzir os movimentos e manteve-se concentrado. $\mathrm{Na}$ continuação da atividade, agora com bolas, as meninas mantiveram-se concentradas e exploraram os movimentos propostos, o sujeito 8 conseguiu coordenar o corpo no macropulso e micropulso alterando pequenos saltos com o lançamento da bola. Já os meninos, especialmente os sujeitos 1 e 7 perderam a concentração e focaram mais em apenas explorar movimentos com a bola, sem muita correlação com a atividade proposta. $\mathrm{O}$ sujeito 1 manteve-se bem desconcentrado, além de tentar interferir no 7. $\mathrm{O}$ sujeito 6 manteve-se concentrado, apesar de ainda não conseguir coordenar o corpo com a proposta. Para a terceira atividade, o sujeito 1 continuou com o comportamento desafiador, mas logo sentou na roda para participar e ouvir as instruções. Durante a realização da atividade sentados, sujeitos 2 e 8 realizaram os movimentos com a mãos e marcaram o micropulso da música com o corpo (balanço lateral), os outrostambém fizeram, porém sem a marcação do corpo. Logo em seguida os alunos tiveram a 
oportunidade de tocar o xilofone, o sujeito 7 apresentou resistência em esperar a hora de tocar, pois queria ser o primeiro. Enquanto a educadora 1 tocava a melodia, os alunos deveriam tocar o outro xilofone marcando o micropulso (movimento simultâneo das duas mãos), todos os alunos apresentaram grande domínio na hora de tocar o xilofone e marcaram o micropulso. Durante o relaxamento todos ficaram deitados e aproveitaram o momento de escuta e apreciação musical. Mantiveram-se calmos e tranquilos, o sujeito 1 movimentou um pouco mais o corpo, mas conseguiu se controlar.

\section{$\underline{6^{\mathrm{a}} \text { AULA }}$}

\section{- Conteúdo:}

$\checkmark$ Percussão corporal;

$\checkmark$ Macropulso e micropulso;

$\checkmark$ Métrica doble;

$\checkmark$ Improviso (métrica doble);

$\checkmark$ Escuta e apreciação musical;

$\checkmark$ Prática instrumental (xilofone).

\section{- Atividades:}

$\checkmark$ MÚSICA FUNGA ALAFIA;

$\checkmark$ MÚSICA PÓ DE CAFÉ;

$\checkmark$ Massagem em círculo com a bolinha;

$\checkmark$ Música do Tchau.

- Presentes: Sujeito 2, Sujeito 3, Sujeito 6 e Sujeito 7.

Comentários: a aula começou com a música de integração "Funga Alafia" e o sujeito 2 cantou a música toda sozinho (ainda não houve o ajuste da voz de peito para a voz de cabeça totalmente), no segundo momento todos os sujeitos cantaram (usando voz de peito). Durante a primeira atividade com a música "Pó de café" os sujeitos ficaram concentrados e houve uma melhora do grupo em relação a coordenação motora, especialmente dos sujeitos 6 e 7. O sujeito 6 apresentou uma desenvoltura maior na hora de realizar a percussão corporal que foi apresentada na segunda parte da música. $\mathrm{Na}$ continuação da atividade as crianças ficaram com baquetas para praticar no tapete o micropulso em movimento simultâneo e alternado. O sujeito 7 apresentou frustração por ter que realizar a prática no tapete e não no instrumento, os sujeitos 2 e 3 conseguiram realizar os dois tipos de movimento. Em continuação, cada aluno ficou com um xilofone 
para realizar a prática instrumental e marcação do micropulso. Os sujeitos 6 e 7 apresentaram uma precisão muito boa na marcação, bem como os sujeitos 2 e 3 . O movimento alternado das baquetas foi mais desafiador para os sujeitos 6 e 7, mas eles se esforçaram para realizar. Já os sujeitos 2 e 3 apresentaram um ótimo domínio da coordenação. Na continuação da atividade as crianças deveriam tocar enquanto cantávamos para em momentos de solo realizar um improviso, o sujeito 2 manteve a métrica doble da música e repetiu o padrão rítmico cantado na frase "pó por pó" (duas colcheias e uma semínima), isso indica que esse padrão já estava internalizado. Os sujeitos 3 e 6 realizaram o improviso, mas sem sentido/contexto musical, já o sujeito 7 , criou um improviso utilizando palavras e o instrumento (sem correlação com a proposta). Nessa aula o foco foi a prática instrumental e ficamos boa parte dela nisso, os meninos demonstraram maior cansaço em ficar em apenas uma atividade, mas conseguiram manter a concentração dentro do esperado. Durante o relaxamos todos os alunos ficaram calmos e tranquilos, aproveitando o momento.

\section{$\underline{7^{\mathrm{a}} \text { AULA }}$}

\section{- Conteúdo:}

$\checkmark$ Dança;

$\checkmark$ Movimento fluido;

$\checkmark$ Macropulso e micropulso;

$\checkmark$ Métrica triple e doble;

$\checkmark$ Escuta e apreciação musical;

$\checkmark$ Percussão corporal.

- Atividades:

$\checkmark$ Funga Alafia

$\checkmark$ BETHENA (palitos de bambu)

$\checkmark$ MÚSICA PICA-PAU (Thiago de Lucca)

$\checkmark$ Música do Tchau

- Presentes: Sujeito 1.; Sujeito 2; Sujeito 4; Sujeito 5; Sujeito 6; Sujeito 7; Sujeito 8.

- Comentários: O sujeito 7 se lembrou da música "pó de café" trabalhada na aula anterior e começou a cantar (com voz de peito). Na música de integração "Funga Alafia" o sujeito 1 ainda apresentou um comportamento mais desafiador ficando deitado no chão, o sujeito 7 quis copiar, mas logo entrou na roda, durante essa atividade apenas o sujeito 
1 não cantou e dançou. Na preparação para a segunda atividade o sujeito 7 cantou mais uma vez um trecho da música "pó de café”. Durante a escuta e apreciação da atividade com a música "Bethena" os alunos ficaram sentados, apenas o sujeito 7, demonstrando frustração, ficou deitado. O sujeito 2 conseguiu marcar com movimentos fluidos o macropulso e explorou bastante a plasticidade do movimento. Os outros também marcaram com o balanço do corpo e braços os macropulso. Logos após as professoras precisaram conversar com os alunos sobre o comportamento pois alguns alunos estavam mais agitados, depois da conversa o comportamento melhorou. Durante a entrega dos palitos rítmicos o sujeito 7 teve um pouco de dificuldade em esperar sua vez e ficou tentando pegar. No primeiro momento foi pedido a marcação do macropulso com os palitos, todos os alunos conseguiram realizar, apesar de ser um movimento mais longo e difícil de controlar. O sujeito 2 apresentou bastante desenvoltura para realizar essa atividade. Na marcação do micropulso o mesmo sujeito também conseguiu coordenar. O sujeito 6 e apresentou uma melhora na coordenação motora e conseguiu realizar os movimentos do micropulso. Os sujeitos 2 , 4 e 5 também conseguiram controlar. $\mathrm{O}$ Sujeito 1 não demonstrou muito interesse e ficou brincando com os palitos rítmicos. Após o término dessa atividade a educadora 2 precisou retirar o sujeito 1 da sala para conversar devido ao comportamento. Na última atividade foi explorado o movimento corporal junto com o ritmo da palavra, os sujeitos 2 e 5, bem como os 4 e 6 participaram e realizaram os movimentos. Nessa aula não houve relaxamento.

\section{$\underline{8^{\mathrm{a}} \text { AULA }}$}

\section{- Conteúdo:}

$\checkmark$ Dança;

$\checkmark$ Movimento fluido;

$\checkmark$ Movimento locomotor;

$\checkmark$ Macropulso;

$\checkmark$ Métrica triple;

$\checkmark$ Escuta e apreciação musical;

\section{- Atividades:}

$\checkmark$ MÚSICA FUNGA ALAFIA (grupo/dupla);

$\checkmark$ Preparação da atividade com música "espacial" para imaginar que estamos andando na lua;

$\checkmark$ MÚSICA “Astronautas” 
$\checkmark$ Massagem

- Presentes: Sujeito 1; Sujeito 2 e Sujeito 6.

- Comentários: A primeira proposta da atividade explorou o movimento locomotor fluido e em tempo lento para imaginar que estávamos no espaço. Os três sujeitos demonstraram grande controle do corpo para realizar o movimento com todas as características. Na segunda proposta os alunos utilizaram a bexiga para marcar o macropulso da métrica ternária (mínima pontuada), o sujeito 2 conseguiu coordenar o corpo e lançamento da bexiga nos macros, o sujeito 6 conseguiu um movimento quase preciso, ele tem apresentado uma melhora na coordenação e percepção ao longo das aulas. O sujeito 1, apesar de perder o foco algumas vezes, também conseguiu fazer a marcação do macropulso. Na terceira proposta, com o parachute, os sujeitos 1 e 6 acabaram perdendo a concentração e não conseguiram marcar o macropulos, porém o sujeito 2 tentou fazer essa marcação. Na quarta proposta, com as lanternas, os sujeitos 2 e 6 conseguiram marcar o macropulso, tampando e tirando a mão da lanterna. No relaxamento os alunos foram alternando para realizar a massagem nos colegas, o sujeito 1 demonstrou grande habilidade em fazer massagem. No final, a educadora 1 ganhou até um penteado feito pelos alunos, rs.

\section{9a AULA}

\section{- Conteúdo:}

$\checkmark$ Dança;

$\checkmark$ Movimento fluido;

$\checkmark$ Movimento locomotor;

$\checkmark$ Macropulso;

$\checkmark$ Métrica triple;

$\checkmark$ Escuta e apreciação musical;

\section{- Atividades:}

$\checkmark$ Música funga alafia (grupo/dupla);

$\checkmark$ Preparação da atividade para conversar com a criança sobre quais são os membros de uma família; explorar como esses membros da família andariam;

\section{$\checkmark$ MÚSICA "FAMÍLIA" (ANA QUILEZ)}

- escuta ativa da peça para identificar os membro da família;

- caminhar de acordo com o ritmo que representa cada membro da família;

- tocar os palitos rítmicos de acordo com o ritmo; 
- separar as crianças em duplas e/ou grupos para criarem movimentos com objetos para representar cada membro da família.

$\checkmark$ Massagem

- Presentes: Sujeito 1 e Sujeito 2.

- Comentários: a aula iniciou com a música de integração "Funga Alafia" utilizando percussão corporal. Os sujeitos apresentaram concentração e coordenação para realizar a proposta. Durante a contextualização da música "Família" o sujeito 1 foi bem comunicativo e participativo, deu vários exemplos de integrantes da família. Durante a apreciação da música "família” o sujeito 1 demonstrou através de movimentos corporais todas as durações das figuras de ritmo que representam cada membro da família, além de marcar com corpo ou macro ou micropulso. Para realizar a segunda proposta da atividade os sujeitos utilizaram os palitos rítmicos para tocar essas mudanças, o sujeito 2 conseguiu tocar as 4 variações rítmicas apresentadas na música. Apesar do sujeito 1 não ter tocado os palitos, ele representou essas variações com movimentos corporais. $\mathrm{Na}$ terceira proposta cada aluno e cada educadora ficou com um material alternativo para explorar movimentos de acordo com cada membro da família que estava representando: educadora 2 - crianças / sujeito 2 - pai e mãe / educadora 1 - avós / sujeito 1 - cachorro. Os sujeitos demonstraram grande criatividade e desenvoltura para representar os papéis e movimentos de cada personagem. Na quarta proposta os sujeitos exploraram o bambolê como material alternativo para fazer as marcações rítmicas de cada personagem. O sujeito 2 explorou e conseguiu realizar as propostas, já o sujeito 1 perdeu a concentração com material e não explorou tanto. No relaxamento os sujeitos ficaram tranquilos e calmos, o sujeito 1 foi solícito ao realizar a massagem.

\section{$10^{\mathrm{a}}$ AULA}

\section{- Conteúdo:}

$\checkmark$ Dança;

$\checkmark$ Movimento fluido;

$\checkmark$ Movimento locomotor;

$\checkmark$ Macropulso;

$\checkmark$ Métrica doble;

$\checkmark$ Escuta e apreciação musical;

\section{- Atividades:}

$\checkmark$ Música funga alafia (grupo/dupla); 
$\checkmark$ Preparação da atividade para explicar que a música imita o movimento dos sinos (explorar o movimento de pêndulo em pé, deitado, em duplas etc.)

$\checkmark$ MÚSICA “LOS CAMPANEROS” (ANA QUILEZ)

$\checkmark$ Massagem

- Presentes: Sujeito 2; Sujeito 3; Sujeito 6 e Sujeito 7.

- Comentários: na música de interação "funga alafia" o sujeito 2 lembrou da música e cantou um trecho sozinha, além disso, os quatro alunos apresentaram bastante desenvoltura para coordenar canto e dança, ouve uma melhora significativa em relação aos sujeitos 6 e 7. Na primeira atividade com a música "los campaneros" foi feita a escuta ativa sentados em roda, os sujeitos 2 e 3 marcaram o macropulso no joelho e os 6 e 7, que no início do semestre apresentaram maior dificuldades para sentir essa pulsação, conseguiram marcar o macropulso de forma fluida e solta. Em uma outra proposta com a mesma música as educadoras começaram a cantar a melodia em PAM e as crianças acompanharam, apenas o sujeito 6 não cantou, o sujeito 7 apresentou bastante segurança em cantar a linha melódica da música. Na proposta com os palitos rítmicos todos marcaram o macropulso e o mesmo aconteceu na proposta com leques. Durante a prática instrumental os alunos também apresentaram uma melhora no domínio da qualidade do som extraída do instrumento além de uma ótima coordenação motora e corporal para tocar o macropulso.

\section{$\underline{11^{\mathrm{a}} \text { AULA }}$}

- Conteúdo:

$\checkmark$ Dança;

$\checkmark$ Movimento fluido;

$\checkmark$ Percussão corporal;

$\checkmark$ Macropulso;

$\checkmark$ Métrica triple;

$\checkmark$ Escuta e apreciação musical;

- Atividades:

$\checkmark$ Música funga alafia (grupo/dupla); 
$\checkmark$ Preparação da atividade para explicar que vamos brincar de esquimós, explorar onde os esquimós vivem, qual o ambiente, como é o estilo de vida, etc.

$\checkmark$ MÚSICA “LOS ESQUIMALES” (ANA QUILEZ)

$\checkmark$ Massagem

$\checkmark$ Música do Tchau

- Presentes: Sujeito 1; Sujeito 4; Sujeito 5, Sujeito 6; Sujeito 7.

- Comentários: na música de interação "funga alafia" todos os sujeitos participaram e cantaram, além de coordenar a dança com o canto. Assim que a música de integração terminou, todos os alunos, com exceção do sujeito 1, sentaram no chão para aguardar as instruções da atividade, inclusive o sujeito 7 pediu para o 1 se sentar. $\mathrm{Na}$ contextualização da primeira atividade com a música "esquimós" os alunos ficaram muito atentos e foram extremamente participativos e fizeram vários comentários, além disso, durante a escuta ativa da peça ficaram atentos e concentrados. Durante a primeira proposta da música com percussão corporal, mesmo sendo uma sequência mais complexa os sujeitos 4,5 e 6 fizeram e tentaram, os movimentos foram fluidos e a conseguiram reproduzir a duração da última figura de ritmo da frase corretamente (mínima pontuada), os sujeitos 1 e 7 não fizeram. A segunda proposta foi feita com a bexiga e os alunos perderam a concentração e não conseguiram explorar tanto o macropulso com esse objeto, depois cada aluno teve a oportunidade de explorar os movimentos da bexiga em pé. A terceira proposta com a prática instrumental dos xilofones e foi dividida em duplas para marcar o macro ou micropulso da métrica triple, a dupla 1 e 5 apresentaram um pouco de dificuldades para marcar o macro e micro, a dupla educadora 2 e sujeito 4 conseguiu marcar o micropulso em alguns trechos da música, a dupla sujeito 6 e 7 também apresentou mais dificuldade para marcar o macro e micropulso.

\section{$\underline{12^{\mathrm{a}} \text { AULA }}$}

\section{- Conteúdo:}

$\checkmark$ Dança;

$\checkmark$ Movimento fluido;

$\checkmark$ Percussão corporal;

$\checkmark$ Macropulso; 
$\checkmark$ Métrica doble;

$\checkmark$ Escuta e apreciação musical;

\section{- Atividades:}

\section{MÚSICA "BIM BAM"}

1. Cantar a música com os alunos fazendo a percussão corporal em roda;

2. Repetir a atividade de percussão em duplas;

3. Tocar com os palitos rítmicos, seção A macrotempo e seção B microtempo - padrão aculturação aculturação.

4. Instrumental Orff: tocar a tônica e quinta enquanto cantamos - padrão

\section{$\checkmark$ Massagem \\ $\checkmark$ Música do Tchau}

- Presentes: Sujeito 2; Sujeito 4; Sujeito 5 e Sujeito 6

- Comentários: na música de interação "funga alafia" os sujeitos 4, 5 e 6 cantaram e realizaram a percussão corporal. Na primeira atividade com a música "Bim Bam" enquanto as educadoras cantavam para apresentar a música para os alunos, eles tentaram cantar junto, o sujeito 5 tentou algumas explorações de vocalizações (balbucios), durante a escuta o sujeito 4 apresentou bastante movimento corporal fluido, o 5. também se movimentou durante a escuta. Na primeira sequência de padrão tonal tipo 1 (grau conjunto) o sujeito 4 reproduziu todos, logo depois o sujeito 2 também imitou os padrões, ao retornar com a música toda e movimentos fluidos todos os alunos cantaram a música, no segundo momento de padrão tonal, foi feito do tipo 2 (arpejo de tônica) e os 3 alunos repetiram e cantaram. Na segunda repetição da música a educadora 2 cantou os padrões tonais tipo 1, os sujeitos 4, 5 e 6 . cantaram o padrão. A próxima proposta, ainda com a mesma música, foi através da prática instrumental com os xilofones, as crianças tocaram e podiam marcar o macro ou micropulso, todos os alunos em alguns trechos conseguiram marcar o micropulso, além disso, na hora de cantar os padrões tonais tipo 1 , todos cantaram. 


\section{$13^{\mathrm{a}}$ AULA}

Atividade interativa de encerramento do semestre para os pais. Alunos e educadoras fizeram uma apresentação musical com xilofones e depois atividades musicais com os pais.

- Presentes: Sujeito 1; Sujeito 2; Sujeito 3; Sujeito 4; Sujeito 6; Sujeito 7.

Conclusão: De forma geral as educadoras observaram que os alunos apresentaram uma melhora e evolução nas práticas e vivências musicais. Ao término do semestre eles estavam com uma maior desenvoltura de movimentos e um maior domínio corporal. Além disso, ao longo do semestre os alunos começaram a cantar mais e tentar explorar essa possibilidade, tanto que no final do semestre começaram a cantar os padrões melódicos. As educadoras também observaram uma maior facilidade para marcar o macro e micro pulso das músicas com métrica doble, pois são mais frequentes na cultura brasileira, ou seja, os alunos provavelmente estão mais aculturados com essa métrica se comparado a métrica triple. Ademais, em relação ao comportamento, todos os alunos apresentaram melhoras sobre seguir as regras estabelecidas da atividade, esperar a sua vez de utilizar um material ou instrumento e mostraram-se mais envolvidos com as propostas. 
5 Conclusões 



\section{CONCLUSÕES}

Crianças usuárias de implante coclear expostas à Musicalização Infantil, apresentaram melhora somente após o procedimento de intervenção. A melhora pode ser percebida de forma estatisticamente significante após as avaliações finais (terceira e quarta avaliação) no repertório de habilidades cognitivas (funções executivas e inteligência geral), sociais (responsabilidade, afetividade, cooperação, assertividade, desenvoltura social, civilidade, autocontrole, enfrentamento e participação), competência acadêmica bem como dos problemas de comportamento externalizantes, hiperatividade do bem-estar e envolvimento.

Sendo assim, concluímos que a estrutura da intervenção para a identificação dos elementos componentes, incluindo a mediação do educador musical, a organização da abordagem musical, do ambiente físico e interativo, os tipos e qualidade dos estímulos e as contigência estabelecidas, são fatores primordiais para que a musicalização infantil tenha um resultado positivo.

Não houve correlações negativas entre a musicalização infantil e habilidades perceptivas, cognitivas e sociais. 



\section{Referências}





\section{REFERÊNCIAS}

Aguiar, A. A. R. D. (2006). Construção e avaliação de um programa multimodal de habilidades comunicativas para a adultos com deficiência mental.

Ahissar M., Nahum M., Nelken I., Hochstein S. (2009). Reverse hierarchies and sensory learning. Philos. Trans. R. Soc. Lond. B Biol. Sci. 364, 28529910.1098/rstb.2008.0253

Akeroyd MA. Are individual differences in speech reception related to individual differences in cognitive ability? A survey of twenty experimental studies with normal and hearingimpaired adults. Int J Audiol. 2008;47(SUPPL. 2).

Araújo, S. R. S. D., Vieira, S. D. S., Salvato, C. D. C., Soares, A. D., \& Chiari, B. M. (2018). Caracterização da percepção musical em usuários de implante coclear. AudiologyCommunication Research, 23.

Areias, J. C. (2016). A música, a saúde e o bem estar. Nascer e Crescer, 25(1), 7-10.

Banai K., Hornikel J., Skoe E., Nicol T., Zecker S., Kraus N. (2009). Reading and subcortical auditory function. Cereb. Cortex 19, 2699-270710.1093/cercor/bhp024

Belochio, C. R. (2003). Formação de professores e educação musical: a construção de dois projetos colaborativos. Educação (UFSM), 28(2), 37-46.

Bevilacqua, M. C., \& Formigoni, G. M. P. (2003). Audiologia educacional: uma opção terapêutica para a criança deficiente auditiva. Pró-fono.

Bevilacqua, M. C., Martinez, M. A. N., Balen, S. A., Pupo, A. C., Reis, A. C. M. B., \& Frota, S. (2011). Tratado de audiologia. São Paulo: Santos, 49.

Bevilacqua, M. C., Moret, A. L. M., \& Costa, O. A. (2011). Conceituação e indicação do implante coclear. Tratado de audiologia, 408-425.

Bird, L. J., Jackson, G. D., \& Wilson, S. J. (2019). Music training is neuroprotective for verbal cognition in focal epilepsy. Brain, 142(7), 1973-1987.

BRASIL. (1998). Referencial Curricular De Educação Infantil. v. 3. 
BRASIL. (2010). Ministério da Educação. Secretaria de Educação Básica. Diretrizes curriculares nacionais para a educação infantil. Secretaria de Educação Básica. Brasília: MEC, SEB.

Bréscia, V. L. P. (2003). Educação Musical: bases psicológicas e ação preventiva. São Paulo: Átomo, 18-9.

Broock, A. M. V. (2013). Crianças na Universidade? Campinas, SP: Papirus. 142-166.

Caballo, V. E. (2009). Manual para la evaluación clínica de los trastornos psicológicos: trastornos de la edad adulta e informes psicológicos/dir. Vicente E. Caballo. Madrid: Pirámide, 2006.

Calamia, M.; Markon, K.; Tranel, D. (2012). Scoring Higher the Second Time Around: MetaAnalyses of Practice Effects in Neuropsychological Assessment. The Clinical Neuropsychologist, 26:4, 543-570.

Campos, P. D., Alvarenga, K. D. F., Frederigue, N. B., Nascimento, L. T. D., Sameshima, K., Costa Filho, O. A., \& Bevilacqua, M. C. (2008). Habilidades de ordenação temporal em usuários de implante coclear multicanal. Revista Brasileira de Otorrinolaringologia, 74(6), 884-889.

Carmona, C. G. H., \& Melo, N. A. (1999). Comunicación interpersonal: programa de entrenamiento en habilidades sociales. Alfaomega.

Carvalho, F. A. H. (2011). Neurociências e educação: uma articulação necessária na formação docente. Trabalho, Educação e Saúde, 8(3), 537-550.

Chandrasekaran B., Kraus N. (2010). The scalp-recorded brainstem response to speech: neural origins and plasticity. Psychophysiology 47, 236-24610.1111/j.1469-8986.2009.00928.

Ching, T. Y. (2015). Is early intervention effective in improving spoken language outcomes of children with congenital hearing loss?. American journal of audiology, 24(3), 345-348.

Cosenza, R., \& Guerra, L. (2009). Neurociência e educação. Artmed Editora.

Costa-Giomi, E. (2001). Los beneficios extramusicales del aprendizaje del piano. $3^{\circ}$ Encontro Latino-Americano de Educação Musical (ISME-SADEM), 8-9.

Dastgheib, S. S., Riyassi, M., Anvari, M., Niknejad, H. T., Hoseini, M., Rajati, M., \& Ghasemi, M. M. (2013). Music training program: a method based on language development 
and principles of neuroscience to optimize speech and language skills in hearing-impaired children. Iranian journal of otorhinolaryngology, 25(71), 91.

De Almeida Silva, A. E. (2010). III encontro de educação musical da UNICAMP. Musicalização para Bebês: A importância da Educação Musical em Creches e Pré Escolas. Educação musical da UNICAMP.72-73.

Del Prette, A. D., \& Del Prette Zilda, A. P. (2004). Psicologia das relações interpessoais: vivências para o trabalho em grupo. In Psicologia das relações interpessoais: vivências para o trabalho em grupo (pp. 231-231).

Del Prette, A., \& Del Prette, Z. A. (2017). Psicologia das habilidades sociais na infância: teoria e prática. Editora Vozes Limitada.

Del Prette, A., \& Del Prette, Z. A. (2017). Psicologia das habilidades sociais na infância: teoria e prática. Editora Vozes Limitada.

Del Prette, A., \& Del Prette, Z. A. P. (2006). Habilidades sociais: conceitos e campo teóricoprático. Acedido em http://www. rihs. ufscar. br.

Del Prette, Z. A., \& Del Prette, A. (1999). Psicologia das habilidades sociais: terapia e educação. Vozes.

Dror, A. A., \& Avraham, K. B. (2009). Hearing loss: mechanisms revealed by genetics and cell biology. Annual review of genetics, 43, 411-437.

Dryden A, Allen HA, Henshaw H. The Association Between Cognitive Performance and Speech-in-Noise Perception for

Eugênio, M. L., Escalda, J., \& Lemos, S. M. A. (2012). Desenvolvimento cognitivo, auditivo e linguístico em crianças expostas à música: produção de conhecimento nacional e internacional. Revista CEFAC, 14(5), 992-1003.

Fernandes, E., \& Rizzo, S. C. (2018). Neurociência e os Benefícios da Música para o Desenvolvimento Cerebral e a Educação Escolar. Revista de Pós-graduação Multidisciplinar, 1(5), 13-20.

Ferreira, A. B. D. H. (2004). Novo dicionário Aurélio da língua portuguesa. In Novo dicionário Aurélio da língua portuguesa (pp. 2012-2012).

Figueiredo, S. L. F. (2012). A educação musical do século XX: os métodos 
tradicionais. MINISTÉRIO DA CULTURA E VALE APRESENTAM, 85.

Fonoaudiologia, C. F. (2017). Sistema de Conselhos Federal e Regionais de Fonoaudiologia. Guia de orientações na avaliação audiológica básica. Brasília: CFFA.

Fortunato, C. A. D. U., Bevilacqua, M. C., \& Costa, M. D. P. R. D. (2009). Análise comparativa da linguagem oral de crianças ouvintes e surdas usuárias de implante coclear. Revista CEFAC, 11(4), 662-672.

Freire, R. D. (2006). Contribuições de Bruner e Gagné para a Teoria da Aprendizagem Musical de Edwin Gordon. Anais do XVI Encontro Nacional da ANPPOM, 1.

Gfeller, K. (2016). Music-based training for pediatric CI recipients: A systematic analysis of published studies. European Annals of Otorhinolaryngology, Head and Neck Diseases, 133, S50-S56.

Gfeller, K., \& Lansing, C. (1992). Musical perception of cochlear implant users as measured by the Primary Measures of Music Audiation: an item analysis. Journal of Music Therapy, 29(1), 18-39.

Gfeller, K., Witt, S., Stordahl, J., Mehr, M., \& Woodworth, G. (2000). The effects of training on melody recognition and appraisal by adult cochlear implant recipients. Journal of the Academy of Rehabilitative Audiology.

Gordon E. (2000). Teoria da Aprendizagem Musical Para Recém Nascidos e Crianças em Idade Pré-Escolar. Lisboa: Fundação Calouste Gulbenkian.

Gordon E. (2013). Quick and Easy Instroductions. Chigado: GIA Publications.

Gordon, E. E. (2008). Teoria de aprendizagem musical para recém-nascidos e crianças em idade pré-escolar. Lisboa: Fundação Calouste Gulbenkian.

Gordon, R. L., Fehd, H. M., \& McCandliss, B. D. (2015). Does music training enhance literacy skills? A meta-analysis. Frontiers in psychology, 6, 1777.

Gresham, F. M. (2009). Análise do comportamento aplicada às habilidades sociais. Psicologia das habilidades sociais: Diversidade teórica e suas implicações, 17-66.

Gresham, F. M., \& Elliott, S. N. (1990). Social skills rating system: Manual. American Guidance Service. 
Gresham, F. M., Sugai, G., \& Horner, R. H. (2001). Interpreting outcomes of social skills training for students with high-incidence disabilities. Exceptional children, 67(3), 331-344.

Gross, A.L. et al. (2016). Predictors of retest effects in a longitudinal study cognitive aging in a diverse community-based sample. J Int Neuropsychol Soc. 1-28.

Jacoby, N., Margulis, E. H., Clayton, M., Hannon, E., Honing, H., Iversen, J., ... \& Perlman, M. (2020). Cross-cultural work in music cognition: Challenges, insights, and recommendations. Music Perception, 37(3), 185-195.

Jaques-Dalcroze, E. (1930) Eurhythmics, Art, and Education, ed. C. Cox, trans. F. Rothwell. North Stratford, NH: Ayer

Jaques-Dalcroze, E. (1967). Rhythm, Music, and Education, rev. edn, trans. H.F. Rubenstein. London: The Dalcroze Society

Khalil, A., Minces, V. H., Iversen, J., Musacchia, G., Zhao, T. C., \& Chiba, A. A. (2019). Music, cognition and education. Developing Minds in the Digital Age, 167-176.

Koelsch, S. \& Siebel, W. (2005). Towards a neural basis of music perception. Trends in Cognitive Sciences, 9(12): 578-584.

Koelsch, S. (2005). Neural substrates of processing syntax and semantics in music. Current Opinion in Neurobiology, 15(2): 207-212.

Kraus N., Chandrasekaran B. (2010). Music training for the development of auditory skills. Nat. Rev. Neurosci. 11, 599-60510.1038/nrm2968.

Lent, R. W. (2005). A Social Cognitive View of Career Development and Counseling.

Levitin, D. J. (2010). A música no seu cérebro: a ciência de uma obsessão humana. Rio de Janeiro: Civilização Brasileira.

linguagem em crianças deficientes auditivas pré-linguais. Pró-Fono Revista de Atualização Científica, 19(3), 295-304.

Linnavalli, T., Putkinen, V., Lipsanen, J., Huotilainen, M., \& Tervaniemi, M. (2018). Music playschool enhances children's linguistic skills. Scientific reports, 8(1), 1-10.

Lopes, R. M. F., Bastos, A. S., \& de Lima Argimon, I. I. (2017). Treino Das Funções Executivas em Idosos: Uma Revisão Sistemática da Literatura. Cuadernos De Psicologia. 
Louro, V. (2012). Fundamentos da aprendizagem musical da pessoa com deficiência. São

Martins, P. D. N. (2014). Efeito da educação musical na promoção das habilidades sociais e escolares em crianças (Doctoral dissertation, Universidade de São Paulo).

Mithen, S., Morley, I., Wray, A., Tallerman, M., \& Gamble, C. (2006). The Singing Neanderthals: the Origins of Music, Language, Mind and Body, by Steven Mithen. London: Weidenfeld \& Nicholson, 2005. ISBN 0-297-64317-7 hardback£ 20 \& US \$25.2; ix +374 pp. Cambridge Archaeological Journal, 16(1), 97-112.

Moreno, S., \& Bidelman, G. M. (2014). Examining neural plasticity and cognitive benefit through the unique lens of musical training. Hearing research, 308, 84-97.

Moret, A. L. M., Bevilacqua, M. C., \& Costa, O. A. (2007). Implante coclear: audição e

Murta, S. G. (2005). Aplicações do treinamento em habilidades sociais: análise da produção nacional. Psicologia: Reflexão e crítica, 18(2), 283-291.

Murta, S. G., Del Prette, A., Nunes, F. C., \& Del Prette, Z. A. P. (2007). Problemas en la adolescencia: contribuciones del entrenamiento en habilidades sociales. Manual de intervención psicológica para adolescentes: Ámbito de la salud y educativo, 2.

Muszkat, M. ET AL. (2000). Música e neurociências. Rev Neurociências, v. 8(2). 70-75.

Muszkat, M., \& Cardoso, T. S. G. (2016). Neuroplasticidade e intervenções precoces. JF Salles, VG Haase, \& LF Malloy-Diniz, Neuropsicologia do Desenvolvimento: Infância e adolescência, 161-166.

Nóbrega, M. D., Weckx, L. L., Juliano, Y., \& Novo, N. F. (1998). Aspectos diagnósticos e etiológicos da deficiência auditiva em crianças e adolescentes. Rev. paul. pediatr, 16(1), 2843.

Parbery-Clark A., Strait D. L., Anderson S., Hittner E., Kraus N. (2011). Musical training and the aging auditory system: implications for cognitive abilities and hearing speech in noise. PLoS ONE 6: e18082.10.1371/journal.pone.0018082

Patel A. D., Iversen J. R. (2007). The linguistic benefits of musical abilities. Trends Cogn. Sci. 11, 369-37210.1016/j.tics.2007.08.003.

Patel, A. D. (2003). Language, music, syntax and the brain. Nature neuroscience, 6 (7), 674681. 
Patel, A. D. (2011). Why would musical training benefit the neural encoding of speech? The OPERA hypothesis. Frontiers in psychology, 2, 142.

Patscheke, H., Degé, F., \& Schwarzer, G. (2019). The effects of training in rhythm and pitch on phonological awareness in four-to six-year-old children. Psychology of Music, 47(3), 376391.

Paulo: Editora Som.

Pinto, M. M., Raimundo, J. C., Samelli, A. G., Carvalho, A. C. M. D., Matas, C. G., Ferrari, G. M. D. S., ... \& Bento, R. F. (2012). Idade no diagnóstico e no início da intervenção de crianças deficientes auditivas em um serviço público de saúde auditiva brasileiro. Arquivos Internacionais de Otorrinolaringologia, 16(1), 44-49.

Raven, J.; Raven, J. C.; Court, J. H. (2018). CPM Raven - Matrizes Progressivas Coloridas de Raven - Manual. 1 ed. Pearson Clinical Brasil: São Paulo.

Ríos AA, Rezende AG, Pela SM, Ortiz KZ, Pereira LD. Teste de padrão harmônico em escuta dicótica com dígitos - TDDH. Rev Soc Bras Fonoaudiol. 2007;12(4):304-9

Rios, A. L. (2007). Implantação de um programa de conservação auditiva: enfoque fonoaudiológico (Doctoral dissertation, Universidade de São Paulo).

Rizzolatti, G., \& Craighero, L. (2004). The mirror-neuron system. Annu. Rev. Neurosci., 27, 169-192.

Rodrigues FM. Sistema online de música e percepção, uma proposta de auxílio à educação musical à distância: aprendizagem significativa e a percepção musical. [Monografia]. Brasília; Universidade de Brasília, Instituto de Ciências Exatas, Departamento de Ciências da Computação; 2008.

Said, P. M., \& Abramides, D. V. M. (2019). Educação musical e habilidades sociais. Educação musical e habilidades sociais, 1-388.

Said, P. M., \& Abramides, D. V. M. (2020). Effect of music education on the promotion of school performance in children. In CoDAS (Vol. 32, No. 1). Sociedade Brasileira de Fonoaudiologia.

Santos, M.F.C. (2011). Processamento auditivo na escola. In: Bevilacqua, M.C.; Martinez, M.A.N; Balen, A.S.; Pupo, A.C.; Reis, A.C.M.B; Frota, S. Tratado de Audiologia. São Paulo: Santos. 570-2. 
Schön, D., Magne, C., \& Besson, M. (2004). The music of speech: Music training facilitates pitch processing in both music and language. Psychophysiology, 41(3), 341-349.

Schwartz RW, Ayres KM, Douglas KH. Effects of music on task performance, engagement, and behavior: A literature review. Psychology of Music. 2017 Sep;45(5):611-27.

Seitz, J. A. (2005). Dalcroze, the body, movement and musicality. Psychology of music, 33(4), 419-435.

Shinn JB. Temporal Processing: The basics. Hear J. 2003;56(7):52.

Sousa, L., Dowson, B., McDermott, O., Schneider, J., \& Fernandes, L. (2020). Music-based interventions in the acute setting for patients with dementia: a systematic review. European Geriatric Medicine, 1-15.

Swanwick, K. (2018). Música, mente e educação. Autêntica.

Teixeira C, Griz S. Sistema Auditivo Central. In: Bevilacqua M, Martinez M, Balen S, Pupo A, Reis A, Frota S, editors. Tratado de audiologia. São Paulo: Editora Santos; 2011. p. 17-28.

Teixeira, A. R., \& Garcez, V. R. C. (2011). Aparelho de amplificação sonora individual: componentes e características eletroacústicas. Bevilacqua MC, Martinez MAN, Balen AS, Pupo AC, Reis ACM, Frota S (organizadoras). Tratado de Audiologia. São Paulo: Santos.

Teixeira, A. R., Almeida, L. G., Jotz, G. P., \& De Barba, M. C. (2008). Quality of life of adults and elderly people after hearing aids adaptation. Revista da Sociedade Brasileira de Fonoaudiologia, 13(4), 357-361.

Theunissen, M., \& Swanepoel, D. (2008). Early hearing detection and intervention services in the public health sector in South Africa. International Journal of Audiology, 47(sup1), S23S29.

Thomas, A., \& Grimes, J. (1995). Best practices in school psychology-III. National Association of School Psychologists, 4340 East West Highway, Suite 401, Bethesda, MD 20814-9457.

Tormin, M. C. (2014). Dubabi Du: uma proposta de formação e intervenção musical na creche (Doctoral dissertation, Universidade de São Paulo).

Tormin, M. C., \& Kishimoto, T. M. (2018). Formação de professores e musicalização nas creches/Teacher training and musicalization in nurseries. Educação em Foco, 21(34), 147-169. 
Torppa, R., \& Huotilainen, M. (2019). Why and how music can be used to rehabilitate and develop speech and language skills in hearing-impaired children. Hearing research.

Vila, E. M. (2005). Treinamento de habilidades sociais em grupo com professores de crianças com dificuldades de aprendizagem: uma análise sobre procedimentos e efeitos da intervenção.

Wilkerson, D. (2000). Current issues in rehabilitation outcome measurement: implications for audiological rehabilitation. Ear and hearing, 21(4 Suppl), 80S-88S.

World Health Organization. (1997). Life skills education for children and adolescents in schools. Pt. 3, Training workshops for the development and implementation of life skills programmes (No. WHO/MNH/PSF/93.7 B. Rev. 1). World Health Organization.

Yang, J., Liang, Q., Chen, H., Liu, Y., \& Xu, L. (2019). Singing Proficiency of Members of a Choir Formed by Prelingually Deafened Children With Cochlear Implants. Journal of Speech, Language, and Hearing Research, 62(5), 1561-1573.

Zatorre, R. (2005). Music, the food of neuroscience?. Nature, 434(7031), 312-315.

Zatorre, R. J. \& Krumhansl, C. L. (2002). Mental models and musical minds. Science, 298(5601): 2138-2139.

Zhang, S. (2020). The Positive Influence of Music on the Human Brain. Journal of Behavioral and Brain Science, 10(1), 95-104.

Zhang, Y. (2018). Enlightenment on Vocal Music Classroom Teaching from the Perspective of Neuroscience. NeuroQuantology, 16(6).

Zhu, Y. (2018). Influence of Music Training on the Plasticity of the Brain. NeuroQuantology, 16(5). 